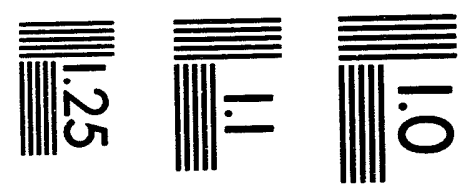

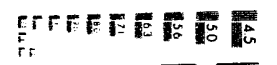

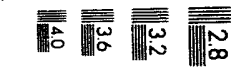

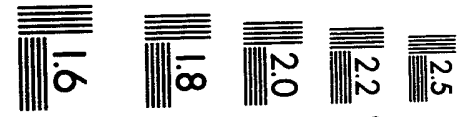



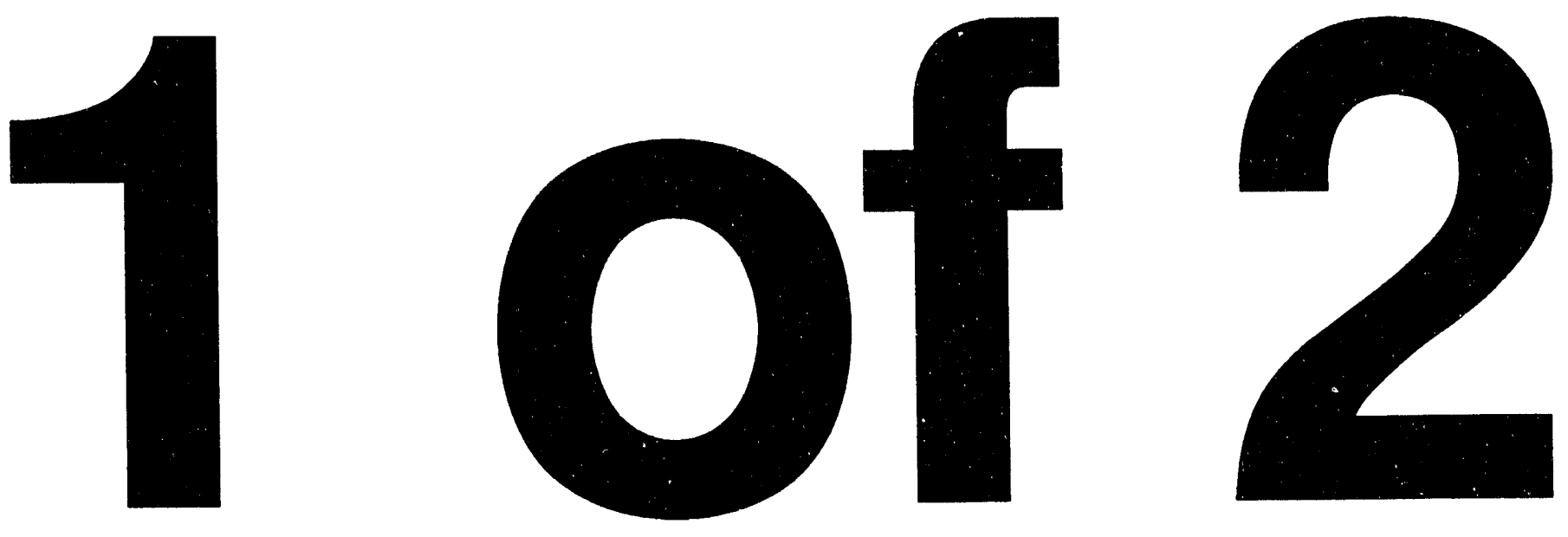


\section{Global Tropospheric Chemistry}

Models for Radiatively Important

Trace Species: Design and

Research Recommendations

W. R. Barchet

R. C. Easter
A. J. Brothers
S. J. Ghan
C. M. Berkowitz
R. D. Saylor

December 1993

Work supported by the U.S. Environmental Protection Agency under a Related Services Agreement with the U.S. Department of Energy Contract DE-AC06-76RLO 1830

Pacific Northwest Laboratory Operated for the U.S. Department of Energy by Battelle Memorial Institute 


\title{
DISCLAIMER
}

This report was prepared as an account of work sponsored by an agency of the United States Government. Neither the United States Government nor any agency thereof, nor Battelle Memorial Institute, nor any of their employees, makes any warranty, expressed or implied, or assumes any legal liability or responsibility for the accuracy, completeness, or usefulness of any information, apparatus, product, or process disclosed, or represents that its use would not infringe privately owned rights. Reference herein to any specific commercial product, process, or service by trade name, trademark, manufacturer, or otherwise does not necessarily constitute or imply its endorsement, recommendation, or favoring by the United States Government or any agency thereof, or Battelle Memorial Institute. The views and opinions of authors expressed herein do not necessarily state or reflect those of the United States Government or any agency thereof.

\author{
PACIFIC NORTHWEST LABORATORY \\ operated by \\ BATTELLE MEMORIAL INSTITUTE \\ for the \\ UNITED STATES DEPARTMENT OF ENERGY \\ under Contract DE-AC06-76RLO 1830
}

Printed in the United States of America

Available to DOE and DOE contractors from the

Office of Scientific and Technical Information, P.O. Box 62, Oak Ridge, TN 37831; prices available from (615) 576-8401. FTS 626-8401.

Available to the public from the National Technical Information Service,

U.S. Department of Commerce, 5285 Port Royal Rd., Springfield, VA 22161. 
PNL -9012

UC -000

GLOBAL TROPOSPHERIC CHEMISTRY MODELS FOR RADIATIVELYY IMPORTANT TRACE SPECIES:

DESIGN AND RESEARCH RECOMMENDATIONS
W. R. Barchet
A. J. Brothers
C. M. Berkowitz
R. C. Easter
S. J. Ghan
R. D. Saylor

December 1993

Work supported by the U.S. Environmental Protection Agency under a Related Services Agreement with the U.S. Department of Energy Contract DE-AC06-76RLO 1830

Pacific Northwest Laboratory Richland, Washington 99352 


\section{EXECUTIVE SUMMARY}

This report summarizes the recommendations of a panel of atmospheric scientists, mathematicians, and computer scientists regarding design considerations for a global tropospheric chemistry modeling system (GTCMS). These recommendations are a preliminary step toward developing a model that addresses radiatively important trace species. Many global tropospheric chemistry models are being currently developed by various entities in academia, institutes in Europe, federal laboratories, and private industry, and one or more of these may serve as the initial basis for the modeling system as conceived in this report.

The GTCMS described in this report is based on the current state of atmospheric chemistry modeling science. The GTCMS design requires the use of the most advanced parameterizations consistent with complete mathematical descriptions of the physical and chemical processes acting on the radiatively important trace species. Consisting of a computational framework and chemical transport models for three classes of radiatively important trace species, the GTCMS will provide global simulations of the distributions of important tropospheric trace gases and aerosols. This report focuses on the atmospheric modeling aspects of the design of a GTCMS and does not address the computer engineering aspects of implementing the design.

Three chemical transport models in the GTCMS, designed to address the modeling needs of short-lived $\left(\mathrm{O}_{3}, \mathrm{NO}_{x}\right.$, CO, nonmethane hydrocarbon compounds), long-lived $\left(\mathrm{CH}_{4}\right)$, and aerosol species that are radiatively important and reactive in the troposphere, are presented. These three models are needed to balance the process detail essential to simulating the tropospheric distribution of the concentrations of these classes of radiatively important trace species. Processes that directly affect their concentrations are treated in considerable detail, whereas processes that are of lesser importance use highly parameterized representations.

Central to the development of all three models is the creation of new chemical mechanisms that deal with the range of chemical mixtures expected on the global scale. That is, these mechanisms must handle the high concentrations found in urbanized areas as well as the very low concentrations found in 
the remote regions of the globe. Research is needed to determine whether the short-lived species model can provide the global concentration fields of the important gas- and aqueous-phase oxidants needed by the long-lived and aerosol species models. Considerable attention must be given to the upper boundary condition (stratosphere-troposphere exchange), especially for the short-lived and long-lived species models because the stratosphere may be a dynamic source, as well as a sink, for these species.

Global-scale computations with the GTCMS will require significant resources. The framework for the model must accommodate or be based on parallel computation as much as possible. The Models-3 system being developed by the U.S. Environmental Protection Agency could provide that framework. Only through the efficient use of computational resources can the GTCMS achieve the performance needed for policy applications. Efficiencies can be gained through the development of new solvers for the sets of stiff differential equations required by the chemical mechanisms, advanced algorithms for using vector and parallel coding, and new parameterizations for the lesscritical process modules. Advanced methods for dea? ing with the size distributions of aerosols and cloud droplets must be developed and tested before the aerosol model can be implemented. Specialized coding to enable uncertainty and sensitivity analyses must be incorporated as the models are built; autodifferentiation needs to be demonstrated as a useful tool.

By developing the three chemical transport models around the same computational framework, input data on topography and land use, emissions inventories and models, and meteorological models can have the same format and structure. Likewise, output data from the three models will have compatible formats and structures to simplify the processing of GTCMS output by other models.

Decision analysis methodologies were applied to the design of the three chemical transport models. Optimal selection of process modules in the model was obtained through a decision analysis method called multiattribute utility theory. This method quantified the decision-making process, forcing participants to carefully examine their choices. A decision-support tool, based on multiattribute utility theory and value-based planning, is presented. 
Application of this tool at two workshops led to the definition of research activities needed to support the development and implementation of the GTCMS.

This research was funded through interagency agreement DW89935712-01-0 between the U.S. Environmental Protection Agency and the U.S. Department of Energy. The technical team responsible for the workshops to gather and then synthesize the research for the GTCMS presented here is from the Earth and Environmental Sciences Center at Pacific Northwest Laboratory, (a) Richland, Washington.

(a) Pacific Northwest Laboratory is operated for the U.S. Department of Energy by Battelle Memorial Institute. 


\section{ACKNOWLEDGMENTS}

The Pacific Northwest Laboratory technical team, the authors of this report, gratefully acknowledge the considerable advice given to them during the course of this project by our technical consultants:

- Gregory Carmichae1

- Graeme Fairweather

- Leonard Peters

- Florian Potra

- Tate Tsang

- Detlof von Winterfeldt
$U-I A$

$U-K Y$

$U-K Y$

$U-I A$

$U-K Y$

USC
Transport and chemical modeling Numerical methods, advanced computing Atmospheric chemical modeling, aerosols Numerical methods, uncertainty, sensitivity

Aerosols, computational methods Decision analysis

Manuscript editing by Beverly V. Johnston and typing by Ruth $A$. Keefe and Environmental Communications Section Text Processing Team are greatly appreciated.

Participation in the two workshops convened during this project to discuss the design of the global tropospheric chemistry modeling system and the research needed to achieve the design by the following scientists and U.S. Environmental Protection Agency/Atmospheric Research and Exposure Assessment Laboratory (EPA/AREAL) staff is also greatly appreciated:

- Cindi Atherton

- Carey Jang

- Harvey Jeffries

- Eric Pani

- Ken Pickering

- Kenneth Reckhow

- Doug Rotman

- Fred Vukovitch

- Dae Won Byun

- Joe Pinto

- Jon Pleim
LLNL Atmospheric and cloud modeling

NCSC Atmosperhic chemical modeling

U-NC Atmospheric/photochemical modeling

U-NELA Meteorological processes

NASA Air quality/mesoscale modeling

Duke Decision and operational analysis

LLNL Global atmospheric chemical modeling

SAIC Meteorology, air quality data analysis

EPA Boundary layer/air quality modeling

EPA Atmospheric chemistry

EPA Meteorological modeling, aerosols

We also gratefully acknowledge the guidance given to all facets of the project by our EPA/AREAL/Ecosystem Exposure Research Division project managers and officers, Pete Finkelstein, Joe Sickles, Jerry Gipson, and John Spence, and EPA/Office of Research and Development program managers, Jack Durham, David Friedman, and Dwight Hlustick. 


\section{ACRONYMS AND CHEMICAL FORMULAS}

\begin{tabular}{|c|c|}
\hline $\begin{array}{l}\text { AREAL } \\
\text { CCN }\end{array}$ & Atmospheric Research and Exposure Assessment Laboratory \\
\hline CFC & the family of chlorofluorocarbon compounds \\
\hline $\mathrm{CH}_{4}$ & methane \\
\hline $\mathrm{CO}$ & carbon monoxide \\
\hline $\mathrm{CO}_{2}$ & carbon dioxide \\
\hline CTM & chemical transport model(s) \\
\hline DMS & dimethyl sulfide $\left(\mathrm{CH}_{3} \mathrm{SCH}_{3}\right)$ \\
\hline EC & elemental carbon aerosol \\
\hline EPA & U.S. Environmental Protection Agency \\
\hline GCM & general circulation or climate model (s) \\
\hline GTCMS & global tropospheric chemistry modeling system \\
\hline GWP & greenhouse warming potential \\
\hline $\mathrm{H}_{2} \mathrm{O}_{2}$ & hydrogen peroxide \\
\hline $\mathrm{H}_{2} \mathrm{SO}_{4}$ & sulfuric acid \\
\hline $\mathrm{HC}$ & hydrocarbon compounds \\
\hline $\mathrm{HCHO}$ & formaldehyde \\
\hline $\mathrm{HNO}_{3}$ & nitric acid \\
\hline $\mathrm{HO}_{2}$ & hydroperoxyl radical \\
\hline${ }^{85} \mathrm{Kr}$ & krypton isotope, atomic weight 85 \\
\hline LANL & Los Alamos National Laboratory \\
\hline LLNL & Lawrence Livermore National Laboratory \\
\hline MAU & multiattribute utility (theory) \\
\hline Models - 3 & EPA's advanced modeling system \\
\hline MSA & methanesulfonic acid $\left(\mathrm{CH}_{3} \mathrm{SO}_{3} \mathrm{H}\right)$ \\
\hline $\mathrm{N}_{2} \mathrm{O}$ & nitrous oxide \\
\hline $\mathrm{N}_{2} \mathrm{O}_{5}$ & dinitrogen pentoxide \\
\hline NASA & National Aeronautics and Space Administration \\
\hline NCSC & North Carolina Supercomputing Center \\
\hline $\mathrm{NH}_{3}$ & ammonia \\
\hline $\mathrm{NH}_{4} \mathrm{NO}_{3}$ & ammonium nitrate \\
\hline$\left(\mathrm{NH}_{4}\right)_{2} \mathrm{SO}_{4}$ & ammonium sulfate \\
\hline NMHC & nonmethane hydrocarbon compounds \\
\hline
\end{tabular}




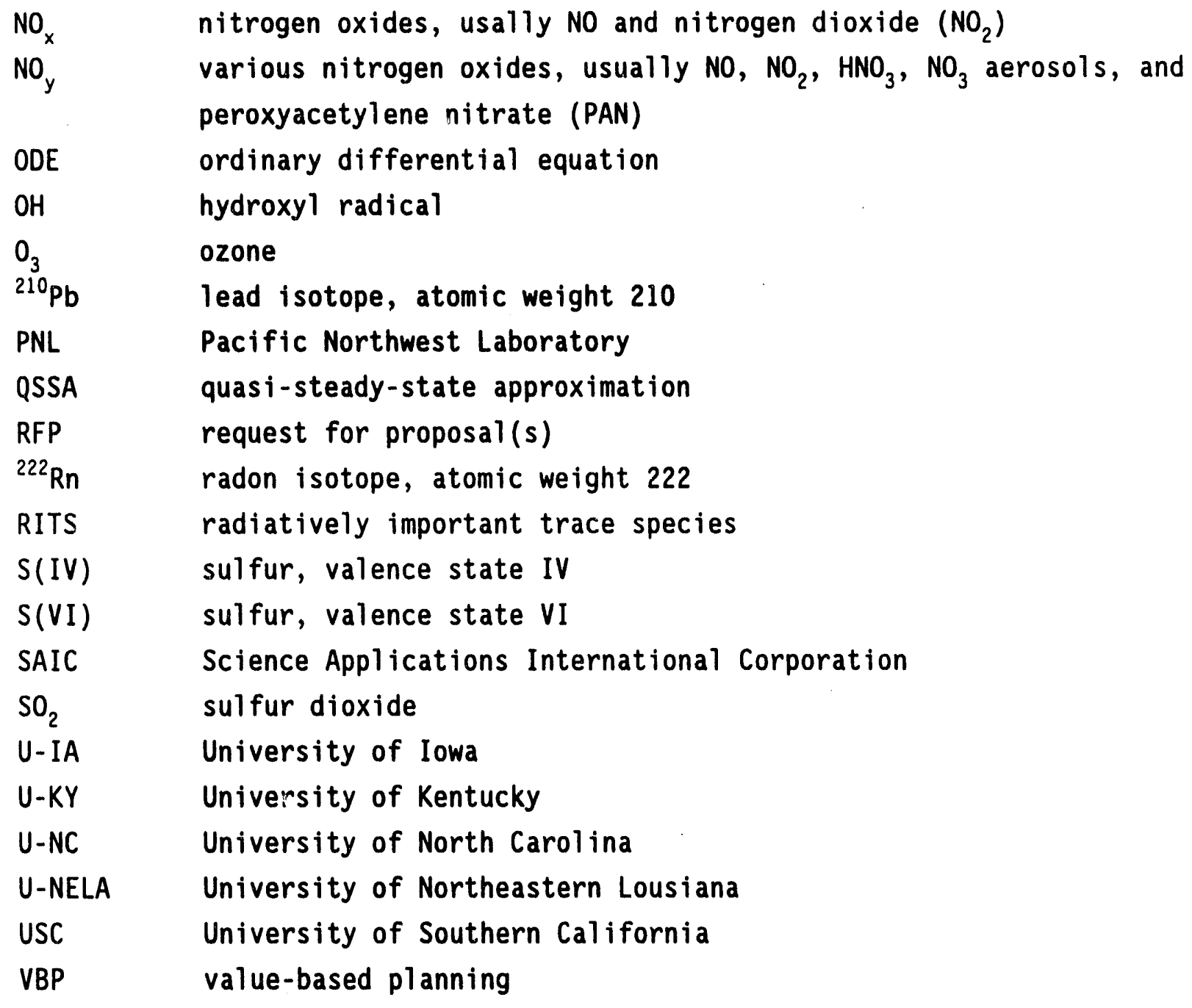




\section{CONTENTS}

EXECUTIVE SUMMARY ......................... . . i . . . . . . .

ACKNOWLEDGMENTS ....................... . . . vii

ACRONYMS AND CHEMICAL FORMULAS ..................... . ix

1.0 INTRODUCTION . . . . . . . . . . . . . . . . . . 1.1

1.1 OVERVIEW OF THE GLOBAL TROPOSPHERIC CHEMISTRY
MODELING SYSTEM . . . . . . . . . . . . . . . . . . . . . 1.2

1.2 THE ROLE OF DECISION ANALYSIS . . . . . . . . . . . 1.5

$1.3 \mathrm{APPROACH}$. . . . . . . . . . . . . . . . . 1.6

1.4 STRUCTURE OF THIS REPORT . . . . . . . . . . . . . . 1.8

2.0 DESIGN AND RESEARCH RECOMMENDATIONS . . . . . . . . . . . . 2.1

2.1 NEED FOR THREE CHEMICAL TRANSPORT MODELS IN

THE GLOBAL TROPOSPHERIC CHEMISTRY MODELING SYSTEM . . . . . . 2.1

2.2 DESIGN DETAILS FOR THE THREE CLASSES OF

CHEMICAL TRANSPORT MODELS ................ 2.3

2.2.1 Short-Lived Species Chemical Transport Model . . . . 2.12

2.2.2 Long-Lived Species Chemical Transport Mode1 . . . . 2.16

2.2.3 Aerosol Chemical Transport Model . . . . . . . . . 2.18

2.3 UNCERTAINTY/SENSITIVITY . . . . . . . . . . . . . 2.24

2.4 GENERAL DISCUSSION OF RESEARCH NEEDS AND ACTIVITIES . . . . . 2.26

2.4.1 Chemistry ................. 2.26

2.4.2 Dynamics . . . . . . . . . . . . . . . 2.30

2.4.3 Cloud Processes ............... . 2.31

2.4.4 Surface Exchange . . . . . . . . . . . . . 2.31

2.4.5 Actinic flux............... . 2.32

2.4 .6 Numerics . . . . . . . . . . . . . 2.32

2.5 GUIDANCE ON RESEARCH PRIORITY . . . . . . . . . . . . 2.33 
3.0 DECISION ANALYSIS FOR MODEL DESIGN AND

RESEARCH PRIORITIZATION ......................... 3.1

3.1 OVERVIEW OF THE DECISION PROCESS .................. 3.1

3.1.1 Vision of Model ............. 3.1

3.1.2 Science Requirements . . . . . . . . . . 3.4

3.1.3 Science Research Needed . . . . . . . . . 3.4

3.1.4 Science Research Proposed . . . . . . . . . . 3.4

3.2 DECISION ANALYSIS USING MULTIATTRIBUTE UTILITY THEORY . . . . 3.5

3.3 APPLICATION OF DECISION ANALYSIS FOR MODEL DESIGN . . . . . 3.7

3.3.1 Chemical Transport Model Alternatives . . . . . 3.7

3.3.2 Evaluation Criteria . . . . . . . . . 3.8

3.3.3 Option Selections ...................... 3.11

3.3.4 Option Evaluation ............ 3.12

3.4 APPLICATION OF DECISION ANALYSIS TO RESEARCH

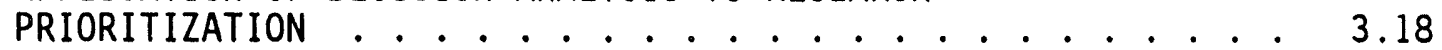

3.5 APPLICATION OF DECISION ANALYSIS TO RESEARCH

PORTFOLIO SELECTION . . . . . . . . . . . . 3.23

3.5.1 Determining Research Needs . . . . . . . . . 3.23

3.5.2 Prioritizing Individual Proposals ........ 3.24

3.5.3 Creating Research Programs ......... . . 3.30

3.5.4 Prioritizing Research Programs .......... 3.32

3.5.5 Value-Based Planning ............ 3.33

4.0 REFERENCES . . . . . . . . . . . . . . . . . . 4.1

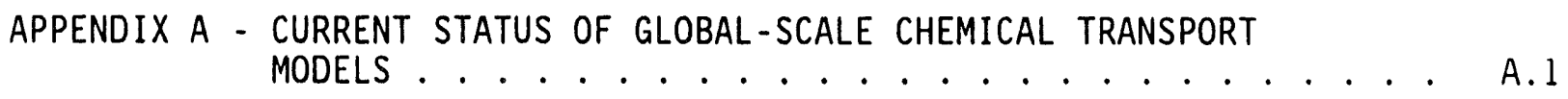

APPENDIX B - DESIGN OPTIONS FOR A GLOBAL TROPOSPHERIC

CHEMISTRY MODEL . . . . . . . . . . . . . . B.1

APPENDIX C - RESEARCH ACTIVITIES DEFINED AT THE SECOND WORKSHOP . . . . . . . . . . . . . . . C.1 


\section{FIGURES}

1.1 Relationship of the Global Tropospheric Chemistry Modeling System to the Components of a Global Policy Analysis System . . . 1.3

3.1 Logical Flow of Activities to Identify Research Needed to Develop a Global Tropospheric Chemistry Modeling System . . . . . 3.2

\section{TABLES}

2.1 Input and Output Variables by Module for the Three Classes of Chemical Transport Models in the Global Tropospheric Chemist:y Modeling System . . . . . . . . . .

2.2 Titles of Research Activities Identified by Participants at the Second Workshop as Needed for the Development of the Global Tropospheric Chemistry Modeling System . . . . . . . . 2.27

2.3 Resarch Activities in Priority Order, Based on Results of Evaluation by Second Workshop Participants . . . . . . . . . . .

3.1 Criteria Used to Evaluate Potential Chemical Transport Models

3.2 Options Selected for Alternative Visions: Short-Lived Species Chemical Transport Model . . . . . . . . . . . . .

3.3 Options Selected for Alternative Visions: Long-Lived Species Chemical Transport Model . . . . . . . . . . . 3.14

3.4 Options Selected for Alternative Visions: Aerosol Chemical Transport Model . . . . . . . . . . . . . . .

3.5 Ratings by Workshop Participants of the Alternative Chemical Transport Model Visions . . . . . . . . . . 3.16

3.6 Options Selected for Top-Rated Alternative Visions . . . . . 3.18

3.7 Criteria Used to Evaluate Research Needs . . . . . . . . . 3.19

3.8 Average Scores for Workshop Participants that Rated Research Activities... . . . . . . . . . . . . 3.21

3.9 Weighted Scores and Rank for Research Activities, Based on Scoring by Workshop Participants . . . . . . . . . . . 3.22

3.10 Typical Worksheet for Scoring Proposals . . . . . . . . . . 3.28 
3.11 Spreadsheet to Determine Overall Value of Individual

Projects .................... . . 3.29

3.12 Comparison of Individual Research Proposals . . . . . . . . . 3.30

3.13 Comparison of Research Programs . . . . . . . . . . . 3.34 


\subsection{INTRODUCTION}

Tropospheric chemistry plays multiple roles in the global climate system. Some chemically reactive tropospheric species are radiatively active, either as greenhouse gases $\left(\mathrm{CH}_{4}, \mathrm{O}_{3}\right)$ or as light-scattering aerosols (sulfate, nitrate, and elemental carbon aerosols). Although the concentrations of these reactive greenhouse gases are much lower than those of the nonreactive species $\left(\mathrm{CO}_{2}\right.$ and water vapor), they are much more effective per molecule. Together, the reactive greenhouse gases contribute some $20 \%$ of the total greenhouse warming potential (GWP) (IPCC 1990). Kaufmann et al. (1991) have estimated that, even though coal and oil combustion emit 120 times as many $\mathrm{CO}_{2}$ molecules as $\mathrm{SO}_{2}$ molecules and even though sulfate aerosols have atmospheric lifetimes several orders of magnitude shorter than $\mathrm{CO}_{2}$, the cooling effect of sulfate aerosols scattering sunlight both directly and indirectly as cloud condensation nuclei ( $\mathrm{CCN}$ ) is comparable to the warming effect of the $\mathrm{CO}_{2}$ emitted in the same combustion process.

Other tropospheric chemical species influence the planetary radiation balance by acting as aerosol precursors $\left(\mathrm{SO}_{2}, \mathrm{NH}_{3}\right.$, dimethylsulfide [DMS], methanesulfonic acid [MSA], $\mathrm{NO}_{x}$, nonmethane hydrocarbons [NMHC]) or by altering the chemical balance that determines the concentration of other greenhouse gases (e.g., $\mathrm{CO}, \mathrm{NO}{ }_{x}$, NMHC influence $\mathrm{CH}_{4}, \mathrm{O}_{3}$ ). Most $\mathrm{CCN}$ are composed of sulfates arising from the oxidation of DMS and $\mathrm{SO}_{2}$ (Twomey 1971), and most direct scattering by aerosols is attributed to sulfate (Charlson et a1. 1992). The concentration of the hydroxyl radical $(\mathrm{OH})$, which controls the lifetime and, hence, influences the concentration of the reactive greenhouse gases and aerosol precursors, is itself influenced by the concentrations of $\mathrm{CO}, \mathrm{NO}_{x}, \mathrm{CH}_{4}$, and $\mathrm{NMHC}$ (Wayne 1991). The GWP of $\mathrm{NO}_{x}$ constitutes $6 \%$ of the total GWP over a 100-year period, solely through its role in altering the concentration of tropospheric $0_{3}$ (IPCC 1990). The GWP of both CO and NMHC is less than $1 \%$, but $\mathrm{CO}$ and NMHC may alter the planetary radiation balance by influencing $\mathrm{OH}$ and, hence, the oxidation of $\mathrm{SO}_{2}$ to form sulfate aerosols.

Changes in the Earth's climate could significantly affect regional and global concentrations of trace species that are criteria pollutants regulated by the U.S. Environmental Protection Agency (EPA). The policy community also 
needs to know how changes in global natural. and anthropogenic emissions of greenhouse gases, particulate aerosols, and aerosol precursors will affect the distribution and concentrations of these pollutants. This report maps out one path for obtaining this information.

\subsection{OVERVIEW OF THE GLOBAL TROPOSPHERIC CHEMISTRY MODELING SYSTEM}

Presented in this section is an overview of the design of the global tropospheric chemistry modeling system (GTCMS) for radiatively important trace species (RITS). (a) The term "modeling system" describes a set of independent models that, taken together, simulate a wide range of chemical and physical processes acting on RITS in the troposphere. This system consists of a core chemical transport model (CTM) designed to provide global simulations for short-lived RITS ( $\mathrm{NO}_{x}, \mathrm{O}_{3}, \mathrm{CO}$, NMHCS) and to provide global distributions of important tropospheric oxidants $\left(\mathrm{OH}\right.$, hydroperoxyl radical $\left[\mathrm{HO}_{2}\right], \mathrm{O}_{3}$, and $\mathrm{H}_{2} \mathrm{O}_{2}$ ). These oxidant concentration fields are used by the other CTMs within the system; namely, a global model for long-lived RITS and a global model for aerosols. These secondary models are dependent on the core model for detailed descriptions of oxidant fields, so that these models can be run for long-term simulations without exacting the full computational cost of the complex, short-1ived species CTM.

The GTCMS will be one component of a larger modeling system for evaluating policy decisions that may change the global concentrations and distributions of RITS. Those policy decisions must account for the potential climatic, social, and economic impacts of those changes and for the changes in the concentrations of criteria pollutants that may occur under other climatic conditions. Other models, not part of the scope of the design of the GTCMS but components of the larger policy-modeling system, are also needed to fully address key policy issues.

Figure 1.1 illustrates the linkages between the GTCMS and the other components of the larger modeling system that will be needed to carry out

(a) RITS include chemical species that are radiatively active (e.g., $\mathrm{CH}_{4}, \mathrm{~N}_{2} \mathrm{O}$ $\mathrm{O}_{3}, \mathrm{CO}_{2}$, aerosols), precursors of the radiatively active species (e.g., $\mathrm{NO}_{x}, \mathrm{NMHC}^{2} \mathrm{SO}_{2}$ ), and species that affect the chemical balances of these species (e.g., $\mathrm{CO}, \mathrm{OH}, \mathrm{H}_{2} \mathrm{O}_{2}$ ). 


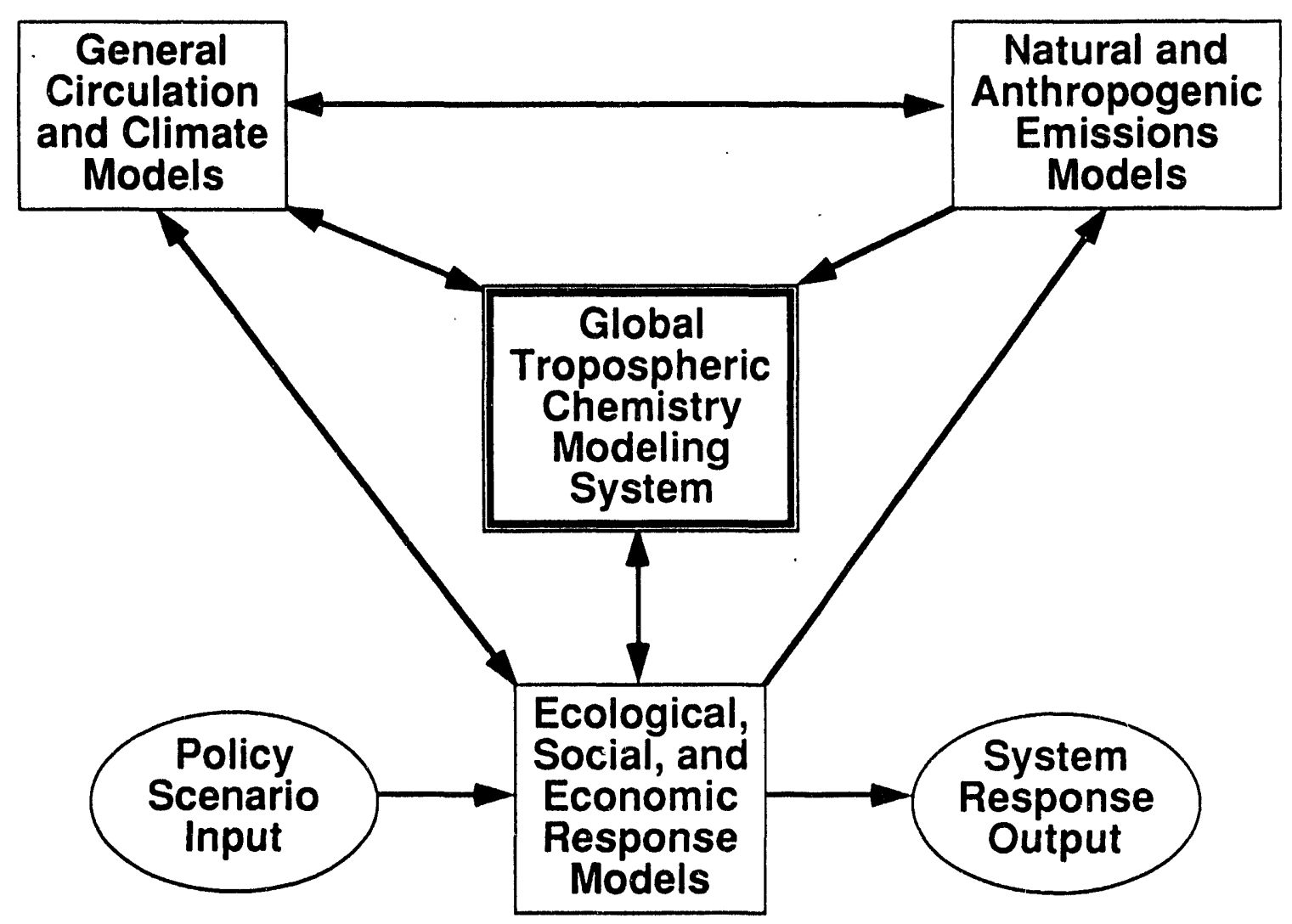

FIGURE 1.1. Relationship of the Global Tropospheric Chemistry Modeling System to the Components of a Global Policy Analysis System

policy analysis. The interconnecting lines indicate the dominant information flows between these models. Policy decisions lead to various scenarios that affect social and economic responses. One or more emissions models respond to the effects of the policy scenario and provide the input of chemical species to the GTCMS. The emissions models predict how policy decisions will affect global emissions of a wide range of compounds that affect RITS concentrations. General circulation or climate models (GCMs) provide global meteorological fields, consistent with current or altered climates, that drive the transport and control the chemistry of RITS and other reactive species in the GTCMS and the emissions of RITS and other reactive species. Ecological, social, and economic response models provide land-use and surface-cover information to both the GTCMS and the GCM and pass this information along with economic and demographic information to the emissions models. The double-arrow interconnecting lines indicate feedbáck paths that further couple the models. 
Ecological response models depend on climate, air quality, and radiation reaching the surface. The GCMs depend on the distribution of radiative forcing caused by the distribution of RITS as provided by the GTCMS. The response of ecological, social, and economic systems to changes in climate and RITS concentrations will result in a system response that policymakers can link to the input policy scenario. The GTCMS must interface as seamlessly as possible with these other models, so that policymakers can address that wide range of policy questions whose answers depend, in part, on changes in RITS concentrations.

The GTCMS described in this report is founded on the current state of atmospheric chemistry modeling science. Whenever possible, the GTCMS design calls for the use of the most advanced parameterizations consistent with complete mathematical descriptions of the physical and chemical processes acting on the RITS. The GTCMS and the larger modeling system of which it is a part will rely heavily on high-performance computing to achieve the timely turnaround needed to support policy analysis and decision making. The computational system will have the memory and computational speed required to handle the complex algorithms in the GTCMS. This report focuses on the atmospheric modeling aspects of the design of the GTCMS and does not address the computer engineering aspects of implementing the design. However, the overall structure and software engineering development of the GTCMS may benefit significantly by taking advantage of the modeling environment as envisioned by the Models-3 development effort (Dennis and Novak 1991).

The conceptual design of the GTCMS as presented in this report does not necessarily require the construction of an entirely new three-dimensional chemistry model. A brief synopsis of current global tropospheric chemistry models is presented in Appendix A. These models include recent efforts at the Geophysical Fluid Dynamics Laboratory (Kasibhatla et al. 1993), Harvard University (Jacob et al. 1993a, 1993b; Balkanski et al. 1993), Max Planck Iristitute for Chemistry (Dentener and Crutzen 1993; Langner and Rodhe 1991), Lawrence Livermore National Laboratory (Penner et al. 1993), Pacific Northwest Laboratory (PNL) (Easter et al. 1993), and Los Alamos National Laboratory (Tie et al. 1992). Additional work in this area is ongoing at the National Center for Atmospheric Reseárch, Cambridge University, Massachusetts Institute of 
Technology, Atmospheric and Environmental Research, Inc., and Goddard Institute for Space Studies. However, because these efforts are in relatively early developmental stages, little or no published information is available. It is conceivable that one or more of these current tropospheric chemistry models may be adequate to serve as the initial basis for the GTCMS as conceived in this report. None of the current global tropospheric chemistry models has exactly the structure or includes all of the processes that are recommended here-for the GTCMS. It is not the purpose of this report to recommend a specific model or models on which to base the GTCMS.

\subsection{THE ROLE OF DECISION ANALYSIS}

The task of designing a GTCMS is extremely complex and must take many considerations into account. Among these are: what level of scientific detail should be included in the model; does the current state of science allow the GTCMS to be developed using existing models; how much risk should be accepted in the development of new modeling tools as part of the GTCMS; is additional research needed for GTCMS development? If additional research is needed, then what are the critical research needs and what components of the GTCMS can be developed with existing science? These considerations illustrate the complexity of the design task and point to the need for a methodology that leads to a logically defensible design of the GTCMS and to the definition of the research and development needed to achieve it.

Decision analysis (see, for example, Keeney and Raiffa 1976 or von Winterfeldt and Edwards 1986) was chosen as the methodology because it $m=$ kes explicit the rationale by which decisions are reached and promotes clarity in the thought process. Decision analysis is a structured, theoretically grounded process for decision making, fostering a conscientious recognition of the factors that enter into decision making (see von Neumann and Morgenstern 1947 and Savage 1954). Applications of decision analysis in this project were threefold: design of the GTCMS, identification of research needs, and development of a decision-support system for the prioritization of research needs and optimization of research resources. Two decision analys is tools were used at key points in the process: multiattribute utility theory and value-based planning. 
Multiattribute utility theory was applied to the selection of module options that form the design of the GTCMS. By setting various design objectives, several versions of each CTM were constructed from a menu of options for each of the major process modules. Evaluation of those versions against specific design criteria resulted in selecting a version for each class of CTM that was considered of greatest value to the GTCMS.

Through a comparison of the current state of development and the design goals for the various modules in the GTCMS, research needs were identified. Based on these needs, research activities were defined that would produce a GTCMS in a 3-year time period. Multiattribute utility theory, combined with value-based planning, yields a decision-support tool for prioritizing those research activities. Illustration of the application of this decision-support toul to the creation of an optimal portfolio of recommended research activities carried the decision process to its logical conclusion. The decision-support tool described herein can be updated and modified as necessary to accommodate new applications. Thus, the methodology described in this report provides a tool that can be used in many settings other than the design of the GTCMS.

\subsection{APPROACH}

This report is the result of the synthesis and expansion of information gathered at two workshops led by the research team at PNL. Participants at the workshops included technical specialists in various aspects of atmospheric chemistry modeling from universities, scientific consulting firms, and federal laboratories and agencies (see Acknowledgments).

The first workshop focused on defining the attributes and capabilities of the modeling system. Here, the distinction was defined between the GTCMS and the larger modeling system of which it is a part. Lists were developed of various approaches to simulating processes and data needs for input and output from the various components of the GTCMS. After the workshop, the PNL team took these data and developed a decision analysis method to select which options for the various process modules were most suitable for the GTCMS. The first workshop provided a broad overview of what the GTCMS must do but did not 
address design details. A summary of this workshop was distributed to the participants.

During preparation of the second workshop, it was recognized that more than one CTM was needed in the GTCMS to deal with the differences between different classes of RITS. Therefore, the second workshop was structured around developing specific designs for each class of CTM using decision analysis. Many of the participants of the first workshop participated in the second, along with other technical specialists. Participants selected those options to the various process models that would yield the best CTM for its class of RITS and specified the research needed to implement those options. Multiattribute utility theory was used to establish priority among the suggested research activities. A summary of this workshop was also provided to the participants.

Following the second workshop, the PNL team synthesized the selected design options into a description of the modular components needed for each class of CTM, expanded the descriptions of research activities that were outlined, and extended the methodology used in the research prioritization to include value-based planning. An illustrative example is presented of the application of value-based planning to the creation of portfolios of recommended research that makes optimal use of available resources.

In this project, the exercises of the first and second workshops illustrated the application of multiattribute utility theory to the desigr of the GTCMS and to the ranking of research needs for GTCMS development. The process was carried further in this report by describing how value-based planning leads to the optimal construction of research portfolios for different resource levels. These processes are generally applicable to many decision processes. Application of multiattribute utility theory and valuebased planning requires input from many perspectives and areas of expertise. Significant attention must be given to setting a clear goal for the process. Definition of evaluation criteria and performance objectives through a group process helps to ensure that the criteria are comprehensive, measurable, and inclusive of all factors that musi be considered. More time should be allocated to this process than was available at our workshops. 


\subsection{STRUCTURE OF THIS REPORT}

Section 2.0 presents recommendations for the design of three interrelated versions of the CTMs, along with recommendations of the research activities needed to support the development and implementation of the GTCMS. Section 3.0 presents an overview of the decision process that was applied to the design of the GTCMS and of the applications of decision analysis to assigning priorities to research activities and to defining optimal portfolios of research activities. References follow in Section 4.0.

Appendix A gives a brief overview of current CTMs. Appendix B presents the matrix of options for the various process modules included in the GTCMS. Expanded descriptions of research activities recommended to support the development and implementation of the GTCMS design are given in Appendix $C$. 


\subsection{DESIGN AND RESEARCH RECOMMENDATIONS}

Recommendations for the design of the GTCMS and for the research needed to support its development and implementation are presented in this section. The need for more than one CTM in the GTCMS is explained. Each of the CTMS that comprise the GTCMS is described in detail. Research that must be carried out to support GTCMS development is described. Guidance on the suggested priority for doing this research is also given.

\subsection{NEED FOR THREE CHEMICAL TRANSPORT MODELS IN}

\section{THE GLOBAL TROPOSPHERIC CHEMISTRY MODELING SYSTEM}

The RITS can be divided into three classes, based on their atmospheric lifetimes, their spatial variability in the troposphere, and their sensitivity to cloud processes and precipitation scavenging:

1. short-1ived species--CO, $\mathrm{NO}_{x}, \mathrm{O}_{3}, \mathrm{NMHC}$; 1 ifetimes of days to weeks (CO is longer); high spatial variability; moderately sensitive to clouds and precipitation

2. long-lived species-- $\mathrm{CH}_{4}, \mathrm{~N}_{2} \mathrm{O}$, chlorofluorocarbons (CFCs); lifetimes of years; low spatial variability; insensitive to clouds and precipitation

3. aerosols $--\mathrm{H}_{2} \mathrm{SO}_{4},\left(\mathrm{NH}_{4}\right)_{2} \mathrm{SO}_{4}, \mathrm{NH}_{4} \mathrm{NO}_{3}, \mathrm{MSA}$, elemental carbon; lifetimes of days to weeks; high spatial variability; high sensitivity to clouds and precipitation.

As discussed below, modeling these different classes of species involves different emphases. A significant racommendation by the research team is that a suite of three interrelated CTMs is needed in the GTCMS to address the distributions of all RITS.

Reaction rates of the short-lived species are comparable or even faster than their rates of vertical mixing and horizontal dispersion in the troposphere. Thus, the model time step will be controlled by the chemical time scale for these species. Concentrations of these species are sensitive to aqueous-phase chemical reactions (Lelieveld and Crutzen 1991) and transport by convective clouds (Brost et al. 1988), so cloud processes are important, though not as much as for aerosol species. Because the short-lived species are photochemically active, the diurnal variation in their concentrations may 
be large. Spatial distributions of the short-lived species are strongly affected by the locations of their (or their precursors) major emissions sources. Hence, the CTM for short-lived species must resolve significant horizontal and vertical gradients in concentrations. Photochemical reactions among the short-lived species give rise to the oxidants; namely, $\mathrm{OH}, \mathrm{HO}_{2}$, $\mathrm{H}_{2} \mathrm{O}_{2}$, and oxygenated organic radicals, that also interact with the long-lived species. Concentrations of these oxidant species calculated by the shortlived species CTM would be used as inputs to the long-lived and aerosol CTMs.

The long-lived species react relatively slowly in the troposphere. CFCS and $\mathrm{N}_{2} \mathrm{O}$ are essentially unreactive in the troposphere; $\mathrm{CH}_{4}$ is slowly reactive. Thus, $\mathrm{CH}_{4}$ is the only radiatively active, long-lived species of concern. For these species, the rates of vertical mixing and horizontal dispersion are considerably greater than the rate of chemical transformation within the troposphere. Thus, the duration of the model time step may be limited by the advective rather than the chemical time scale. By being rapidly well mixed in the troposphere, the vertical and horizontal resolutions of the CTM for the long-lived species need not be as fine as for the other species. Most of these species have rather low solubilities and, hence, are not appreciably affected by cloud microphysical processes. As a result, a simplified treatment of clouds that focuses more on convective cloud transport than on scavenging is appropriate for the long-lived species CTM. Furthermore, because of their low reactivity and solubility, dry deposition of these species to the surface is not considered to be an important lower boundary sink. However, the upper boundary, typically set at or above the tropopause, needs special attention because the stratosphere may act as a source or sink for these species. $\mathrm{CO}_{2}$ is not included among the long-lived species because it is not at all reactive in the troposphere. The tropospheric chemical reactions giving rise to $\mathrm{CO}_{2}$ (oxidation of $\mathrm{CO}, \mathrm{CH}_{4}$, and $\mathrm{NMHCS}$ ) have only a minor effect on its tropospheric abundance. Also, because of the importance of the oceanic reservoir of $\mathrm{CO}_{2}$ and changes in the reservoir resulting from changes in ocean circulations associated with climate changes, a stand-alone atmospheric model for $\mathrm{CO}_{2}$ would be of limited value.

Aerosols need to be treated separately from either the short-lived or long-lived gaseous species because of the need to resolve their size-dependent 
composition, their interaction with cloud microphysical processes, and their heterogeneous chemical reactions. Unlike gas-phase species, which are affected by but have little effect on clouds, aerosols significantly affect cloud microphysics. Within the troposphere, photochemical production of aerosols through the oxidation of precursor gaseous species, such as $\mathrm{SO}_{2}$ and DMS, and neutralization reactions of acidic species $\left(\mathrm{H}_{2} \mathrm{SO}_{4}\right.$ and $\left.\mathrm{HNO}_{3}\right)$ by $\mathrm{NH}_{3}$ occur at rates comparable to reactions between the short-lived species. Interactions between aerosol and cloud and raindrops are so highly size dependent that correct treatment requires simulating the size distribution of these classes of particles. Detailed information is needed on aerosol sizedependent concentration and composition to properly calculate the radiative transfer properties of aerosols and clouds in the troposphere.

While it is conceptually possible to devise a single CTM that handles all classes of RITS, the development of separate CTMs in the GTCMS for each class is recommended. In practice, the three CTMs would utilize different modules in the common computational framework provided by the GTCMS. As noted elsewhere herein, the Models-3 system (Dennis and Novak 1991) could provide that framework. Through a common computational framework (i.e., common input/output formats, grid structure, numerical solvers, and mcdular design), the three CTMs can be kept internally and externally consistent.

\subsection{DESIGN DETAILS FOR THE THREE CLASSES OF CHEMICAL TRANSPORT MODELS}

A basic premise of the design of the GTCMS is that it will be modular (i.e., to the maximum extent possible, the various processes to be simulated by the model will be treated in separate sections of code, herein called modules). The exchanges of information among modules will need to be well defined by the modeling system. The Models-3 framework for modular code development and execution, currently being developed by the EPA's Atmospheric Research and Exposure Assessment Laboratory (AREAL) for use with air quality models, has the potential of also serving as the framework for the GTCMS.

The various inputs required and outputs provided by each module are listed for the three CTMs in Table 2.1. The table is partitioned into broad categories of key processes (e.g., chemistry, dynamics, etc.) with which key subprocesses are listed (e.g., gas-phase chemistry, aqueous-phase chemistry, 
IABLE 2.1. Input and Output Variables by Module for the Three Classes of Chomical Transport Models in the Global Tropospheric Chemistry Modeling System

\begin{tabular}{|c|c|c|c|}
\hline \multirow{2}{*}{$\begin{array}{c}\text { Module/ } \\
\text { Class }\end{array}$} & \multicolumn{2}{|c|}{ Input } & \multirow[b]{2}{*}{ Output Field } \\
\hline & Field & Source & \\
\hline & \multicolumn{2}{|r|}{ CHEMISTRY } & \\
\hline \multicolumn{4}{|c|}{$\begin{array}{l}\text { Gas phase: Calculates changes in species concentrations from gas-phase chemical } \\
\text { reactions }\end{array}$} \\
\hline Short-lived CTM & $\begin{array}{l}\text { Species concs. } \\
\text { Rate constants } \\
\text { Actinic flux } \\
\text { Water vapor } \\
\text { Temperature }\end{array}$ & $\begin{array}{l}\text { Primary } \\
\text { Model parameters } \\
\text { Primary } \\
\text { Meteorological model } \\
\text { Meteorological model }\end{array}$ & $\begin{array}{l}\text { Species concs. } \\
\text { Production rates }\end{array}$ \\
\hline Long-lived CTM & $\begin{array}{l}\text { Hydroxyl }(\mathrm{OH}) \\
\text { Rate constants } \\
\text { Temperature } \\
\mathrm{CH}_{4} \text { concs. }\end{array}$ & $\begin{array}{l}\text { Short-lived CTM } \\
\text { Model parameters } \\
\text { Meteorological model } \\
\text { Primary }\end{array}$ & $\mathrm{CH}_{4}$ concs. \\
\hline Aerosol CTM & $\begin{array}{l}\text { Hydroxyl }(\mathrm{OH}) \\
\text { Rate constants } \\
\text { Species concs. } \\
\text { Temperature }\end{array}$ & $\begin{array}{l}\text { Short-lived CTM } \\
\text { Model parameter } \\
\text { Primary } \\
\text { Meteorological model }\end{array}$ & $\begin{array}{l}\text { Species concs. } \\
\text { Production rates }\end{array}$ \\
\hline
\end{tabular}

Aqueous phase: Calculates changes in species concentrations from aqueous-phase chemical reactions

Short-lived CTM

Long-lived CTM
Gas-phase spec. concs.

Mass transfer coeff.

Cloud water

Cloud droplet number

Rain water

Rain drop number

Aqu. rate constants

Henry's law consts.

Equilibrium consts.

Temperature

None
Primary

Model parameters

Primary

Primary

Primary

Primary

Model parameter

Model parameter

Model parameter

Meteorological model

None
Gas-phase spec. concs.

Aqu.-phase spec. concs.

None 
TABLE 2.1. (contd)

\begin{tabular}{|c|c|c|c|}
\hline \multirow{2}{*}{$\begin{array}{c}\text { Module/ } \\
\text { Class }\end{array}$} & \multicolumn{2}{|c|}{ Input } & \multirow[b]{2}{*}{ Output Field } \\
\hline & Field & Source & \\
\hline Aerosol CTM & $\begin{array}{l}\mathrm{H}_{2} \mathrm{O}_{2} \text { and } \mathrm{O}_{3} \text { concs. } \\
\text { Gas-phase S spec. } \\
\text { concs. } \\
\text { Mass transfer } \\
\text { coefficients } \\
\text { Cloud water } \\
\text { Cloud droplet number } \\
\text { Rain water } \\
\text { Rain drop number } \\
\text { Aqu. S rate consts. } \\
\text { Henry's law consts. } \\
\text { Equilibrium consts. } \\
\text { Temperature }\end{array}$ & $\begin{array}{l}\text { Short-lived CTM } \\
\text { Primary } \\
\text { Model parameter } \\
\text { Primary } \\
\text { Primary } \\
\text { Primary } \\
\text { Primary } \\
\text { Model parameter } \\
\text { Model parameter } \\
\text { Model parameter } \\
\text { Meteorological model }\end{array}$ & $\begin{array}{l}\text { Gas-phase S spec. concs. } \\
\text { Aqu.-phase S spec. concs. }\end{array}$ \\
\hline
\end{tabular}

Aqueous size dependence: With bulk approach, variations in aqueous-phase sfecies concentrations with cloud or rain droplet size are not treated

$\begin{array}{cccc}\text { Short-lived CTM } & \begin{array}{c}\text { Mean cloud droplet } \\ \text { radius }\end{array} & \begin{array}{c}\text { Model parameter } \\ \text { (or primary) }\end{array} & \begin{array}{c}\text { Bulk aqueous-phase } \\ \text { species concs. }\end{array}\end{array}$

Long-lived CTM None None None

Aerosol CTM Mean rain drop Model parameter radius (or primary)

Subgrid: Calculates species concentrations in point source or urban plumes until they become fully mixed in model grid cells

\begin{tabular}{|c|c|}
\hline Short-lived CTM & $\begin{array}{l}\text { Point source } \\
\text { emissions } \\
\text { Subgrid point source } \\
\text { locations } \\
\text { Wind components } \\
\text { Mixed layer depth } \\
\text { Species concs. } \\
\text { at nodes }\end{array}$ \\
\hline
\end{tabular}

Long-lived CTM

Aerosol CTM

$$
\begin{aligned}
& \text { Emissions inventory/ } \\
& \text { model } \\
& \text { Emissions inventory/ } \\
& \text { model } \\
& \text { Meteorological model } \\
& \text { Meteorological model } \\
& \text { Primary }
\end{aligned}
$$

Modified species

Concs. at nodes

(no module needed)

(no module needed)

\section{5}


TABLE 2.1. (contd)

Module/
Class

Field Inout

Aerosols: Calculates changes in aerosol chemical composition and physical size distribution from condensation and evaporation of gases, coagulation, new particle formation, and heterogeneous chemical reactions

\begin{tabular}{|c|c|c|c|}
\hline Short-lived CTM & $\begin{array}{l}\text { Aerosol mass } \\
\text { Aerosol composition } \\
\text { Aerosol size } \\
\text { distrib. params. } \\
\text { Volatile gas conc. } \\
\text { Nonvolatile species } \\
\text { production rates } \\
\left(\mathrm{H}_{2} \mathrm{SO}_{4} \text {, etc.) }\right. \\
\text { Aerosol emissions } \\
\text { (mass and } \\
\text { composition) } \\
\text { Temperature } \\
\text { Pressure } \\
\text { Relative humidity }\end{array}$ & $\begin{array}{l}\text { Primary } \\
\text { Primary } \\
\text { Model parameters } \\
\text { Primary } \\
\text { Primary } \\
\text { Emissions inventory/model } \\
\text { Meteorological model } \\
\text { Meteorological model } \\
\text { Meteorological model }\end{array}$ & $\begin{array}{l}\text { Aerosol mass } \\
\text { Aerosol composition } \\
\text { Volatile gases conc. }\end{array}$ \\
\hline Long-lived CTM & None & None & None \\
\hline Aerosol CTM & $\begin{array}{l}\text { Aerosol number } \\
\text { Aerosol mass } \\
\text { Aerosol composition } \\
\text { Aerosol size } \\
\text { distrib. params. } \\
\text { Volatile and nonvolatile } \\
\text { gas concentrations } \\
\text { Aerosol emissions } \\
\text { (number, mass and } \\
\text { composition) } \\
\text { Temperature } \\
\text { Pressure } \\
\text { Relative humidity }\end{array}$ & $\begin{array}{l}\text { Primary } \\
\text { Primary } \\
\text { Primary } \\
\text { Model parameters } \\
\text { Primary } \\
\text { Emissions inventory/model } \\
\text { Meteorological model } \\
\text { Meteorological model } \\
\text { Meteorological model }\end{array}$ & $\begin{array}{l}\text { Aerosol number } \\
\text { Aerosol mass } \\
\text { Aerosol composition } \\
\text { Volatile gases conc. }\end{array}$ \\
\hline
\end{tabular}

\section{DYNAMICS}

Transport: Calculates changes in species concentrations from advection by resolved winds and turbulent motions

$\begin{array}{llll}\text { Short-lived CTM } & \begin{array}{c}u, v, w \text { wind } \\ \text { components }\end{array} & \text { Meteorological model } & \text { Species concs. } \\ \text { Long-lived CTM } & \text { Species concs. } & \text { Primary } & \text { Species concs. }\end{array}$


IABLE 2.1. (contd)

\begin{tabular}{|c|c|c|c|}
\hline \multirow{2}{*}{$\begin{array}{c}\text { Module/ } \\
\text { Class }\end{array}$} & \multicolumn{2}{|c|}{ Inout } & \multirow[b]{2}{*}{ Output Field } \\
\hline & Field & Source & \\
\hline Aerosol CTM & $\begin{array}{l}\text { Eddy diffusivities } \\
\text { Boundary conditions } \\
\text { Transport time step }\end{array}$ & $\begin{array}{l}\text { Primary } \\
\text { Model input } \\
\text { Model parameter }\end{array}$ & Species concs. \\
\hline
\end{tabular}

Boundary layer/turbulence: Calculates turbulent transport parameters (e.g., eddy diffusivities) from other meteorological pa:ameters

$\begin{array}{llll}\text { Short-lived CTM } & \text { Temperature } & \text { Meteorological model } & \begin{array}{c}\text { Vertical mass transfer } \\ \text { rates }\end{array} \\ \text { Long-lived CTM } & \text { Pressure } & \text { Meteorological model } & \begin{array}{c}\text { Vertical mass transfer } \\ \text { rates }\end{array} \\ \text { Aerosol CTM } & \begin{array}{l}\text { U,v,w wind } \\ \text { components } \\ \text { Moisture } \\ \text { Stability }\end{array} & \text { Meteorological model } & \text { Vertical mass transfer } \\ & \begin{array}{l}\text { Terrain } \\ \text { Land use }\end{array} & \begin{array}{l}\text { Meteorological model } \\ \text { Meteorological model }\end{array} & \\ & \text { Surface roughness } & \begin{array}{l}\text { Fixed } \\ \text { Fixed }\end{array} & \\ & \text { Fixed }\end{array}$

Stratosphere/troposphere exchange: Calculates changes in species concentrations from transport between the troposphere and stratosphere

$\begin{array}{llll}\text { Short-lived CTM } & \begin{array}{c}\text { Climatology of strat. } \\ \mathrm{O}_{3} \text { and } \mathrm{NO}_{y} \text { concs. } \\ \text { Julian day }\end{array} & \text { Model parameters } & \begin{array}{c}\text { Strat./tropo. flux } \\ \text { of } \mathrm{O}_{3} \text { and } \mathrm{NO}_{y}\end{array} \\ \text { Long-lived CTM } & \begin{array}{c}\text { Strat. } \mathrm{O}_{3} \text { and } \mathrm{NO}_{y} \\ \text { concs. }\end{array} & \text { Model parameters } & \begin{array}{c}\text { Strat./tropo. flux } \\ \text { of } \mathrm{O}_{3} \text { and } \mathrm{NO}_{4}\end{array} \\ \text { Aerosol CTM } & \begin{array}{c}\text { Strat. } \mathrm{O}_{3} \text { and } \mathrm{NO}_{4} \\ \text { concs. }\end{array} & \text { Model parameters } & \begin{array}{c}\text { Strat./tropo. flux } \\ \text { of } \mathrm{O}_{3} \text { and } \mathrm{NO}_{y}\end{array}\end{array}$

\section{CLOUD PROCESSES}

Microphysics: Calculates microphysical parameters (cloud water concentration, precipitation rate, ...) from other meteorological parameters for use by other modules. Calculates subgrid spatial variations of cloud parameters in stratiform and shallow convective clouds for use by other modules 
IABLE 2.1. (contd)

\begin{tabular}{c}
$\begin{array}{c}\text { Module/ } \\
\text { Class }\end{array}$ \\
\hline
\end{tabular}

Short-lived CTM

Long-lived CTM

Aerosol CTM
Input

\begin{tabular}{l}
\hline \multicolumn{1}{c}{ Field } \\
\hline Water vapor \\
Temperature \\
Pressure \\
Vertical velocity \\
Cloud water mass \\
Precipitation rate
\end{tabular}

None

Water vapor
Temperature
Pressure
Vertical velocit

Vertical velocity

Subgrid vert. vel.

Cloud drop. nuc. rate

Mean cloud water mass, number

Mean cloud ice mass, Primary number

Mean rain water mass, Primary number

Mean precipitation rate Primary

Cloud water variance Primary

Cloud drop number var. Primary

Cloud ice variance Primary

Cloud ice number var. Primary

Precipitation variance Primary
Source

Meteorological model

Meteorological model

Meteorological model

Meteorological model

Primary

None

Meteorological model

Meteorological model

Moteorological mode

Primary

Primary
Cloud water mass

Precipitation rate

Subgrid cloud fraction

None

Mean cloud water mass

and drop number

Mean cloud ice mass

and ice crystal number

Mean precipitation

Variance of cloud water

mass and drop number

Variance of cloud ice mass and ice crystal number

Variance of precipitation rate

Subgrid cloud fraction

Scavenging: Calculates changes in species concentrations from interactions with cloud and precipitation particles and precipitation fallout

\begin{tabular}{|c|c|c|c|}
\hline Short-lived CTM & $\begin{array}{l}\text { Cloud water } \\
\text { Precipitation } \\
\text { Subgrid cloud fraction } \\
\text { Gas concentrations } \\
\text { Rain water } \\
\text { Rain drop number } \\
\text { Aerosol mass } \\
\text { Aerosol composition } \\
\text { Aerosol size } \\
\text { distrib. params. } \\
\text { Dissolved gas conc. } \\
\text { Dissolved aero. mass } \\
\text { Dissolved aero. comp. }\end{array}$ & $\begin{array}{l}\text { Primary } \\
\text { Primary } \\
\text { Primary } \\
\text { Primary } \\
\text { Primary } \\
\text { Primary } \\
\text { Primary } \\
\text { Primary } \\
\text { Model parameters } \\
\text { Primary } \\
\text { Primary } \\
\text { Primary }\end{array}$ & $\begin{array}{l}\text { Soluble gases conc. } \\
\text { Aerosol mass } \\
\text { Aerosol composition }\end{array}$ \\
\hline
\end{tabular}


TABLE 2.1. (contd)

Module/
Class

Long-lived CTM

Aerosol CTM
Input

Field

None

Cloud water Cloud drop number

Precipitation

Subgrid cloud fraction

Gas concentrations

Aerosol number, mass. composition

Aerosol size

dist. params.

Dissolved gas conc. Primary

Dissolved aero. number, Primary

mass, composition

None

Primary

Primary

Primary

Primary

Primary

Primary
Model parameters

Source

Outout Field

None

Soluble gas concs.

Aerosol number, mass, composition

Activation: Calculates activation of aerosols to cloud droplets during cloud formation

$\begin{array}{ll}\text { Short-lived CTM } & \begin{array}{l}\text { Aerosol mass } \\ \text { Aerosol composition } \\ \text { Aerosol size } \\ \text { distrib. params. } \\ \text { Vertical velocity } \\ \text { Temperature } \\ \text { Pressure }\end{array} \\ & \text { None } \\ \text { Long-lived CTM } & \text { Aerosol number } \\ \text { Aerosol CTM } & \begin{array}{l}\text { Aerosol mass } \\ \text { Aerosol composition } \\ \text { Aerosol size } \\ \text { distrib. params. } \\ \text { Vertical velocity } \\ \text { Subgrid vert. vel. } \\ \text { Temperature } \\ \text { Pressure }\end{array}\end{array}$

Primary

Primary

Model parameters

Meteorological model Meteorological model Meteorological model

None

Primary

Primary

Primary

Model parameters

Meteorological model

Meteorological model Meteorological model Meteorological model
Aerosol mass

Aerosol composition

Cloud drop nucleation

rate

None

Aerosol number

Aerosol mass

Aerosol composition

Cloud drop nucleation rate

Convective clouds: Calculates changes in species concentrations from vertical transport by convective clouds

Short-lived CTM Cumulus mass flux Gas concentrations
Meteorological model Primary
Gas concentrations

Aerosol mass 
TABLE 2.1. (contd)

\begin{tabular}{|c|c|c|c|}
\hline \multirow{2}{*}{$\begin{array}{l}\text { Module/ } \\
\text { Class }\end{array}$} & \multicolumn{2}{|c|}{ Input } & \multirow[b]{2}{*}{ Output Field } \\
\hline & Field & Source & \\
\hline & $\begin{array}{l}\text { Aerosol mass } \\
\text { Aerosol composition }\end{array}$ & $\begin{array}{l}\text { Primary } \\
\text { Primary }\end{array}$ & Aerosol composition \\
\hline Long-lived CTM & $\begin{array}{l}\text { Cumulus mass flux } \\
\text { Gas concentrations }\end{array}$ & $\begin{array}{l}\text { Meteorological model } \\
\text { Primary }\end{array}$ & Gas concentrations \\
\hline Aerosol CTM & $\begin{array}{l}\text { Cumulus mass flux } \\
\text { Gas concentrations } \\
\text { Aerosol number } \\
\text { Aerosol mass } \\
\text { Aerosol composition }\end{array}$ & $\begin{array}{l}\text { Meteorological model } \\
\text { Primary } \\
\text { Primary } \\
\text { Primary } \\
\text { Primary }\end{array}$ & $\begin{array}{l}\text { Gas concentrations } \\
\text { Aerosol number } \\
\text { Aerosol mass } \\
\text { Aerosol composition }\end{array}$ \\
\hline
\end{tabular}

\section{SURFACE EXCHANGE}

Calculates changes in species concentrations from exchange between the atmosphere and land/ocean surfaces

\begin{tabular}{|c|c|c|}
\hline Short-lived CTM & $\begin{array}{l}\text { Gas-phase species } \\
\text { emissions rates } \\
\text { Gas-phase species } \\
\text { concs. } \\
\text { Canopy resistance by } \\
\text { spacies and land use } \\
\text { Surface wind speed } \\
\text { Surface temperature } \\
\text { Stability } \\
\text { Surface roughness } \\
\text { and cover }\end{array}$ & $\begin{array}{l}\text { Emissions inventory/ } \\
\text { model } \\
\text { Primary } \\
\text { Model parameters } \\
\text { Meteorological model } \\
\text { Meteorological model } \\
\text { Meteorological model } \\
\text { Fixed }\end{array}$ \\
\hline Long-lived CTM & $\begin{array}{l}\text { Gas-phase species } \\
\text { emissions rates } \\
\text { Gas-phase species } \\
\text { conc. } \\
\text { Deposition velocities } \\
\text { by species }\end{array}$ & $\begin{array}{l}\text { Emissions inventory/ } \\
\text { model } \\
\text { Primary } \\
\text { Model parameters }\end{array}$ \\
\hline Aerosol CTM & $\begin{array}{l}\text { Gas-phase species } \\
\text { emissions rates } \\
\text { Gas-phase species } \\
\text { conc. } \\
\text { Aerosol emissions rate } \\
\text { Aerosol concentration }\end{array}$ & $\begin{array}{l}\text { Emissions inventory/ } \\
\text { model } \\
\text { Primary } \\
\text { Emissions inventory/ } \\
\text { model } \\
\text { Primary }\end{array}$ \\
\hline
\end{tabular}
Gas-phase species net removal rate at surface Aerosol net removal rate at surface
Gas-phase species net removal rate at surface


TABLE 2.1. (contd) Class Input

\begin{tabular}{l}
\hline Field \\
\hline Canopy resistance by \\
species and land use \\
Surface wind speed \\
Surface temperature \\
Stability \\
Surface roughness \\
and cover
\end{tabular}

\section{ACTINIC FLUX}

Radiative transfer: Calculates actinic fluxes and photolysis rates and effect of subgrid spatial variability of clouds on actinic fluxes and photolysis rates

\begin{tabular}{|c|c|c|c|}
\hline Short-lived CTM & $\begin{array}{l}\text { Latitude and longitude } \\
\text { Local time } \\
\text { Altitude } \\
\text { RITS concentrations } \\
\text { Subgrid cloud fraction } \\
\text { Cloud water mass } \\
\text { Cloud droplet number }\end{array}$ & $\begin{array}{l}\text { Primary } \\
\text { On-line calculation } \\
\text { Primary } \\
\text { Primary } \\
\text { Primary } \\
\text { Primary } \\
\text { Primary }\end{array}$ & Actinic flux \\
\hline Long-lived CTM & $\begin{array}{l}\text { Latitude and longitude } \\
\text { Local time } \\
\text { Altitude }\end{array}$ & $\begin{array}{l}\text { Primary } \\
\text { On-line calculation } \\
\text { Primary }\end{array}$ & Actinic flux \\
\hline Aerosol CTM & $\begin{array}{l}\text { Latitude and longitude } \\
\text { Local time } \\
\text { Altitude } \\
\text { Temperature } \\
\text { Pressure } \\
\text { Relative humidity } \\
\text { RITS concentrations } \\
\text { Subgrid cloud fraction } \\
\text { Cloud water mass and } \\
\text { droplet number } \\
\text { Cloud ice mass and } \\
\text { ice crystal number } \\
\text { Aerosol mass, number, } \\
\text { and composition } \\
\text { Aerosol size dist. } \\
\text { parameters }\end{array}$ & $\begin{array}{l}\text { Primary } \\
\text { On-line calculation } \\
\text { Primary } \\
\text { Meteorological model } \\
\text { Meteorological model } \\
\text { Meteorological model } \\
\text { Primary } \\
\text { Primary } \\
\text { Primary } \\
\text { Primary } \\
\text { Primary } \\
\text { Model parameters }\end{array}$ & Actinic flux \\
\hline
\end{tabular}


etc.). Within each subprocess category, the input fields are listed, the source of the input fields is given, and the output fields are listed. Input and output fields are specified for each of the three CTMs. Variables whose source is identified as "primary" are variables that must be defined at all grid nodes within the GTCMS and need to be accessible to a large number of modules. Some variables are provided to the GTCMS from external models or data bases. All meteorological variables (temperature, pressure, relative humidity, wind, etc.) are primary variables that are supplied by the meteorological driver model, which, for example, could be a GCM or hemispheric prognostic model. Emissions inventories and models provide input rates for gaseous and aerosol species in each grid cell for point and area sources of anthropogenic and natural origin. Model inputs include many parameters, such as chemical reaction rate and solubility constants, that are set and remain constant. Also, there are many fixed or prescribed inputs, such as terrain elevation, land use, grid spacings, and time steps. Initial and boundary conditions (species concentrations, physical variables) must be specified for all primary variables internal to the GTCMS.

\subsubsection{Short-Lived Species Chemical Transport Model}

The short-lived species CTM is designed to simulate global $0_{3}$ distributions in the troposphere. To accurately predict $\mathrm{O}_{3}$ distributions, it is necessary to also simulate $\mathrm{NO}_{x}, \mathrm{CO}$, and hydrocarbon $(\mathrm{HC})$ distributions. Thus, the short-lived species CTM must account for the emission, transport, and photochemical transformations of $\mathrm{NO}_{x}$, $\mathrm{NO}_{y}$, various $\mathrm{HCS}$ (including $\mathrm{CH}_{4}$ and $\mathrm{CO}$ ), and $O_{3}$. It is recommended that the short-lived species CTM be used to provide oxidant concentration distribution fields to the long-lived species CTM and possibly, in certain cases, to the aerosol CTM. Consequently, the optimal model reflects the most advanced science that could reasonably be achieved within the 3-year project period. The short-lived species CTM is the core of the GTCMS.

\subsubsection{Chemistry}

To account for the photochemical production and destruction of $\mathrm{O}_{3}$, a gasphase chemical mechanism is required that includes basic $\mathrm{NO}_{x} / \mathrm{O}_{3} / \mathrm{HC}$ photochemistry. In remote regions, $\mathrm{CH}_{4} / \mathrm{CO}$ chemistry must be included; while in 
near-continental areas, a multiple lumped HC representation is needed to account for anthropogenic and biogenic emissions. The most important aspect of the multiple lumped $\mathrm{HC}$ mechanism is the inclusion of appropriate radicalradical reactions,

$$
\mathrm{RO}_{2}+\mathrm{RO}_{2}-\cdots \text { products }
$$

Radical-radical reactions are not usually significant for the accurate representation of radicals in polluted environments (Seinfeld 1989); however, on a global scale and remote areas in particular, these reactions will be an important sink for odd-oxygen species (Lurmann et a1. 1986). Thus, a gasphase mechanism must be developed that appropriately represents these reactions while keeping in mind that the chemical transformation calculations account for $>90 \%$ of the total model computational burden. Also, the gas-phase sulfur reactions, DMS $\mathrm{LS} \mathrm{SO}_{2}$ and $\mathrm{MSA}$ and $\mathrm{SO}_{2}$ to $\mathrm{H}_{2} \mathrm{SO}_{4}$, need to be included to treat aerosol processes correctly within the optimal model (Kreidenweis et al. 1991).

In the aqueous phase, the reactions of S(IV) oxidation to $S$ (VI) are included, which requires that $\mathrm{NO}_{y} / \mathrm{O}_{3} / \mathrm{H}_{2} \mathrm{O}_{2}$ aqueous reactions be included (Finlayson-Pitts and Pitts 1986). Aqueous radical reactions of the type proposed by Lelieveld and Crutzen (1991) should be included because these may have a significant effect on $0_{3}$ distributions globally. The heterogeneous reaction of $\mathrm{N}_{2} \mathrm{O}_{5}$ on wetted aerosol particles producing $\mathrm{HNO}_{3}$ (Dentener and Crutzen 1993) appears important to the global $\mathrm{NO}_{x}$ budget and should also be included. No size dependence to aqueous chemistry or aerosol properties can be justified for inclusion at this time into the short-lived species CTM.

The subgrid treatment of chemical processes would be an important aspect of the short-lived species CTM. In the near future, computational resource limits will prevent global models having the horizontal resolution necessary to fully resolve major $\mathrm{NO}_{\mathrm{x}}$ plumes from large urban areas. Within these subgrid plumes, substantial $0_{3}$ production can take place that is not translated to the large-scale grid when using only instantaneous dispersion of subgrid sources. The exact form that this subgrid treatment should take is not clear, though it is clear that the instantaneous dispersion treatment is 
not be desirable. Development of a plume-in-grid or statistical method (e.g., Sillman et al. 1990) should be a priority research topic.

\subsubsection{Dynamics}

While K-theory approximations will be adequate for the short-lived species CTM, some higher-order dynamics can be incorporated in a relatively straightforward manner by using a turbulent kinetic energy model to generate eddy diffusivity values (e.g., Yamada and Mellor 1975). The K-theory approximation will be adequate in light of the inclusion of a convective cloud parameterization to redistribute material between layers in a nonlocal fashion. For stratosphere/troposphere exchange, a simple boundary condition treatment will not be adequate to accurately simulate the global distribution of $\mathrm{O}_{3}$.

Thus, the model domain should be extended into the lower stratosphere in which some type of $\mathrm{O}_{3}$ and $\mathrm{NO}_{y}$ climatology is specified. No chemical calculations would be performed in the lower stratosphere, but a GCM would be used to provide dynamic exchange information for the transport of material across the tropopause. The exchange of mass between the stratosphere and troposphere is currently not very well understood (Slinn 1993) and should receive significant emphasis in the design of the short-lived species CTM.

\subsubsection{Cloud Processes}

The effects of clouds are an important, though not dominant, factor in the design of the short-lived species CTM. Consequently, bulk treatments of cloud microphysics, scavenging processes, and aerosol activation (nucleation of cloud drops) were chosen. Further, a fractional subgrid cloud treatment is adequate, with cloud convective processes implemented in a manner consistent with the treatment of cumulus convection in the GCM used to provide the meteorological data.

\subsubsection{Surface Exchange}

A surface-exchange model was chosen as a feasible goal for inclusion in the short-lived species CTM. The dry deposition/resistance approach (Wesely 1989) does not allow for the possible two-way exchange of material across the soil/atmosphere or ocean/atmosphere interfaces. Thus, a surface-exchange 
model should be developed that can more adequately treat surface-exchange processes. Progress by the agricultural science community on surface-exchange processes should be examined and adapted by the atmospheric science community to the GTCMS.

\subsubsection{Actinic Flux}

The actinic flux calculations for the short-lived species CTM must be more realistic than present-day, look-up-table approaches (e.g., Peterson 1977 ) but short of on-line radiative flux calculations. The actinic flux will be parameterized to dynamically depend on cloud amounts and will vary with the total cloud fraction and type of cloud within the grid cell. This information would be accessible through look-up tables.

\subsubsection{Numerics}

Time splitting, coupled with either a one-dimensional finite-difference method or a one-dimensional finite-element method on a regular, uniform grid, would suffice for solving the transport equations for this model. The use of an irregular horizontal grid (Mathur et al. 1992) would allow the a priori specification of a grid that would have finer resolution over the continents and coarser grid spacing over remote ocean areas, providing finer resolution only where it is really needed. Although the use of an irregular grid has significant advantages, implementing and testing such a scheme within the 3-year project period is not likely. However, because irregular grids will likely be used in future versions of the model, time splitting with a onedimensional finite-element method is recommended for the initial version. This would allow for the relatively straightforward modification of the code in future years to use time splitting with irregular two-dimensional elements in the horizontal plane.

Although a new stiff ordinary differential equation (ODE) solver is a high priority for improving the integration of the chemistry rate equations, the quasi-steady-state approximation (QSSA) method (Hesstvedt et al. 1978) is recommended because of its economy and current widespread use. of course, if a faster, yet accurate, method became available during the development of the model, it should be incorporated. 


\subsubsection{Long-Lived Species Chemical Transport Model}

The long-lived species CTM is capable of simulating the distribution and chemical reactions of RITS over a time scale of decades. The only long-lived species that is chemically reactive in the troposphere is $\mathrm{CH}_{4}$. The gas-phase chemistry mechanism will require carrying additional reactive species that are not radiatively important, such as $\mathrm{OH}$ and certain classes of NMHCs. Nonreactive species, such as the CFCs and $\mathrm{N}_{2} \mathrm{O}$, can be carried in the model as inert tracérs.

\subsubsection{Chemistry}

Gas-Phase Reactions. The primary reactions to be explicitly described in the long-lived species CTM are those related to $\mathrm{CH}_{4}$. It was deemed infeasible to explicitly calculate the $\mathrm{OH}$ concentrations necessary for describing the full $\mathrm{CH}_{4} / \mathrm{OH} / \mathrm{CO}_{2}$ sequence for model runs on decadal time scales. A necessary alternative is to prescribe the oxidant fields in advance, using output from the short-lived species CTM. In addition to tabulating (or describing in some other readily accessible form) the $\mathrm{OH}$ concentrations, information on the sensitivity of $\mathrm{OH}$ to $\mathrm{CH}_{4}$ and other species involved in the $\mathrm{CH}_{4}$ cycle is needed. These values would have to reflact trends in time (on a seasonal scale) and space.

A significant reduction in computer time would result by not having to carry all the species necessary to calculate $\mathrm{OH}$ fields. In addition, the resulting kinetic equations could be evaluated using a nonstiff differential equation integrator, resulting in an additional reduction in computer costs. The use of precalculated $\mathrm{OH}$ concentration fields would be the single most important simplification incorporated into the long-lived species CTM so that it could be run in a timely manner for a multitude of planning and policy issues.

Aqueous Reactions. The explicit inclusion of detailed cloud fields, and, hence, of aqueous-phase reactions, would be impossible over the time scales this model would be called on to simulate. If the $\mathrm{CH}_{4}$ fields respond to cloud processes, those processes would have to be included in some statistical fashion or reflected in the look-up tables for $\mathrm{OH}$ (and its associated derivatives). 
Aerosols. Aerosols were considered to be significant over decadal time scales only if a feedback process between the chemistry and the atmospheric dynamics were to be simulated. Because this is beyond the scope of the requested design, a simulation of aerosol processes was considered an unnecessary computational burden for this model.

\subsubsection{Dynamics}

Planetary Boundary Layer/Turbulence. A simple first-order turbulence scheme is satisfactory to account for turbulent mixing in the planetary boundary layer.

Stratosphere/Troposphere Exchange. This is an area requiring research, and one where the results could greatly affect simulations of the distribution of the long-lived species in the troposphere. It is unlikely that a detailed mechanistic treatment of stratosphere/troposphere exchange can be included in the GTCMS. Thus, the research should yield a parameterized representation of this process.

\subsubsection{Cloud Processes}

The only cloud process to be explicitly included in the long-lived species CTM is that of convective mixing. A simple formulation, using either mixing coefficients derived from the convective scheme of the GCM that provides the meteorological fields or a decoupled mechanism (Walcek and Taylor 1986 or Berkowitz et a1. 1989), would be adequate. The choice of cloud processes parameterizations should be consistent with the approach taken in the GCM that is used to provide the meteorological fields for the GTCMS. This would maintain consistency between the meteorological fields obtained from the GCM and the convective process simulations within the GTCMS.

The omission of an explicit treatment of cloud water may affect the simulated removal of $\mathrm{HCHO}$, which is a soluble species known to play an active role in the $\mathrm{CH}_{4}$ chemistry. Further research is needed to determine if this omission will have a significant effect. 


\subsubsection{Surface Exchange}

Transfer coefficients obtained from the GCM are used to calculate the exchange of $\mathrm{CH}_{4}$ between the ocean and the atmosphere. $\mathrm{CFCS}$ and $\mathrm{N}_{2} \mathrm{O}$ can be assumed to have negligible interaction with the surface.

Emissions are a component of the surface boundary condition that is very important to the simulation of the concentrations of the long-lived species. In particular, the geographic and seasonal distribution of $\mathrm{CH}_{4}$ emissions must be thoroughly specified.

\subsubsection{Actinic Flux}

The use of look-up tables, based on aerosol and trace gas concentrations and meteorological conditions, is recommended for both the magnitude of the actinic flux and its subgrid variability.

\subsubsection{Numerics}

Transport. The Lagrangian method is not recommended for reasons related to computational effort. Although the method of moments is very accurate, the computational effort was not felt to be necessary in light of other simplifications associated with this model. Other than these two caveats, any mass conserving, accurate integration scheme would be acceptable.

Chemistry. Any currently used integration package would be acceptable, though the Gear routine offers the advantage of automatically adjusting the time step to an optimal increment. However, further analysis will be needed to determine how the numerical time steps of a nonstiff chemical integrator would relate to the time steps used in the meteorological driver.

\subsubsection{Aerosol Chemical Transport Model}

The aerosol CTM will simulate the global distribution of anthropogenic aerosols and their impact on the planetary radiation balance; both by direct scattering and absorption of sunlight, and by serving as CCN. To do this, it is quite clear that the model shouid treat aerosols of differing composition (e.g., $\left[\mathrm{NH}_{4}\right]_{2} \mathrm{SO}_{4}, \mathrm{NH}_{4} \mathrm{HSO}_{4}, \mathrm{H}_{2} \mathrm{SO}_{4}, \mathrm{EC}, \mathrm{HC}$, and silicate) that have different optical and cloud nucleating properties and often compete with each other. In addition, the model should distinguish between anthropogenic and natural 
aerosols and between aerosols in the fine, accumulation, and coarse modes. The options selected to meet sse objectives optimally are discussed below.

\subsubsection{Chemistry}

Aerosol chemistry is not independent of gas-phase chemistry nor, for that matter, is aqueous-nhase chemistry independent of gas-phase chemistry. The separation is primarily for conceptual purposes: it is easier to think about these three aspects of chemistry individually rather than all at once. They are, of course, all linked by mass transfer (gases $\longleftrightarrow-->$ cloud water and gases $\longleftrightarrow$ aerosols). In the model, the chemistry ODE solver might call all three of these chemistry routines to get the rates of change for gaseous, aqueous, and aerosol chemical species. Alternately, the gas and aqueous chemistry might be solved separately from the aerosol chemistry because of differing time scales (stiffness). In this case, the $\mathrm{N}_{2} \mathrm{O}_{5}$ (gas) $\rightarrow \mathrm{HNO}_{3}$ (aerosol) reaction might be treated in the gas-phase chemistry module, and the resulting change in $\mathrm{HNO}_{3}$ (aerosol) over the model time step would then be passed to the aerosol module.

The gas- and aqueous-phase chemistry important to the aerosol model involves the transformation of aerosol precursors ( $\mathrm{SO}_{2}$, DMS, organics) to aerosol species. Thus, oxidant species involved in these transformations $(\mathrm{OH}$, $\mathrm{HO}_{2}, \mathrm{H}_{2} \mathrm{O}_{2}, \mathrm{O}_{3}$ ) must be available. The appropriate gas-phase mechanism for simulating these oxidants is a hybrid mechanism that treats $\mathrm{NO}_{x}, \mathrm{O}_{3}, \mathrm{CO}, \mathrm{CH}_{4}$, and several lumped HCs over continental regions with significant $H C$ emissions but ignores $\mathrm{HCs}$ over other regions to reduce computational costs. Sulfur chemistry ( $\mathrm{SO}_{2}$ and DMS) clearly must be included. Note that because sulfur chemistry has little effect on $\mathrm{OH}$ concentrations, multiple simulations with differing $\mathrm{SO}_{2}$ and particle emissions (but fixed $\mathrm{NO}_{x}$ and $\mathrm{HC}$ emissions) could be performed by saving the $\mathrm{OH}$ from the first simulation and reusing it in subsequent simulations. A much simpler, though less realistic, alternative for obtaining $\mathrm{OH}$ is to parameterize it as a function of several variables, such as actinic flux, humidity, temperature, $\mathrm{CO}, \mathrm{O}_{3}$, and $\mathrm{NO}_{\mathrm{y}}$ (Spivakovsky et al. 1990). Further evaluation of this approach versus the direct computation of $\mathrm{OH}$ is needed. $\mathrm{NH}_{3}$ is very important because it determines whether sulfate is present as $\mathrm{H}_{2} \mathrm{SO}_{4}, \mathrm{NH}_{4} \mathrm{HSO}_{4}$, or $\left(\mathrm{NH}_{4}\right)_{2} \mathrm{SO}_{4}$. Because $\mathrm{NH}_{3}$ emissions are poorly known, it is not clear whether direct computation or an 
empirical parameterization of its concentration would produce better results. An approach following Sillman (1991) is recommended for the time integration of the full chemistry; if $\mathrm{OH}$ is prescribed, the chemical system is no longer stiff and a simple, nonstiff scheme is adequate.

Aqueous-phase chemical reactions could be limited to the reactions of dissolved $\mathrm{SO}_{2}$ with $\mathrm{H}_{2} \mathrm{O}_{2}$ and $\mathrm{O}_{3}$. Other reactions, such as $\mathrm{SO}_{2}$ oxidation by trace metals and $\mathrm{OH}$, and aqueous-phase $\mathrm{H}_{2} \mathrm{O}_{2}$ production are currently felt to be of secondary importance. The main difficulty with the $\mathrm{SO}_{2}$-trace metal reaction is specifying trace metal concentrations. Simulating aqueous free radical chemistry is computationally expensive. Solution chemistry involving soluble gases $\left(\mathrm{NH}_{3}, \mathrm{HNO}_{3}\right)$ and aerosol species $\left(\mathrm{NH}_{4}, \mathrm{NO}_{3}\right.$, etc.) should also be included. In addition to gas- and aqueous-phase chemistry, some heterogeneous reactions involving gases and aerosols should be considered. Examples are the oxidation of $\mathrm{SO}_{2}$ to sulfate in deliquescent sea-salt particles (Chameides and Stelson 1992) and the reaction of $\mathrm{N}_{2} \mathrm{O}_{5}$ on wetted aerosol particles producing $\mathrm{HNO}_{3}$. Although evidence is accumulating that aqueous-phase chemistry depends to some extent on cloud droplet size, it was not felt that this has a primary effect on aerosol concentrations and size distributions, and including it in the model is not justified because of the added computational burden.

Because aerosol light-scattering and droplet-nucleating properties are strongly size dependent, some information on the aerosol size distribution must be included in the model to caiculate the radiative effects of aerosols. The method of moments offers an efficient means of representing the size distribution of each aerosol moment without the very large computational burden of explicitly treating the size distribution. Each mode of the size distribution is expressed in terms of an analytic function (log-normal is generally used) whose parameters can be related to just a few moments of the aerosol size distribution. The parameters of the log-normal distribution (total number, geometric mean radius, and geometric standard deviation) can be related to any three integer moments of the size distribution. This approach is physically justified by the fact that observed aerosol size distributions can often be accurately approximated by combinations of log-normal functions (Whitby 1978). Considerable development of the method of moments was done by 
Giorgi (1986) and Whitby et al. (1991). The method is currently being used in EPA's Regional Particulate Model.

Aerosol growth processes, such as coagulation, vapor condensation, surface reactions, and aqueous chemical reactions in cloud drops followed by drop evaporation, lead to aerosol particles that are mixtures of several chemical species. Such internal mixtures can have optical and nucleating properties that are quite different from external mixtures of single-component aerosols, so the degree of internal mixing of the aerosol components is an important issue. There are three strategies for modeling the aerosol composition. The external mixing strategy assumes that individual particles are composed of a single chemical species (i.e., sulfate and carbon are found in different particles). The internal mixing strategy assumes that, within a given mode, each particle is the same mixture of the chemical components of the mode (i.e., each particle is $70 \%$ sulfate and $30 \%$ carbon). Both of these strategies are easily implemented but neither is realistic, though the internal mixing strategy is fairly good for the accumulation mode. The partial mixing strategy recognizes that, at a given size, particles with many different chemical mixtures exist. This strategy is most appropriate for the aerosol model; however, it is not straightforward and additional research is needed to implement it.

\subsubsection{Dynamics}

Turbulent mixing should be treated in a manner consistent with the treatment in the meteorological model. First-order $K$-theory is adequate for the optimal model. Tropospheric-stratospheric exchange is of secondary importance for aerosols and can be treated as an inflow-outflow boundary with prescribed stratospheric concentrations.

\subsubsection{Cloud Processes}

Cloud microphysical processes play a critical role in processing aerosols and in determining indirect radiative impacts of aerosols. The treatment of cloud microphysics considered most attractive for this application is the method of moments, in which a few moments of the cloud particle-size distribution are predicted (Clark 1976; Clark and Hall 1983; Ziegler 1985; Verlinde et al. 1990). As a minimum, the cloud particle number and volume would be 
predicted, which permits a treatment of the influence of aerosols on cloud particle size and provides adequate information on cloud radiative properties. cloud microphysical processes and their impact on each moment would be treated by assuming idealized cloud particle-size distributions. Cloud ice should be distinguished from cloud liquid water because it affects aerosols and gaseous precursors in a much different manner. It may be possible to ignore cloud ice in the GTCMS (though not in the meteorological driver) because cloud ice generally has a much smaller impact than cloud water on aerosols and gases.

The nucleation of cloud droplets on aerosols (activation) should be treated by accounting for the influence of preferential nucleation on all moments of each aerosol mode. The competition between different aerosol components and different aerosol modes must be represented.

Given that the method of moments is used to represent both aerosols and cloud particles, it is natural to use the method of moments to treat aerosol scavenging by clouds. Analytic integrations over size distributions of aerosol and precipitation would be performed using assumed idealized size distributions.

When aerosols enter a cloud, two different aerosol populations are formed: those in the interstitial air and those in cloud droplets. Each of these have separate size distributions and are affected by different processes (e.g., aqueous chemical reactions and cloud droplet coalescence affect those in cloud droplets). A methodology for treating these two populations and combining them when a cloud evaporates needs to be developed.

A realistic treatment of subgrid variability in clouds and cloud processes is critical for global chemistry models. Two options are considered. Subgrid variability could be expressed in terms of idealized probability distributions of each cloud variable, with several moments of the probability distribution (e.g., mean and variance) predicted by integrating all microphysical processes over the probability distributions of the cloud variables. Although this approach is likely to be the state of science within 5 years, it relies on estimates of subgrid variability in vertical velocity, which is a very challenging task. The optimal model would, instead, simply express subgrid variability in terms of a cloud fraction, with the clear and cloudy 
fractions assumed to be homogeneous. Although this is a crude representation of subgrid variability, it captures much of the variability and is much easier to parameterize than a full probability distribution.

Vertical transport and scavenging of chemical species by convective clouds should be treated in a manner consistent with the treatment of cumulus convection in the meteorology model. A single-piume updraft/downdraft version of the mass flux scheme of Arakawa and Schubert (1974) is optimal, for it provides a straightforward means of treating transport and scavenging of all species without the high computational cost of the full spectral Arakawa and Schubert (1974) parameterization.

\subsubsection{Surface Exchange}

Global emissions inventories are needed for each primary particulate aerosol type and all aerosol precursors. For primary particles, emissions of smoke and soot from industrial sources, transportation, and biomass burning (natural and agricultural) and suspension of dust are needed. Gaseous precursors to aerosols include $\mathrm{SO}_{2}, \mathrm{DMS}, \mathrm{NH}_{3}, \mathrm{NO}_{x}$, and organics. For natural emissions, dependence on wind speed and stability should be represented using resistance formulations. For anthropogenic emissions, seasonal dependence should be accounted for. The treatment of surface exchange involving emission products should also use the resistance formulation.

\subsubsection{Actinic Flux}

For the purpose of simulating $\mathrm{OH}$, actinic flux is needed for photochemical mechanisms. The look-up-table approach should be augmented by an on-line treatment of the influence of clouds on actinic flux. This can be accomplished simply by using a two-stream radiation model with the cloud optical properties and subgrid variability to determine the ratio of the cloudy sky actinic flux to that for clear-sky conditions. The ratio should not vary much with wavelength, so that the same ratio can be applied to the clear-sky look-up table for all photochemical absorption bands.

\subsubsection{Numerics}

Transport should be calculated with a one-dimensional finite-difference or finite-element algorithm. The added complexity of two-dimensional or 
method of moments is not warranted; a fixed irregular grid system would be optimal because higher resolution could be given to source regions with little additional computational burden. However, additional software development is required for interpolating meteorological, emissions, and land-use data from a regular to irregular grid and for analysis of simulation results. Unless the irregular grid is selected for another model (e.g., short-lived gases), this development may not be justified.

\subsection{UNCERTAINTY/SENSITIVITY}

Model uncertainty has several components. Uncertainty arises from the fact that the mathematical descriptions of physical and chemical processes in the model only approximate real-world processes. Additional uncertainty arises from the spatial resolution of the model (100 to $500 \mathrm{~km}$ in a GTCMS), which leaves smaller-scale processes unresolved. The techniques described below apply primarily to quantifying uncertainty from indeterminant model parameters (e.g., chemical reaction rates), initial conditions, and boundary conditions. Sensitivity analyses quantify the response of model output (e.g., a predicted concentration) to variations in a particular model parameter or input variable about a base state. Note that while model uncertainty is ultimately of most interest, calculation of model sensitivity is of value and is easier to do. Also note that performing a complete sensitivity of a threedimensional atmospheric chemistry model is a gigantic computational task. At best, uncertainty is dealt with through an analysis of the sensitivity of the model to various inputs and model parameters. Various approaches for uncertainty and sensitivity analyses are briefly discussed below.

The Monte Carlo method, used for both sensitivity and uncertainty analyses, involves doing repeated model simulations with different values of an uncertain model parameter or initial or boundary condition. The sensitivity of a model prediction (e.g., $\mathrm{O}_{3}$ concentration) to a model parameter is simply the change of the predicted value relative to the change in the model parameter between two different simulations. To obtain the uncertainty of a model prediction, probability distributions for all model parameters of concern must be specified. (This could be simply a normal distribution with 
specified mean and standard deviation.) The mean and standard deviation for the predicted values give a measure of model uncertainty.

The direct decoupled method is a sensitivity analysis technique that has been applied primarily to photochemical mechanisms (Dunker 1984). Additional code is added to the model so that it predicts both concentrations of various species and the sensitivities of these concentrations to one or more model parameters or initial or boundary conditions. The similarity of the ODEs for the sensitivity coefficients and those for the species concentrations results in considerable computational savings during solution of the equations.

While the Monte Carlo and direct decoupled methods compute the sens $i$ tivity of all model predictions (every species at every grid point) to a single model parameter, the adjoint method computes the sensitivity of a single prediction (e.g., a spatial and temporal average of the $0_{3}$ concentration) to multiple model parameters (Hall et al. 1982). The method involves construction and solution of a second model, called the adjoint, that predicts the sensitivity coefficients. This method is receiving much interest in four-dimensional data assimilation, and methods for automatic generation of adjoint codes are being developed. Monte Carlo analyses are impractical for the computationally intensive short-lived species CTM. An adjoint technique, implemented with automatic differentiation (Griewank and Corliss 1991), is a very attractive option if it could be implemented within the project time period.

The stochastic variables method is a new and promising technique for uncertainty analysis. Stochastic variables are a set of orthogonal random variables. The probability distribution for each uncertain model parameter and initial condition is expressed as a series of one or more stochastic variables. The resulting model predictions then become a series of these stochastic variables (rather than just a number), and this series represents the probability distribution of the predicted value.

Automatic differentiation is a major breakthrough in scientific computing (see Griewank and Corliss 1991), is a fundamentally new technology for reliably computing derivatives of large computer codes many times faster compared to current approaches, and is based on a completely different 
approach than the finite-difference approximation of derivatives or symbolic differentiation. This emerging technology has been recently incorporated in general-purpose automatic differentiation software packages, such as ADIFOR and $A D O L-C$ developed at Argonne National Laboratory. Given a Fortran program describing how "dependent" variables $y 1, y 2, \ldots, y n$ are obtained from "independent" variables $x 1, \times 2, \ldots, x m$, ADIFOR automatically generates a Fortran code for the computation of the derivatives of the dependent variables with respect to the independent variables. ADOL-C is a similar tool for automatic differentiation of programs written in $\mathrm{C}$ or $\mathrm{C}++$.

It is clear that tools for integrating uncertainty and sensitivity analyses into complex numerical models now exist and are rapidly being improved. It is recommended that these state-of-science methods be incorporated into the numerical codes for the GTCMS as it is developed.

\subsection{GENERAL DISCUSSION OF RESEARCH NEEDS AND ACTIVITIES}

Each class of CTM in the GTCMS represents a model development goal. Many of the options that define a chosen CTM do not exist; however, for nearly every module, at least one option is available. The options that are available define the starting point for developing the GTCMS. By analyzing what research was needed to move from the current existing option to the chosen option for each module, several research areas were identified that could be addressed within a 3 -year time frame and that could significantly improve the performance of the GTCMS. Very brief descriptions of the research activities in each research area were developed. Table 2.2 gives the title of those research activities and associates the title with an abbreviated title that is used in other tables. A more detailed description of these research activities is given in Appendix $C$.

The design and construction of the GTCMS will be a complex undertaking that will ultimately require scientific and systems advances along many pathways that must be integrated and coordinated to make the GTCMS a reality.

\subsubsection{Chemistry}

Many of the research activities associated with the chemistry modules are interrelated and most are critical for the development of a scientifically 
TABLE 2.2. Titles of Research Activities Identified by Participants at the Second Workshop as Needed for the Development of the Global Tropospheric Chemistry Modeling System

Module

Abbreviation

\section{Research Activity}

\section{Clouds, Aerosols, Radiation}

Nucleation

Subgrid Cloud Processes

Aerosols

Scavenging

Actinic Flux

\section{Chemistry}

$\stackrel{y}{\sim}$

Gas Phase

Emissions

Aqueous Reactions

Clouds

Other Chemistry

\section{Meteorology and Numerics}

Dynamics

Strat/tropo exch

Nonlocal

Surface Exchange

Transport/Grid System

Numerics

Uncertainty

Subgrid variability

Moments/species

Evaluate moments

Primary einissions

Aerosols/clouds

Update J-values

$\mathrm{NO} / \mathrm{O} \mathrm{O}_{3} / \mathrm{HC}$

Grid res/No

Chen/aeroso

Emissions inven

Aerosols $/ 0_{3}$

Clouds/ $\mathrm{CH}_{4} / \mathrm{CO}$

Interfaces

$\mathrm{OH}$ fields

DAS chemistry

Irreg grid chen
Mixed aerosols Parameterize nucleation on mixed aerosols

Pevelop treatant of subgrid variability in clouds and cloud processes

Develop species-resolved manents of aerosol-size distributions

Evaluate species-resolved moments method

Emissions of primary particulate and aerosol precursors

Processing of aerosols by clouds using moments method

Update actinic flux J-value look-up tables

Develop appropriate $1 \mathrm{O} / \mathrm{O}_{3} / \mathrm{HC}$ chemical mechanism for species CTH

Evaluate effect of grid resolution on $\mathrm{HO}_{x} \mathrm{cycling}$ and $\mathrm{O}_{3}$ production Develop chemical module for aerosol CTM

Develop enissions inventories required for the GTCMS

Evaluate effect of aerosols on tropospheric $0_{3}$

Evaluate effects of clouds on tropospheric 0

Role of clouds in $\mathrm{CH} / \mathrm{CO}$ cycle vis-a-viz $\mathrm{HCHO}$ and organic acids

Devel op interface between short-lived. long-lived. and aerosol CTMs

Evaluate use of short-lived species CTM in providing OH fields for use in long-lived and aerosol CTMs

Evaluate adequacy of gas-phase oxidation mechanisms of OMS and resulting production of $\mathrm{CCN}$

Stratosphere/troposphere exchange

Planetary boundary layer/turbulence nonlocal closure

Synthesize into consistent framework models for hydrology, surface exchange. emissions. and deposition

Develop irregular grid method for chemistry

Develop numerically fast chemistry integrator

Carry out demonstration of autodifferentiation using test model or module 
credible GTCMS. Many of the activities could be grouped into a larger single activity with smaller tasks within this larger project. Considering that the chemical mechanisms for the GTCMS will be a vitally important part of the entire system and that, by definition, there should be a high degree of chemical consistency between the classes of CTMs, a composite project may be desirable.

\subsubsection{Gas Phase}

A primary research task will be the development of a gas-phase chemical mechanism that will be appropriate for the short-lived species CTM. This must include an appropriate, but not excessive, number of lumped $H C$ categories and associated secondary organic products. Particularly important for a global model will be the proper representation of radical-radical reactions in low$\mathrm{NO}_{x}$ regimes. Further, the chemical module must be designed for flexibility, so that future advances can be readily incorporated. An excellent way to begin the chemical mechanism construction process would be to conduct a workshop that would bring together experimental atmospheric chemists and modelers to compile the latest understanding of gas-phase chemical processes that are important on the global scale.

One portion of the overall task of constructing an appropriate gas-phase chemical mechanism will be to evaluate the current understanding of DMS tropospheric chemistry. This will include the relative production of $\mathrm{SO}_{2}$ and MSA from DMS and the resulting production of $\mathrm{CCN}$. This activity must be coordinated with the mechanism development effort and, thus, must begin early in the design process.

For the aerosol CTM, sulfur chemistry will be important but also sources and precursors of aerosols, such as dust, sea salt, biomass-burning emissions, $\mathrm{HNO}_{3}$, and $\mathrm{NH}_{4}$. As a consequence, a gas- and aqueous-phase chemical module will have to be developed for the aerosol CTM that takes these other aerosol sources and precursors into account.

Within the GTCMS, the long-lived species and aerosol CTMs act as engineering models in which the short-lived species CTM would provide oxidant fields for detailed scenario analyses by the engineering models. This concept would be similar to the design of the EPA's Regional Acid Deposition/ 
Engineering Models. Consequently, it is recommended that a project be initiated to evaluate the feasibility of using $\mathrm{OH}, \mathrm{O}_{3}$, and $\mathrm{H}_{2} \mathrm{O}_{2}$ fields from the short-lived species CTM as input into the long-lived species and aerosol CTMs. If the concept proves feasible, then an interface must be designed between the short-lived species CTM and the other CTMs. The interface should allow for both a "screening mode" (coarse temporal and spatial resolution) transfer of fields and a "detailed mode" (fine temporal and spatial resolution).

\subsubsection{Subgrid}

On the regional scale, much recent work has concerned itself with the effect of subgrid chemical effects. Within the typical $80-\times 80-k m$ regional model grid cell, separate plumes from major point or area sources are not resolved. Consequently, the production/destruction of $\mathrm{O}_{3}$ that would take place in these plumes is not adequately resolved. A research activity should be initiated to investigate the impact of even coarser horizontal grid resolutions that will be required for global-scale simulations and, if possible, to recommend parameterizations to account for these subgrid effects in the global scale.

\subsubsection{Aqueous Phase}

Two related research activities were identified that deal with the effect of cloud processes and aerosols on the production/destruction of $\mathrm{O}_{3}$ in the troposphere. Recent research has indicated that $0_{3}$ production/destruction may be significantly affected by heterogeneous chemical processes in the troposphere. Aqueous-phase processes have been shown to yield a net destruction of $O_{3}$ in the presence of clouds (Lelieveld and Crutzen 1991), and sea-salt particles in the marine boundary layer have been implicated as possible sites of heterogeneous $\mathrm{O}_{3}$ destruction (Chameides and Stelson 1992). These processes should be investigated further to determine their significance for globalscale $\mathrm{O}_{3}$ distributions.

A similar study should be carried out to evaluate the chemical impact of neglecting cloud processes in the long-lived species CTM. To a first approximation, the neglect of cloud processes is justified because of the relatively small direct effect that aqueous-phase processes have on $\mathrm{CH}_{4}$ and $\mathrm{CO}$ 
concentrations. However, $\mathrm{HCHO}$, an intermediate product in the oxidation of $\mathrm{CH}_{4}$ to $\mathrm{CO}$, is relatively soluble in the aqueous phase and its distribution will probably be significantly affected by the presence or absence of clouds. An investigation should be performed to determine the impact of these processes on the long-lived spectes predictions.

\subsubsection{Aerosols}

Considerable research is needed to develop the aerosol CTM. The method of moments needs to be developed for multiple aerosol-size modes and aerosol compositions, with treatments of aerosol formation, condensation, coagulation, deliquescence, cloud-drop nucleation, resuspension, scavenging, and settling. Nucleation of drops on aerosols of varying size and composition requires particular attention. Global emissions inventories are needed for primary particles and aerosol precursors. The simulation of aerosols by the model must be evaluated by comparisons with observations.

\subsubsection{Dynamics}

\subsubsection{Stratosphere/Troposshere Exchange}

The justification for a clear understanding of this exchange process seems evident; it controls inflow and outflow at the top of the entire GTCMS domain. Unfortunately, not only the magnitude but also the direction of this exchange process are uncertain. Part of the difficulty in assigning even a climatological/global-scale average value to this exchange process is that it now appears to have a systematic geographic variability, with net upflow in the tropics and downflow associated with tropopause folding in midlatitudes and upflow in polar latitudes (Hoerling et al. 1993). Additional discussion of our lack of understanding of this process is found in Slinn (1993).

Additional basic research in this area is not recommended for two reasons. First, resolution of these difficulties will not likely occur within the 3-year time frame proposed for development of the GTCMS. Second, the National Aeronautics and Space Administration, National Science Foundation, and various groups in Europe have major programs related to stratospheric chemistry and dynamics. It is strongly recommended that parameterizations be developed that make use of results from these other programs. 


\subsubsection{Planetary Boundary Layer/Turbulence}

In classic turbulence exchange (e.g., K-theory), material can be exchanged only among adjacent grids. Nonlocal closure refers to turbulence schemes that describe the transport of material from one layer of a model to another, nonadjacent layer. Work with such nonlocal descriptions using regional-scale models has resulted in significant differences in the final fields, relative to results using more traditional approaches. A key difference is that such methods allow for the transport of material up the concentration gradient; though such processes do occur in nature, they cannot be accounted for in traditional K-theory.

\subsubsection{Cloud Processes}

Cloud parameterization in GCMs is being addressed by other programs, but certain aspects of clouds may require additional attention for chemistry applications. Subgrid-scale variability in cloud properties and cloud processes has a strong influence on soluble gases and aerosols through deposition, heterogeneous oxidation, activation, scavenging, and resuspension. A "physically based treatment of subgrid cloud variability is needed to account for the influence of the variability on soluble gases and aerosols.

\subsubsection{Surface Exchange}

\subsubsection{Surface Fluxes}

Much work remains to be done before scientists can adequately describe the flux of key chemicals over ocean waters and from developing nations. It is recommended that methods for calculating surface exchange, derived from hydrology, oceanography, urban meteorology, and agriculture, be used. These methodologies, based on vegetation, ocean characteristics, or urban geography, have the potential of making a significant contribution to the GTCMS.

\subsubsection{Emissions}

Emissions, of course, will play a significant role in the design and use of the GTCMS. It is recommended that a research activity be initiated to analyze the emissions requirements of the GTCMS. The emissions needs of each model should include both the species that are necessary for the particular model and the characteristics (e.g., temporal and spatial resolution) of the 
inventories that will be important for the model's use. The emissions inventories should cover natural and anthropogenic emissions from 1 and and ocean areas (and aircraft). Species felt to be of particular importance inciude $\mathrm{NH}_{3}, \mathrm{NO}_{x}, \mathrm{SO}_{x}, \mathrm{CH}_{4}$, and $\mathrm{NMHC}$. Estimating the source terms for these species over regions difficult to sample (for reasons related to logistics or politics) will be a large but essential undertaking.

\subsubsection{Actinic Flux}

The look-up tables used to determine photolysis rates need to be revised. Consideration should be given to compatibility with on-line cloud effects on actinic flux.

\subsubsection{Numerics}

\subsubsection{Grid System}

A key research area that may be resolved within the 3-year time frame of this project is the development of a nested grid system that can interact with the surrounding coarser grid. The uses of a nested grid could be extensive. A few examples of possible applications include enhanced definition of subgrid mixing associated with point sources and simplification of the descriptions necessary for predicted subgrid processes (e.g., cloud fields or other discontinuous physical features).

One difficulty that would have to be addressed prior to including nested grids in the GTCMS is the magnitude of the numerical errors resulting from calculations within the nested grid. This would be a somewhat separate problem from error estimates within just the coarse grid because the boundary conditions within the nested domain would be defined by the surrounding coarser grid. Thus, errors could easily increase within the subdomain.

Related to this question of error propagation was the possibility of designing an integration system that would make the nested grid a "super convergent" system. Super convergence characterizes numerical techniques that result in local accuracy well in excess of what would be expected on a global basis (Fairweather 1978; Oden and Carey 1983). Research on this subject should include this objective as a desirable goal. 


\subsubsection{Numerical Schemes for the Chemistry Integrator}

Although many schemes already exist for numerically evaluating the coupled differential equations that describe atmospheric chemical kinetics, few offer any degree of flexibility in their treatment of alternative mechanisms while concurrently maintaining computational efficiency. The development of a fast and flexible chemistry integrator would, therefore, be distinct from an integrator that was fast only for a given mechanism.

Development of this type of chemistry integrator should be pursued. A recent extension of the QSSA by Sillman (1991) results in a large reduction in computational cost and added flexibility. In QSSA, numerical efficiency is increased by lumping together species having similar chemical properties. sillman's new method, based on reordering species and using an implicit Runge Kutte integration, is suitable for use with stiff equations. Preliminary tests with this extension of the QSSA have resulted in reduced computational complexity and significant reductions in computer resource requirements.

\subsection{GUIDANCE ON RESEARCH PRIORITY}

Participants at the second workshop applied decision analysis methods (Section 3.4) to rank the research activities listed in Table 2.2. Based on the discounted, weighted average score received by each activity, the activities are ranked in Table 2.3. Highest priority was given to the development of a numerically fast integrator for solving the stiff set of ODEs common to most atmospheric chemistry mechanisms. Considerable progress on this activity has recently been made by Jacobson and Turco (1993) of the University of California at Los Angeles. Their sparse matrix, vectorized Gear solver is being implemented by EPA/AREAL in the UAM-IV and Models-3 system.

Development of a chemical mechanism that addresses the large dynamic range of global trace gas concentrations was the second highest-ranked research activity. This work would support the development of all three classes of CTMs needed in the GTCMS. In a similar fashion, a test of autodifferentiation also addresses all aspects of uncertainty and sensitivity estimation for the GTCMS. 
TABLE 2.3. Research Activities in Priority Order, Based on Results of Evaluation by Second Workshop Participants

\begin{tabular}{|c|c|}
\hline Rank & Module \\
\hline $\begin{array}{l}1 \\
2 \\
3 \\
4\end{array}$ & $\begin{array}{l}\text { Numerics } \\
\text { Gas Phase } \\
\text { Uncertainty } \\
\text { Aqueous Reactions }\end{array}$ \\
\hline 5 & Other Chemi stry \\
\hline $\begin{array}{l}6 \\
7 \\
8\end{array}$ & $\begin{array}{l}\text { Emissions } \\
\text { Aerosols } \\
\text { Aerosols }\end{array}$ \\
\hline $\begin{array}{c}9 \\
10\end{array}$ & $\begin{array}{l}\text { Other Chemistry } \\
\text { Surface Exchange }\end{array}$ \\
\hline $\begin{array}{l}11 \\
12\end{array}$ & $\begin{array}{l}\text { Aqueous Reactions } \\
\text { Transport/Grid System }\end{array}$ \\
\hline $\begin{array}{l}13 \\
14 \\
15 \\
16\end{array}$ & $\begin{array}{l}\text { Subgrid Cloud Processes } \\
\text { Dynani':s } \\
\text { Actinic Flux } \\
\text { Scavenging }\end{array}$ \\
\hline $\begin{array}{l}17 \\
18 \\
19 \\
20\end{array}$ & $\begin{array}{l}\text { Aerosols } \\
\text { Gas Phase } \\
\text { Gas Phase } \\
\text { Clouds }\end{array}$ \\
\hline $\begin{array}{l}21 \\
22\end{array}$ & $\begin{array}{l}\text { Nucleation } \\
\text { Other Chemi stry }\end{array}$ \\
\hline 23 & Dynamics \\
\hline
\end{tabular}

Abbreviation

Fast integrator

$$
\mathrm{NO} / \mathrm{OO}_{3} / \mathrm{HC}
$$

Autodiff demo

Aerosols $/ \mathrm{O}_{3}$

OH fields

Emissions inven

Evaluate moments

Moments/species

Interfaces Hydro/met synth

Clouds $/ \mathrm{O}_{3}$

Irreg grid chem

Subgrid variability Strat/tropo exch

Update $\mathrm{J}$-values

Aerosols/clouds

Primary emissions

Grid res/NO

Chem/aerosof

Clouds $/ \mathrm{CH}_{4} / \mathrm{CO}$

Mixed aerosols

DMS chemistry

Nonlocal
Research Activity

Develop numerically fast chemistry integrator

Develop appropriate $\mathrm{HO} / \mathrm{O}_{3} / \mathrm{HC}$ chemical mechani sm for GTCMS

Carry out demonstration of autodifferentiation using test model or module

Evaluate the effect of aerosols on tropospheric $\mathrm{O}_{3}$

Evaluate use of short-lived species CTM in providing $\mathrm{OH}$ fields for use in long-lived and aerosol CTMs

Develop entissions inventories required for GTCMS

Evaluate species-resolved moments method

Develop species-resolved moments of aerosol-size distributions

Develop interface between short-lived, long-lived, and aerosol CTMs

Synthesize into consistent framework models for hydrology, surface exchange,

emissions, and deposition

Evaluate effects of clouds on tropospheric $\mathrm{O}_{3}$

Develop irregular grid method for chemistry

Develop treatment of subgrid variability in clouds and cloud processes

Stratosphere/troposphere exchange

Update actinic flux J-value look-up tables

Processing of aerosols by clouds using moments method

Emissions of primary particulate and aerosol precursors

Evaluate effect of grid resolution on $\mathrm{NO}_{x}$ cycling and $\mathrm{O}_{3}$ production

Develop chemical module for aerosol CTM

Role of clouds in $\mathrm{CH}_{4} / \mathrm{CO}$ cycle vis-a-viz $\mathrm{HCHO}$ and organic acids

Parameterize nucleation on mixed aerosols

Evaluate adequacy of güs-phase oxidation mechanisms of DMS and resulting production of CCN

Planetary boundary layer/turbulence nonlocal closure 
Rankings below third place change when different scores are used. However, evaluation of the use of the short-lived CTM to generate oxidant fields for the long-lived and aerosol CTMs ranked high by all measures. Work on emissions inventories and methods to estimate emissions also ranked high. 


\subsection{DECISION ANALYSIS FOR MODEL DESIGN AND \\ RESEARCH PRIORITIZATION}

Presented in this section are the underlying rationale that was used to create a vision of the GTCMS, a process for identifying and prioritizing needed research, and a methodology for optimizing the value of a research program, given limited resources. Formal decision analysis methods are described for each of these three activities. The multiattribute utility (MAU) theory is used to identify an optimal vision of the GTCMS and to identify needed research. MAU theory, in combination with value-based planning (VBP), is used to optimize the needed research activities. An optimal GTCMS vision and prioritized set of research activities were generated using MAU in the two workshops. This section describes the decision analysis process and some key results, along with additional activities that would build on these results and make possible the realization of a research and development program.

\subsection{OVERVIEW OF THE DECISION PROCESS}

Figure 3.1 shows the sequence of decisions used to identify the research needed to develop the GTCMS, along with some of the major considerations that bear on those decisions and their interrelationships. Rectangles represent decisions; ovals represent factors outside direct control. Bolded rectangles represent major decisions. The general flow of the process is along the diagonal from upper left to lower right. The main steps in the process are 1) develop a vision for the GTCMS, 2) determine the science requirements to create the mode1, 3) define the research needed to produce the model, and 4) prioritize the proposed research.

\subsubsection{Vision of Model}

The first step in the process is to develop a vision of the model. The vision represents the best collective judgment of the research team as to what the ultimate product of this research effort should be. By clearly specifying the model development goal, it then becomes possible to identify, in a logical manner, what research is needed to attain it. Shown in Figure 3.1 by arrows 


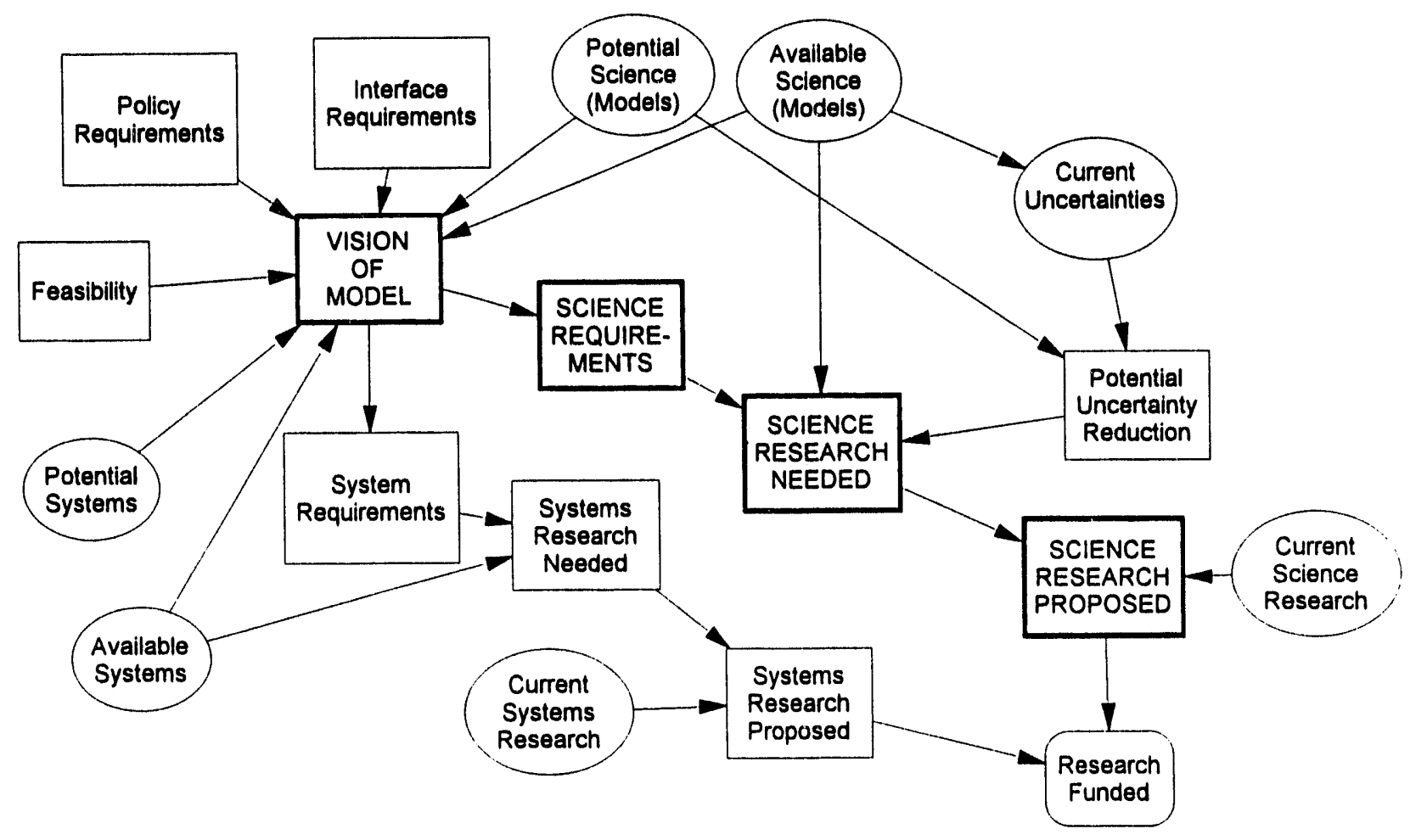

FIGURE 3.1. Logical Flow of Activities to Identify Research Needed to Develop a Global Tropospheric Chemistry Modeling System

pointing to the box labeled "Vision of Model" are the various considerations that enter into the formulation of the vision.

The initial basis for a vision is the science that is available. For each potential module needed to make up the GTCMS, modules may already exist that could be used to perform the required function(s). Collectively, these define what is currently possible and provide a foundation from which the vision evolves.

Potential science represents possible ways to create a GTCMS that improves on the science that is currently available. Potential science can consist of modules that are in various stages of development or alternative approaches for performing a particular module's function. These represent possibilities for expanding the envelope of potential models to the leading edge of what is possible to create within the next few years. 
Feasibility addresses the likelihood that the necessary research and development could be carried out within the specified time frame, here defined to be 3 years. Enhancing existing modules and models with potential science may generate some wonderful ideas; however, some of these may need to be tempered with a dose of reality. Some ideas may border on science fiction and others, while sound, may require an extensive effort to carry out, which may not be possible in the allotted time frame. Thus, feasibility considers the risk that may be associated with an ambitious research program that may be required by a given configuration of the model.

Whatever model is chosen, it must be implemented in some hardware environment. The hardware could range from a workstation to a supercomputer; it may be a sequential processor or a parallel processor; less complex models may be better suited to a workstation environment; some models may be better adapted to parallel processors than are others. Consequently, it is necessary to consider what hardware is available and what may be forthcoming.

The GTCMS is envisioned to be a component, albeit a central and essential one, of a more inclusive global change model. Such a model must meet the needs of the policymakers it is being designed to serve. However, it is difficult to predict in advance what the policymakers' concerns will be, and these needs tend to evolve over time. Consequently, this requires that the model be designed to be as flexible as possible in terms of answering a variety of questions under a variety of assumptions and/or background conditions. Every assumption about the model is a potential parameter to be adjusted by the policy user. The ideal model would allow the user to create a variety of scenarios in which to play "what-if" games; realism would be maintained by cautioning against the creation of logically inconsistent conditions. In addition, the ideal model would have the flexibility to interface with the larger global climate change policy modeling system, of which it is one component. This larger system will most likely be identified and/or created after the GTCMS; thus, the GTCMS needs to be adaptable to take a variety of potential input forms and also to provide a variety of outputs and formats as may be required. Also to be considered is the fact that, as a global model, the input data may come from a variety of sources. The ideal 
model will be capable of accepting this variety of data either directly or indirectly or via some type of add-on translation capability.

\subsubsection{Science Requirements}

As shown in Figure 3.1, the next step in the process is to determine the science requirements of the model. A clear specification of the model vision leads directly to the science requirements needed to support its realization. This is the science that makes up the various modules that define the GTCMS. Consideration of the vision for the GTCMS also leads to the identification of system requirements; however, it was decided to focus the design effort on identifying the scientific research necessary to construct a GTCMS.

\subsubsection{Science Research Needed}

The next step in the sequence shown in Figure 3.1 is to determine the scientific research that is needed for developing and implementing the GTCMS. This depends on what science is required and what is available. Decisions regarding research needed should also consider the potential for reducing uncertainty. The potential for uncertainty reduction depends on the difference between the current uncertainties in the existing science and the anticipated uncertainties in the potential state of science of the options that were selected for each module to create the vision of the model.

\subsubsection{Science Research Proposed}

Two decisions are necessary to establish what research to propose. In the first decision, areas of research must be selected that are essential to the realization of the model and/or that have the greatest potential for improving currently available science. Decisions regarding which areas need additional research should be based on an evaluation using a well-defined set of criteria that include consideration of research that is currently being carried out elsewhere. In the second decision, proposals must be chosen for specific research projects within each defined research area. Criteria for evaluating proposals should include considerations, such as the prior experience and capabilities of the research organization, in addition to the value of the research. Decision analysis methods can be applied to both derisions. By applying optimization techniques based on decision analysis, one or more 
portfolios of research projects can be defined that account for various budget scenarios.

\subsection{DECISION ANALYSIS USING MULTIATTRIBUTE UTILITY THEORY}

The MAU theory was used to identify an optimal GTCMS vision, to prioritize research needs, and is integral to the recommended process for the optimization of portfolios of research activities. This section provides a description of the main steps in the MAU process, as well as some brief, but general, comments concerning its practical application. Subsequent sections provide additional guidance, as necessary, for the specific applications described.

The MAU decision analysis process consists of the following steps:

- identify objectives to be achieved

- identify alternatives that meet the objectives

- develop measures and values functions for each objective

- develop relative weights for the objectives based on their relative importance

- evaluate alternatives using an objective function and relative weights.

Objectives are statements of what we want to achieve (Keeney 1992). For example, if one were buying a car, some objectives might be to maximize performance, minimize cost, and maximize good looks and styling. For evaluation purposes, objectives are put in a hierarchical form, starting with the overall goal and the fundamental objectives that are further divided into more specific components of those objectives until one arrives at the level of criteria or performance measures. In the example for buying a car, performance might be further divided into acceleration and handling.

The identification of alternatives requires a high level of creativity and should be guided by the overall goal and the specific objectives to be achieved (Keeney 1992). A varied set of alternatives increases the likelihood that a near-optimal alternative will be selected. 
Performance measures (also called criteria or attributes) specify the degree to which the objectives are achieved. For example, in the car-purchase scenario, acceleration could be measured by the time (in seconds) required to accelerate from 0 to $60 \mathrm{mi} / \mathrm{h}$. The number of seconds is a natural scale. Often, natural scales are not available, in which case scales must be constructed. Scales should be constructed so as to minimize ambiguity as to what is meant by a given level of performance.

Value functions measure the importance of a criterion. These functions take as their input the various levels of performance and typically map them into the range 0 to 1 , or sometimes 0 to 100 . The importance of an objective may not be linear with its scale. In the acceleration example, an improvement from 15 to $10 \mathrm{~s}$ may be judged more valuable than an improvement from 10 to $5 \mathrm{~s}$. For constructed scales, it is common practice to only specify the composite function of performance level with value. Thus, for example, a score of 75 would specify both the level of performance and the value of that level of performance on a 0 to 100 scale.

Whereas value functions capture the importance of a single criterion, weights capture the tradeoffs among criteria. For example, how much gas mileage is one willing to give up for an additional second-quicker acceleration from 0 to $60 \mathrm{mi} / \mathrm{h}$. Weights logically depend on the ranges in performance over which the alternatives vary. A common mistake is to specify the relative importance of objectives in a "top-down" process without considering the ranges in performance over which the alternatives can vary. A better procedure is to develop weights for criteria in a "bottom-up" process, by taking into account the anticipated performance range for various alternatives over all criteria. "Swing weighting" is a standard decision analys is procedure for accomplishing this. Swing weighting is further described in Section 3.5 .

Finally, a mathematical expression, called an objective function, is needed to roll up all the above judgments into a single number by which the alternatives can be compared. The correct functional form for the objective function depends on the preferential independence relationships among the criteria (Keeney and Raiffa 1976). 


\subsection{APPLICATION OF DECISION ANALYSIS FOR MODEL DESIGN}

Selecting a "vision of model" is critical to the creation of a GTCMS. The vision will guide future decisions and determine what research is needed and to what extent. Thus, determining a model vision is a key decision, and a formal decision analysis approach is applied.

An analysis of the functions and requirements of a GTCMS was used to identify its modular components. The selection of particular models for these modular components provides the realization of a GTCMS vision. This section discusses the use of different areas of design emphasis to guide the selection of module options, the criteria for evaluating those selections, and the methods for quantifying the evaluation of alternative designs using the MAU theory.

\subsubsection{Chemical Transport Model Alternatives}

A formal process was used to identify a variety of model visions that were then evaluated to determine which model is best suited to the needs of policymakers. A shell was provided (see Appendix B) that consisted of the various modules that were identified as being the necessary components of a GTCMS. Alternative approaches were identified that could perform the necessary functions for each of the modules. The selection of an alternative for each module in the shell, when taken collectively, defines a candidate vision for a CTM. Workshop participants also had the opportunity of identifying additional options and/or needed modules.

The design of the CTMs must satisfy a variety of objectives and functional requirements and must consider development constraints as well as the needs of the larger policy analysis system. Many of these objectives are conflicting and require tradeoffs. For example, a simple model is unlikely to maximize its predictive validity. Furthermore, it was not clear in the initial stages of the study which of these requirements was most important. Thus, the strategy chosen was to create a rich variety of potential visions of a CTM that could be evaluated against criteria to be developed. Then, by having experts weight the importance of the criteria and evaluate the potential models against these criteria, the model with the best overall value to 
the GTCMS would emerge. The success of this strategy requires a variety of potential models be available for evaluation.

A wide variety of potential CTMs were identified by creating candidate models representing a variety of design emphases. Five design emphases were identified:

- maximize predictive validity and be representative of the best state-of-the-art science

- maximize simplicity while still meeting the performance requirements

- minimize cost of development by using available models

- maximize feasibility by only requiring additional research and development with a minimum of risk

- optimize balance among all the above considerations in the design of the model.

These design emphases are intended to be partially mutually exclusive. The tradeoffs between one or more design emphases were addressed as options for the various modules chosen. Model visions were created for each of these design categories. This resulted in a rich set of visions that could then be formally evaluated. Criteria were developed to choose a vision that would best serve the needs of the policy-making community and be feasible to develop within a 3-year time frame. The evaluation process was carried out within the framework of the MAU theory.

\subsubsection{Evaluation Criteria}

The criteria developed to evaluate the visions are shown in Table 3.1. Seven criteria were identified as having an impact on the value of a CTM. Most of these scales were constructed from a series of scenarios that represent different levels of performance on the criteria. Each of these scenarios is directly associated with some number in the range of 0 to 100 that represents the value of that level of performance. Thus, for example, a predictive validity score of 70 represents the value to the GTCMS on a scale of 0 to 100 of an R-squared of approximately 0.4 on a scale ranging from 0.1 to 0.7 .

For many scales, the level of performance of a particular CTM may be difficult to judge, and one might wonder why define the scale in such a 


\section{TABLE 3.1. Criteria Used to Evaluate Potential Chemical Transport Models}

Predictive Validity: Measures how well modules simulate the real-world processes that they are designed to model, as measured by the squared correlation coefficient between the predicted and observed values and the absolute value of their difference.

Short-Lived Species: Estimate the average validity, as defined above, across those modules that are most important for predicting the concentration and distribution of short-lived greenhouse gases.

$100 \mathrm{High}$, average R-squared is approximately 0.6 to 0.7 . and the absolute value of the difference between observed and predicted values is approximately 1.5 or less.

70 Medium, average R-squared is approximately 0.3 to 0.5 , and the absolute value of the difference between observed and predicted values is approximately a factor of 5 .

0 Low, average R-squared is approximately 0.1 to 0.2 , and the absolute value of the difference between observed and predicted values is approximately a factor of 10 .

Long-Lived Species: Estimate the average validity, as defined above, across those moduies that are most important for predicting the concentration and distribution of long-1ived greenhouse gases.

$100 \mathrm{High}$, average R-squared is approximately 0.6 to 0.7 , and the absolute value of the difference between observed and predicted values is approximately 1.5 or less.

70 Medium, average $R$-squared is approximately 0.3 to 0.5 , and the absolute value of the difference between observed and predicted values is approximately a factor of 5 .

0 Low, average $R$-squared is approximately 0.1 to 0.2 . and the absolute value of the difference between observed and predicted values is approximately a factor of 10.

Aerosols: Estimate the average validity, as defined above, across those modules that are most important for predicting the distribution and concentration of aerosols.

$100 \mathrm{High}$, average R-squared is approximately 0.6 to 0.7 , and the absolute value of the difference between observed and predicted values is approximately 1.5 or less.

70 Medium, average R-squared is approximasely 0.3 to 0.5 , and the absolute value of the difference between observed and predicted values is approximately a factor of 5 .

0 Low, average R-squared is approximately 0.1 to 0.2 , and the absolute value of the difference between observed and predicted values is approximately a factor of 10 .

Other Modules: Estimate the average validity, as defined above, across all the other modules.

$100 \mathrm{High}$, average R-squared is approximately 0.6 to 0.7 , and the absolute value of the difference between observed and predicted values is approximately 1.5 or less.

70 Medium, average $R$-squared is approximately 0.3 to 0.5 , and the absolute value of the difference between observed and predicted values is approximately a factor of 5 .

0 Low, average R-squared is approximately 0.1 to 0.2 , and the absolute value of the difference between observed and predicted values is approximately a factor of 10 .

Maximize Computational Speed: Measures the average complexity of the individual modules, as reflected by the number of computer operations necessary to carry out the calculations factored by degree of parallelism.

100 Fast--measured by few operations per time steps.

50 Moderate--measured by a moderate number of operations per time steps.

0 slow--measured by many operations per time steps. 


\section{TABLE 3.1. (contd)}

Maximize Potential for Uncertainty/Sensitivity Analysis: Measures the potential for quantifying uncertainty and the potential ease of sensitivity analysis.

100 The amount of uncertainty in each of the modules can be quantified and there are easy methods avallable for carrying out sensitivity analysis.

80 Approximately $80 \%$ of the modules produce quantitative estimates of uncertainty and there are methods available for carrying out sensitivity analysis.

50 Approximately $50 \%$ of the modules produce quantitative estimates of uncertainty and there are methods available for carrying out sensitivity analysis OR approximately $80 \%$ of the modules produce quantitative estimates of uncertainty and sensitivity analysis can be carried out only with great difficulty.

0 Less than $20 \%$ of the modules produce quantitative estimates of uncertainty and sensitivity analysis can be carried out only with great difficulty.

Closeness to Best Science: Measures how close the model is to the best science.

$10080 \%$ of the models represent state-of-the-art science and the remainder is good science.

$7040 \%$ of the models represent state-of-the-art science and the remainder is good science.

$010 \%$ of the models represent state-of-the-art science and the remainder is good science.

Flexibility: The extent to which the system can address a variety of policy issues.

100 The system can be easily adapted to answer a large variety of questions.

50 The system can be modified with reasonable effort to answer a standard set of questions.

0 The system is designed to answer a specific set of questions and would be difficult to modify.

Feasibility of Required Research: Measures the likelihood that the research can be successfully carried out within the allotted 3-year time period.

100 Nearly certain that all the required research and development will be successfully accomplished within 3 years.

80 Approximately $80 \%$ of the required research is very "straightforward:" remaining $20 \%$ is somewhat problematic.

$5050 \%$ of the required research is very "straightforward:" $50 \%$ is somewhat problematic.

20 Approximately $20 \%$ of the required research is very "straightforward;" remaining $80 \%$ is somewhat problematic.

0 All the required research is based on highly speculative ideas that may or may not work.

Cost of Research and Development: Measures the cost in person-years for additional research and development to create the model as configured.

100 Entire model can be developed for use as a policy model with approximately 12 person-years of effort. For example, 12 modules require 1 person-year each to develop.

85 Total effort required for development as a policy model is approximately 18 person-years.

70 Total effort required for development as a policy model is approximately 24 person-years.

55 Total effort required for development as a policy model is approximately 36 person-years.

15 Total effort required for development as a policy model is approximately 48 person-years.

0 On average, each of the 18 modules will require 3 person-years to develop, for a total approximate cost of 54 person-years of research. 
precise manner. This is done to provide a clear definition of the scale that will pass the "clarity test." This test requires that a clairvoyant, with knowledge of all events, past, present, and future, would be able to unambiguously assign a score for the criterion (assumirg that the CTM vision is also clearly defined). Definitions that pass the clarity test serve the function of ensuring that everyone is in agreement with what is meant by a particular criterion. The actual judgment of performance level is based on the best available scientific judgments. These judgments may be based on limited data; but, by clearly defining the concept, consistency of judgment is improved, and so is the overall validity of the process. Additional comments on the criteria/scales (see Table 3.1) follow:

- Predictive Validity--In cases where a model or module did not yet exist, predictive validity was based on expected performance.

- Computational Speed--Computational speed was designed to be independent of the hardware system in which the model was realized.

- Potential for Uncertainty/Sensitivity Analysis--While this is difficult to estimate, it is important to policy analysts and was included in the evaluation.

- Closeness to Best Science--lt is possible for a model to have good predictive validity without actually providing a realistic model of the processes that it is designed to predict. Also, the closer the model is to state-of-the-art science the more likely it is to be acceptable to the science community. Thus, this criterion captures important considerations besides those of predictive validity.

- Flexibility--This was necessary to ensure the ability of the model to address a variety of policymaker concerns, many of which are not currently known.

- Feasibility of Required Research--This provides assurance that the model can be created within the allotted time frame.

- Cost--Cost estimates were based on CTM visions defined by a collection of modules. Some of these modules already exist, others will need research to create. The cost estimates were based on the discrepancy between existing science and what would be needed to create a particular model.

\subsubsection{Option Generation}

Multiple visions for the three classes of CTMs, based on the different design emphases, were created in the second workshop. The process consisted 
of independent judgments regarding option selection, followed by discussion withir small groups dedicated to a particular class of CTM. These selections were then compared in small working groups to arrive at a consensus for each of the design emphases. This resulted in a rich set of models that could then be formally evaluated to choose a vision that would best serve the needs of the GTCMS and be practical to develop within the time constraints.

Tables 3.2 through 3.4 present, for each of the three classes of CTMs, the options selected for each of the design emphases. Initial and final optimal designs tended to be very similar. The final optimal design was generated to provide an opportunity for revision after considering the specific design emphases. Designs emphasizing predictive validity tended to include those options with the greatest process detail. In contrast, designs that emphasized computational speed used options with greater degrees of process parameterization. Designs highlighting low cost of development and feasibility usually made use of existing options and parameterized processes.

\subsubsection{Option Evaluation}

Participants at the second workshop evaluated the various options for each class of CTM. This was carried out in three small groups--each group being dedicated to a particular class of CTM. Group members represented a variety of backgrounds, thus ensuring that the relevant expertise was available. The results of these evaluations are presented in Table 3.5. The design emphases for the three classes of CTMs are shown along the top; the rating criteria are shown to the left. The body of the upper portion of the table gives the score each version received when rated by the participants on the criteria. The scores were averaged acros the participants in the relevant small group. The scores, while averages, are a result of discussions leading to group consensus in most cases. The weights represent value judgments concerning the relative importance of the various criteria. The weights were assigned using the swing-weighting process described in Section 3.5. The weighics used in the analysis are the average of the weights assigned by all the workshop participants, and therefore, reflect their collective judgment.

The value associated with each version was calculated by multiplying the score by the weight and summing over all the criteria, except feasibility. 
TABLE 3.2. Options Selected for Alternative Visions: Short-Lived Species Chemical Transport Model

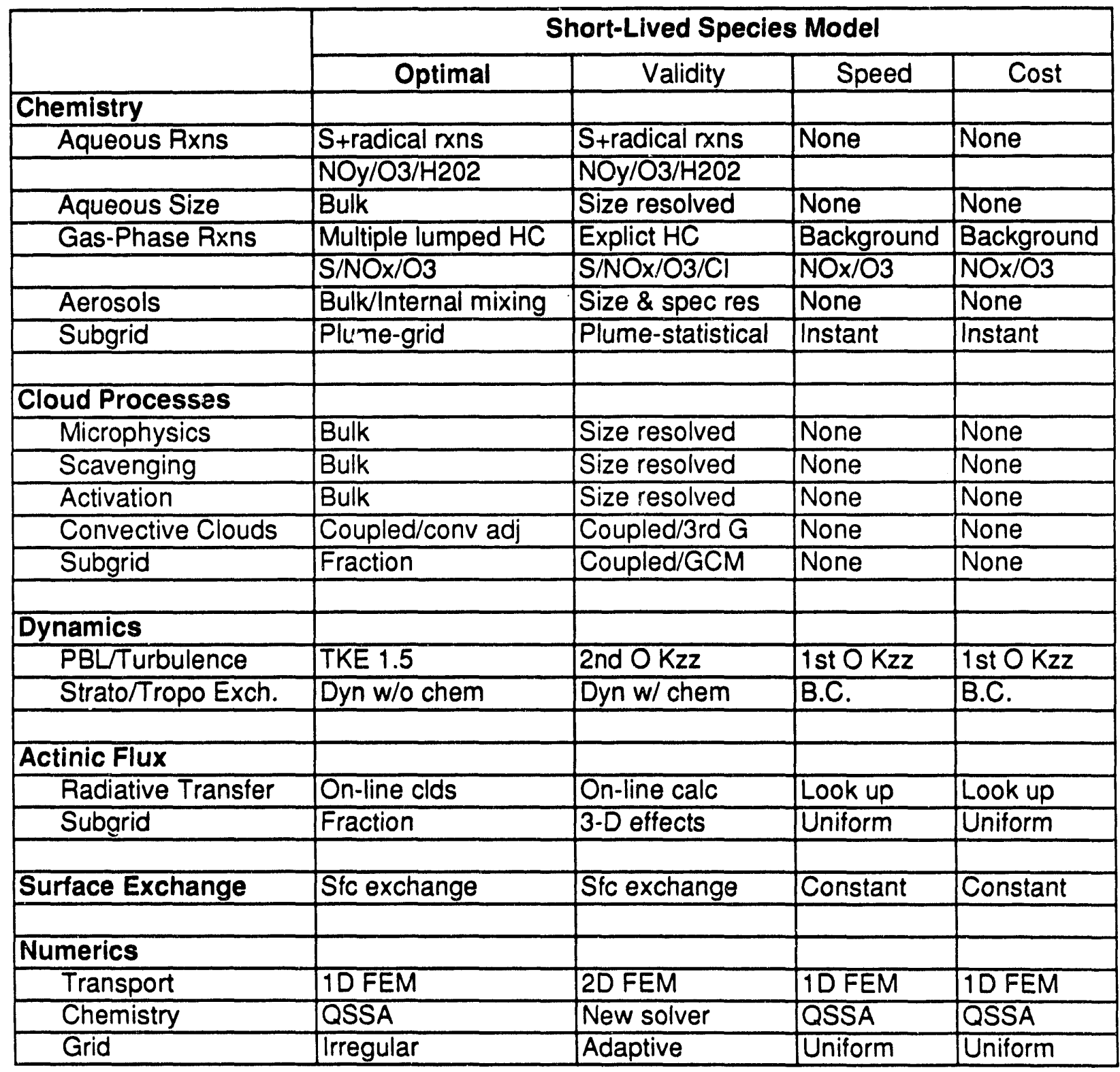


TABLE 3.3. Options Selected for Alternative Visions: Long-Lived Species Chemical Transport Model

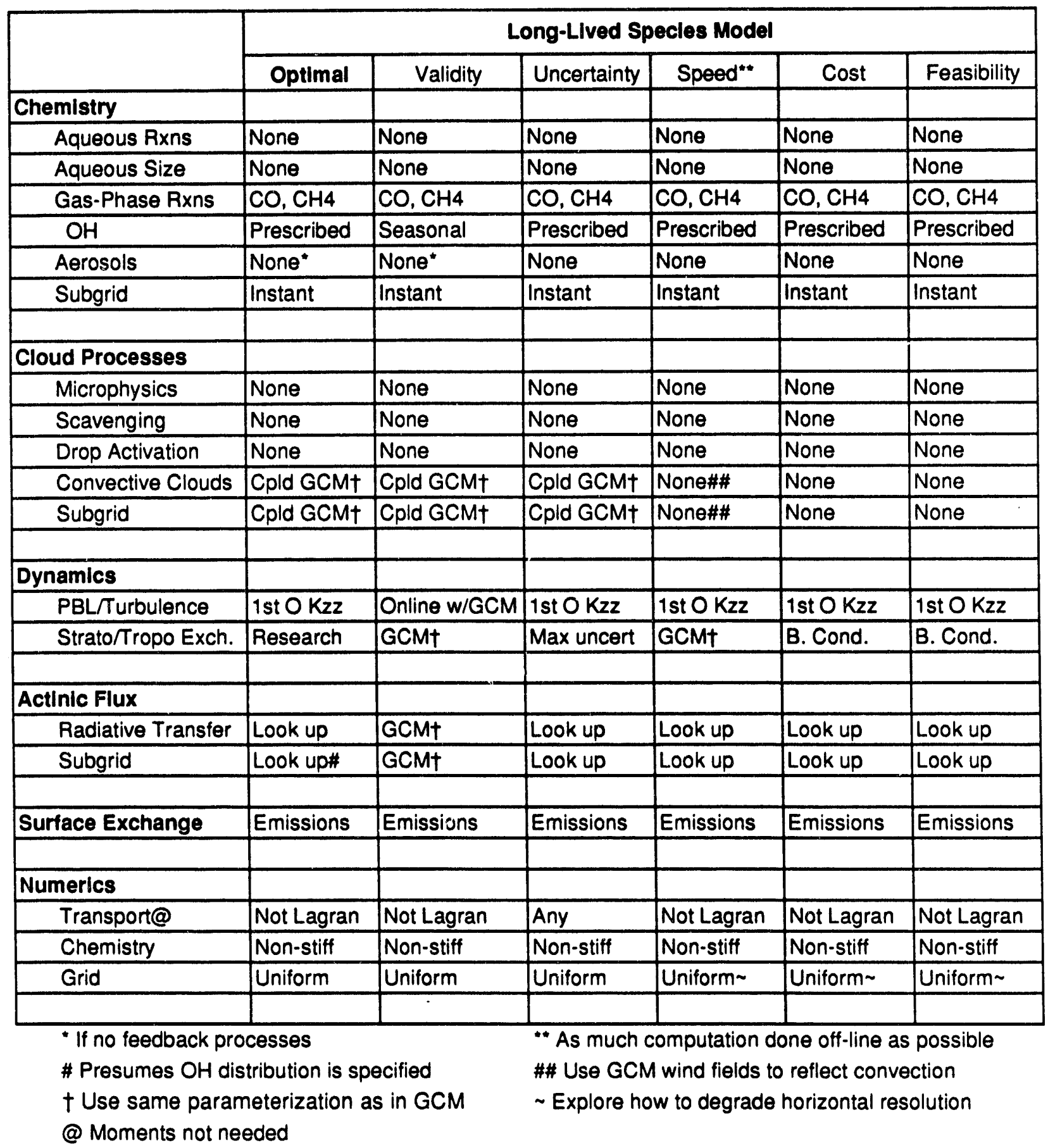


IABLE 3.4. Options Selected for Alternative Visions: Aerosol Chemical Transport Model

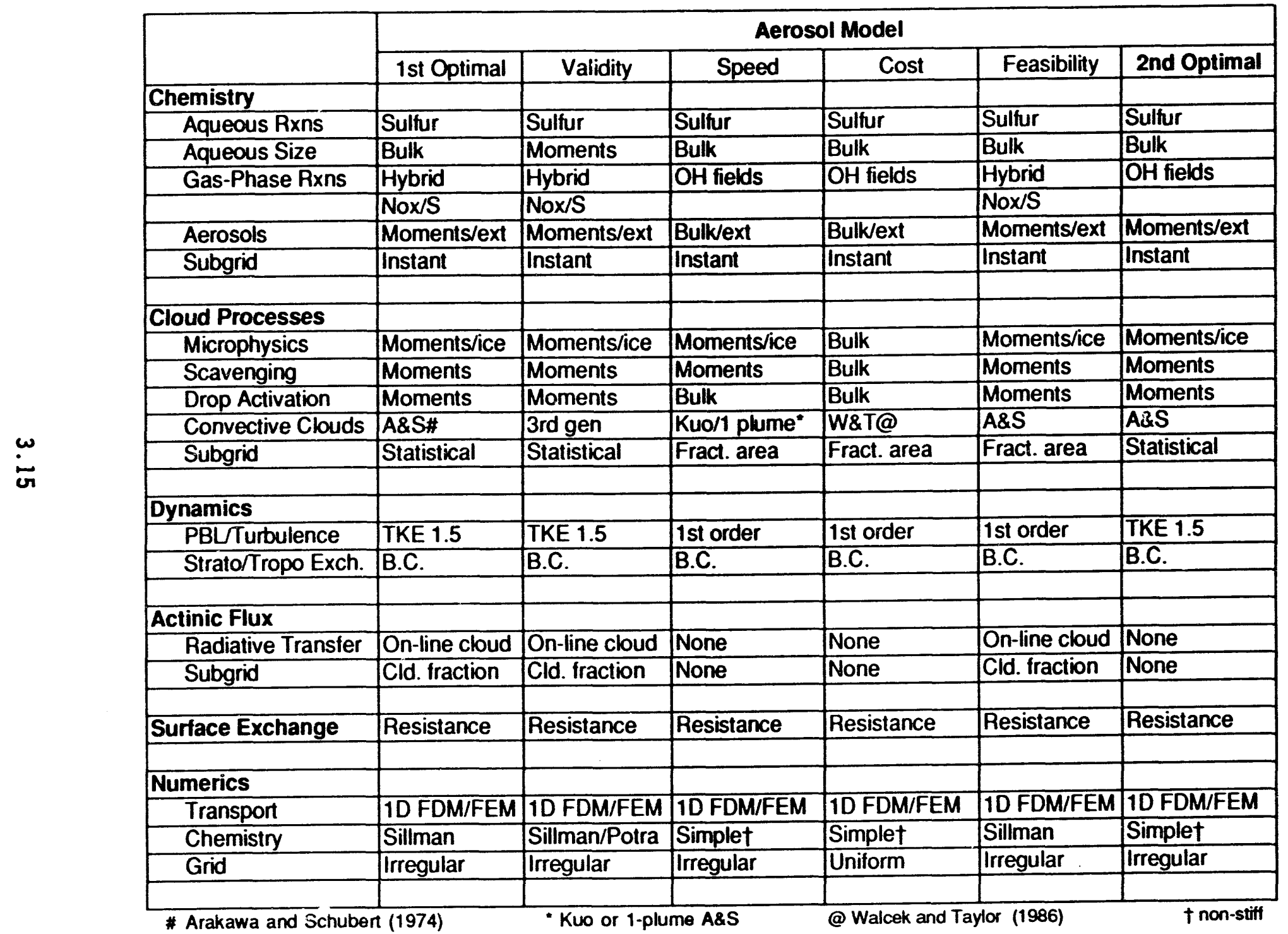


TABLE 3.5. Ratings by Workshop Participants of the Alternative Chemical Transport Model Visions

\begin{tabular}{|c|c|c|c|c|c|c|c|c|c|c|c|c|c|c|}
\hline CRITERIA & \multirow[b]{2}{*}{ WEGHT } & \multicolumn{13}{|c|}{ MODELS } \\
\hline & & \multicolumn{4}{|c|}{ LONG LIVED } & \multicolumn{3}{|c|}{ SHORT LIVED } & \multicolumn{6}{|c|}{ AEROSOL } \\
\hline PREDICTIVE VALIDITY & & Opt & PV & Unc & $S C F$ & $\mathrm{PV}$ & $s c F$ & Opt & Opt & $P V$ & Speed & Cost & Feas & F Opt \\
\hline Aeroso's & 0.07 & 0 & 0 & 0 & 0 & 70 & 0 & 35 & 78 & 85 & 51 & 45 & 69 & 78 \\
\hline Short-Lived Species & 0.08 & 0 & 0 & 의 & 0 & 80 & 50 & 70 & 58 & 70 & 38 & 35 & 54 & 35 \\
\hline Long-Lived Species & 0.13 & 70 & 70 & 70 & 70 & 80 & 70 & 80 & 의 & 0 & 10 & 0 & 의 & \\
\hline Other Modues & 0.04 & 0 & 0 & of & 0 & 0 & 0 & 0 & of & 0 & 요 & 0 & 의 & 의 \\
\hline TOTAL PV weight & 0.32 & & & & & & & & & & & & & \\
\hline COMPUTATIONAL SPEED & 0.13 & 90 & 80 & 80 & 100 & 0.1 & 30 & 10 & 58 & 64 & 86 & 90 & 70 & 78 \\
\hline UNCERTAINTY ANALYSIS POTENTIAL & 0.14 & 60 & 30 & 80 & 30 & 50 & 50 & 50 & 55 & 64 & 76 & 79 & 65 & 73 \\
\hline FLEXIBILTYY FOR ALTERNATIVE POLICY USES & 0.17 & 25 & 25 & 25 & 25 & 75 & 40 & 70 & 51 & 72 & 40 & 40 & 50 & 42 \\
\hline CLOSENESS TOBEST SCIENCE & 0.23 & 50 & 50 & 50 & 50 & 100 & 5 & 70 & 89 & 93 & 60 & 55 & 72 & 68 \\
\hline & & & & & & & & & & & & & & \\
\hline FEASIBILTYY & & 100 & 100 & 100 & 100 & 10 & 100 & 70 & 80 & 60 & 90 & 95 & 90 & 90 \\
\hline & & & & & & & & & & & & 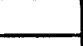 & 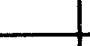 & \\
\hline VALUE ( $($ (WEIGHT*SCORE)) & & & & & & & & & & & & & & \\
\hline VALUE 1: PV weights on all modules & & 45 & 39 & 46 & 42 & 64 & 32 & 55 & 54 & 62 & 50 & 48 & 52 & 51 \\
\hline VALUE 2: 0.32 weight on main module & & 58 & 53 & 60 & 55 & 68 & 35 & 59 & 69 & 78 & 59 & 57 & 65 & 68 \\
\hline EXPECTED VALUE (VALUE"FEASIBILITY/100) & & & & & & & & & & & & & & \\
\hline E-VALUE 1: PV weights on all modules & & 45 & 39 & 46 & 42 & 6 & 32 & 38 & 44 & 37 & 45 & 46 & 47 & 46 \\
\hline E-VALUE 2: 0.32 weight on main module & & 58 & 53 & 60 & 55 & 7 & 35 & 41 & 55 & 47 & 53 & 54 & 59 & 61 \\
\hline & & & & & & & & & & & & & & \\
\hline EFFORT AND COST (Person-Years) & & 6 & 7 & 8 & 5 & 54 & 12 & 32 & 18 & 26 & 13 & 12 & 16 & 15 \\
\hline & & & & & & & & & & & & & & \\
\hline
\end{tabular}

Opt Initial optimal design

PV Emphasis on predictive validity

Unc Emphasis on uncertainty analysis

Speed Emphasis on computational speed

Cost Emphasis on low cost of development

Feas Emphasis on high feasibility of research and development

SCF Designs for speed, cost, and feasibility were identical

F Opt Final optimal design 
Value 1 is calculated using each of the four categories of predictive validity treated as a separate criterion. Because of the low scores given to the predictive validity for all but the modules relevant to the particular class of model, the Value 1 calculation deemphasizes the overall importance of the predictive validity criterion.

Value 2 gives more weight to predictive validity by associating the total weight for the predictive validity criterion, with the score given to the group of modules corresponding to the class of model being evaluated. Thus, Value 2 does not favor those designs that could have predictive validity for more than one class of model. The expected value rows show the overall value discounted by the feasibility of carrying out the necessary research and development within the allotted 3-year time frame. This row is the value score multiplied by the feasibility score. Because feasibility is a probability measure, this product is the expected value of each of the CTM visions, where expected value has the standard interpretation used in statistics and decision analysis. The last row of Table 3.5 shows the estimated level of effort required to produce the model in person-years.

Based on the ratings presented in Table 3.5, one vision for each class of CTM was selected as the target for the GTCMS design. For the long-lived species CiM, the initial optimal version and the version for ease of uncertainty analysis score closely, with the latter estimated to require slightly more effort to develop; the optimal design was selected. The group that developed the selections for the short-lived species CTM found many of the design emphases to lead to essentially the same option selections. In the rating of their visions, the final optimal design ranked highest and was selected. Although the version designed to maximize its predictive validity scored very high in all criteria but feasibility, this design was given little chance of being developed within the 3-year time frame and its cost would be high. Rating of the alternative visions for the aerosol CTM resulted in the most feasible and final optimal designs to have very similar ratings and require a modest level of effort; the final optimal design was selected. Option selections for the top-rated alternative visions for each class of CTM in the GTCMS are given in Table 3.6. Collectively, these define the GTCMS and provide the basis for identifying research necessary for its realization. 
IABLE 3.6. Options Selected for Top-Rated Alternative Visions

\begin{tabular}{|c|c|c|c|}
\hline \multirow{3}{*}{ Module } & \multicolumn{3}{|c|}{ Class of CTM } \\
\hline & LONG-LIVED & SHORT-LIVED & AEROSOL \\
\hline & Optimal & Optimal & Optimal \\
\hline \multicolumn{4}{|l|}{ Chemistry } \\
\hline Aqueous Rxns & None & S+radical rxns+NOy/O3/H2O2 & Sulfur \\
\hline Aqueous Size & None & Bulk & Bulk \\
\hline Gas-Phase Rxns & $\mathrm{CO}, \mathrm{CH} 4, \mathrm{OH}$ prescribed & S/NOX/O3/lumped HCs & OH fields prescribed \\
\hline Aerosols & None* & Bulk/internally mixed & Moments/species resolved \\
\hline Subgrid & Instant dispersion & Plume-in-grid & Instant dispersion \\
\hline \multicolumn{4}{|l|}{ Cloud Processes } \\
\hline Microphysics & None & Bulk & Moments/ice \\
\hline Scavenging & None & Bulk & Moments \\
\hline Drop Activation & None & Bulk & Moments \\
\hline Convective Clouds & Coupled to GCM & Coupled/convective adjustment & Coupled/Arakawa \& Schubert \\
\hline Subgrid & Coupled to GCM & Fraction & Statistical \\
\hline \multicolumn{4}{|l|}{ Dynamics } \\
\hline PBLTTurbulence & K-theory, 1st O Kzz & K-theory, $1.50 \mathrm{Kzz}$ (TKE) & K-theory, $1.50 \mathrm{Kzz}$ (TKE) \\
\hline Strato/Tropo Exch. & Research & Dynamic w/o chemistry & Boundary condition \\
\hline \multicolumn{4}{|l|}{ Actinic Flux } \\
\hline Radiative Transfer & Look up & On-line clouds & None \\
\hline Subgrid & Look up, $\mathrm{OH}$ prescribed & Fraction & None \\
\hline Surface Exchange & On-line GCM for $\mathrm{CO} 2$ & Surface exchange model & Resistance \\
\hline \multicolumn{4}{|l|}{ Numerics } \\
\hline Transport & Not Lagrangian & 10 FEM & 1D FDM/FEM \\
\hline Chemistry & Gear & QSSA & Simple (non-stiff) \\
\hline Grid & Uniform & Irregular & irregular \\
\hline
\end{tabular}

\subsection{APPLICATION OF DECISION ANALYSIS TO RESEARCH PRIORITIZATIION}

This section describes the process by which the MAU theory was applied in the second workshop to prioritize the list of research needs (see Table 2.2). The criteria for the prioritization of research activities were designed to maximize the value of research carried out for the creation of the three model visions that were earlier identified as optimal. The criteria and scales are shown in Table 3.7.

Again, the numerical values shown in Table 3.7 combine the performance measures and the value functions. Thus, for Improve Predictive Validity, an increase in the value of $R$-squared by 0.2 is scored a value of 50 because it 


\section{TABLE 3.7. Criteria Used to Evaluate Research Needs}

Improve Predictive Validity: Measures the expected improvement in predictive validity.

100 R-squared for a module for which RITS are sensitive could increase by approximately 0.5 and/or the difference between the observed and predicted values could greatly diminish.

50 R-squared for a module that plays a central role in the overall predictive validity could increase by approximately 0.2 and/or the difference between the observed and predicted could become smaller OR $R$-squared for a module that plays a peripheral role in the overall validity could increase by 0.5 and/or the difference between the observed and predicted values could greatly diminish.

25 R-squared for a module that plays a peripheral role in the overall validity could increase by 0.2 and/or the difference between the observed and predicted values could become smaller.

0 There is no potential to improve the science in a module.

Reduce Computation Time: Measures the expected reduction in computation time.

100 Time for computationally expensive module could be reduced to $10 \%$ of current value.

50 Time for computationally expensive module could be reduced to $50 \%$ of its current value oR time for a moderately costly module could be reduced by $90 \%$.

20 Time for computationally expensive module could be reduced to $80 \%$ of its current value UR time for a moderately costly module could be reduced by $50 \%$.

0 No potential to reduce computational time.

Scope of Application: Measures the number and importance of the modules for which the research applies.

100 fully supports a module that is very important for several models OR several modules that are very important for a single model.

50 Fully supports a module that is somewhat important for several models OR several modules that are somewhat important for a single model.

25 Fully supports a single module that applies to one model OR partially supports a module that is very important for several models.

0 Only partly supports a single module that applies to one model.

Intrinsic Scientific Value: Measures the value of the research to the scientific community.

100 Research has substantial intrinsic scientific value with broad implications beyond the scope of the GTCMS effort.

50 Research has intrinsic scientific value with some implications beyond the scope of the GTCMS effort.

0 Research has primarily value for the GTCMS effort but little additional scientific value.

Extent of Independent Funding: Measures the extent of funding by EPA would duplicate efforts el sewhere.

100 No independent research is currently being funded or there is an opportunity to participate in an ongoing research project.

50 Moderate amount of independent research is being funded.

0 Research is al ready fully funded.

Likelihood of Success: Measures probability of success in allotted time. Estimate probability from 0 to 1 .

Cost: Measures person-years, or their equivalent cost in equipment, for completing research and development necessary to incorporate results into model. Estimate number of person-years. 
is thought to have one half of the value of an increase by 0.5 , which is scored 100 .

Workshop participants individually evaluated the research activities using the criteria and scoring outlined in Table 3.7. Table 3.8 gives the scores averaged over all participants submitting scores for the research activities for each of the criteria. The relative weights for the criteria were determined during the workshop using the swing-weighting technique described in Section 3.5. These are shown across the top row.

Table 3.9 gives the weighted scores and rankings for the 23 research activities. The raw score is based on the weights for the first four criteria. The adjusted scores multiplicatively factor in the scores given for independent funding (Fndg) and likelihood of success (Feas) separately and combined. Except for the two highest-ranked activities, developing a fast integrator for stiff differential equations and developing a chemical mechanism for global-scale photochemistry, either or both of these multiplicative criteria significantly affected the ranking of research activities. For instance, evaluation of the effects of aerosols on tropospheric $\mathrm{O}_{3}$ ranked 13 th in raw score, but because little research in this area is being currently funded, its adjusted score put it at 4 th. Alternatively, research into the exchange of mass between the stratosphere and troposphere, which ranked 5 th in raw score, dropped to 14th in the combined adjusted score because of a low score on likelihood of success within a 3-year time frame.

The MAU process used here to arrive at the raw and adjusted scores shown in Tables 3.8 and 3.9 enables a ranking of research activities without consideration of the resources required to accomplish the work. Introducing this factor into the decision process requires additional tools. A methodology for prioritizing research and optimizing the utilization of funding resources is described in the next section. 
IABLE 3.8. Average Scores for Workshop Participants that Rated Research Activities

\begin{tabular}{|c|c|c|c|c|c|c|c|}
\hline Weight & 40 & 20 & 18 & 22 & & & \\
\hline Module & PRED. & COMP. & & SCIENT. & INDEP. & succ. & EFFORT \\
\hline Research Activity & VALUE & SPEED & SOOPE & VALUE & FNDG & PROB. & (PYrs) \\
\hline \multicolumn{8}{|c|}{ Clouds, Aerosols, Radiation } \\
\hline \multicolumn{8}{|l|}{ Nucleation } \\
\hline Mixed Aerosols & 44.6 & 8.2 & 40.8 & 61.9 & 54.6 & 66.3 & 3.5 \\
\hline \multicolumn{8}{|l|}{ Subgrid Cloud Processes } \\
\hline Subgrid Var. & 57.7 & 18.9 & 56.9 & 64.2 & 61.3 & 69.6 & 4.6 \\
\hline \multicolumn{8}{|l|}{ Aerosols } \\
\hline Moment/Species & 61.9 & 20.1 & 58.5 & 68.1 & 59.2 & 77.3 & 7.8 \\
\hline Evaluate Moments & 59.6 & 12.2 & 52.5 & 63.3 & 64.2 & 78.8 & 3.7 \\
\hline Primary Emissions & 75.4 & 8.9 & 71.5 & 58.1 & 46.7 & 77.1 & 4.5 \\
\hline \multicolumn{8}{|l|}{ Scavenging } \\
\hline Aerosols/Clouds & 54.2 & 18.5 & 48.1 & 59.2 & 60.8 & 73.5 & 2.7 \\
\hline \multicolumn{8}{|l|}{ Actinic Flux } \\
\hline Update J-Values & 61.7 & 13.4 & 67.5 & 60.8 & 49.0 & 82.7 & 2.4 \\
\hline & & & & & & & \\
\hline \multicolumn{8}{|l|}{ Chemistry } \\
\hline \multicolumn{8}{|l|}{ Gas Phase } \\
\hline $\mathrm{NO} \times / \mathrm{O} / \mathrm{HC}$ & 75.9 & 30.9 & 77.3 & 70.5 & 61.5 & 82.0 & 6.5 \\
\hline Grid Res/NOX & 63.2 & 40.5 & 63.6 & 58.2 & 48.6 & 70.6 & 3.3 \\
\hline Chem/Aerosol & 62.5 & 22.7 & 50.5 & 65.5 & 49.1 & 71.4 & 2.3 \\
\hline \multicolumn{8}{|l|}{ Emissions } \\
\hline Emissions Inventory & 76.8 & 14.5 & 80.5 & 56.8 & 54.5 & 81.5 & 2.5 \\
\hline \multicolumn{8}{|l|}{ Aqueous Reactions } \\
\hline Aerosols/O3 & 70.5 & 14.2 & 50.0 & 64.1 & 67.0 & 75.0 & 2.9 \\
\hline Clouds/O3 & 71.8 & 13.7 & 51.8 & 65.5 & 59.0 & 73.5 & 2.9 \\
\hline \multicolumn{8}{|l|}{ Clouds } \\
\hline Clouds/CH4/CO & 49.5 & 20.5 & 44.1 & 54.1 & 59.0 & 70.0 & 2.6 \\
\hline \multicolumn{8}{|l|}{ Chemistry } \\
\hline Interfaces & 61.4 & 27.3 & 65.0 & 39.5 & 62.2 & 78.0 & 2.6 \\
\hline OH Fields & 73.6 & 31.4 & 67.3 & 59.5 & 57.5 & 77.5 & 3.6 \\
\hline DMS Chemistry & 53.9 & 12.2 & 50.0 & 58.3 & 46.3 & 68.1 & 2.1 \\
\hline \multicolumn{8}{|c|}{ Meteorology \& Numerics } \\
\hline \multicolumn{8}{|l|}{ Dynamics } \\
\hline Strat/Tropo Exch & 75.4 & 13.0 & 65.8 & 68.3 & 56.4 & 64.1 & 5.2 \\
\hline Non-Local & 44.5 & 20.6 & 50.0 & 47.5 & 43.9 & 73.3 & 3.1 \\
\hline \multicolumn{8}{|l|}{ Surface Exchange } \\
\hline Hydro/Met Synth & 74.0 & 11.0 & 77.0 & 59.0 & 52.5 & 77.8 & 4.8 \\
\hline \multicolumn{8}{|l|}{ Transport/Grid System } \\
\hline Irreg Grid Chem & 56.7 & 47.9 & 71.3 & 60.0 & 54.5 & 73.6 & 3.5 \\
\hline \multicolumn{8}{|l|}{ Numerics } \\
\hline Fast Integrator & 61.2 & 86.2 & 89.6 & 75.8 & 70.4 & 79.2 & 4.0 \\
\hline \multicolumn{8}{|l|}{\begin{tabular}{|l|} 
Uncertainty \\
Autodiff demo
\end{tabular}} \\
\hline Autodiff demo & 41.1 & 48.9 & 81.5 & 79.0 & 65.0 & 77.5 & 1.9 \\
\hline
\end{tabular}


IABLE 3.9. Weighted Scores and Rank for Research Activities, Based on Scoring by Workshop Participants

\begin{tabular}{|c|c|c|c|c|c|c|c|c|c|}
\hline & & \multicolumn{4}{|c|}{ Welghted Scores } & \multicolumn{4}{|c|}{ Rank } \\
\hline & & & & & Fndg & & & & Fndg \\
\hline \multicolumn{2}{|c|}{ Module } & Raw & Fndg & Foas & \& Feas & Raw & Fndg & Foas & \& Foas \\
\hline & Research Activity & Score & Adj & Ad) & Adj & Score & Ad) & Ad) & Adj \\
\hline \multicolumn{10}{|c|}{ Clouds, Aerosols, Radiation } \\
\hline \multicolumn{10}{|c|}{ Nucleation } \\
\hline & Mixed Aerosols & 40 & 22 & 27 & 15 & 23 & 21 & 23 & 21 \\
\hline \multicolumn{10}{|c|}{ Subgrid Cloud Processes } \\
\hline & Subgrid Var. & 51 & 31 & 36 & 22 & 16 & 12 & 18 & 13 \\
\hline \multicolumn{10}{|c|}{ Aerosols } \\
\hline & Moment/Species & 54 & 32 & 42 & 25 & 12 & 9 & 10 & 8 \\
\hline & Evaluate Moments & 50 & 32 & 39 & 25 & 18 & 10 & 15 & $\underline{7}$ \\
\hline & Primary Emissions & 58 & 27 & 44 & 21 & 10 & 17 & 7 & 17 \\
\hline \multicolumn{10}{|c|}{ Scavenging } \\
\hline & Aerosols/Clouds & 47 & 29 & 35 & 21 & 19 & 15 & 19 & 16 \\
\hline \multicolumn{10}{|c|}{ Actinic Flux } \\
\hline & Update J-Values & 53 & 26 & 44 & 21 & 15 & 19 & 8 & 15 \\
\hline & & & & & & & & & \\
\hline \multicolumn{10}{|c|}{ Chemistry } \\
\hline \multicolumn{10}{|c|}{ Gas Phas ${ }^{3}$} \\
\hline & $\mathrm{NO} \times / \mathrm{O} / \mathrm{HC}$ & 66 & 41 & 54 & 33 & 2 & 2 & 2 & 2 \\
\hline & Grid Res/NOx & 58 & 28 & 41 & 20 & 9 & 16 & 11 & 18 \\
\hline & Chem/Aerosol & 53 & 26 & 38 & 19 & 14 & 18 & 17 & 19 \\
\hline \multicolumn{10}{|c|}{ Emissions } \\
\hline & Emissions Inventory & 61 & 33 & 49 & 27 & 4 & 7 & 3 & 6 \\
\hline \multicolumn{10}{|c|}{ Aqueous Reactions } \\
\hline & Aerosols/O3 & 54 & 36 & 41 & 27 & 13 & 4 & 12 & 4 \\
\hline & Clouds/O3 & 55 & 33 & 41 & 24 & 11 & 8 & 13 & 11 \\
\hline \multicolumn{10}{|c|}{ Clouds } \\
\hline & Clouds/CH4/CO & 44 & 26 & 31 & 18 & 21 & 20 & 21 & 20 \\
\hline \multicolumn{10}{|c|}{ Chemistry } \\
\hline & Interfaces & 50 & 31 & 39 & 24 & 17 & 13 & 14 & 9 \\
\hline & OH Fields & 61 & 35 & 47 & 27 & 3 & 5 & 4 & 5 \\
\hline & DMS Chemistry & 46 & 21 & 31 & 14 & 20 & 22 & 20 & 22 \\
\hline \multicolumn{10}{|c|}{ Meteorology \& Numerics } \\
\hline \multicolumn{10}{|c|}{ Dynamics } \\
\hline & Strat/Tropo Exch & 60 & 34 & 38 & 22 & 5 & 6 & 16 & 14 \\
\hline & Non-Local & 41 & 18 & 30 & 13 & 22 & 23 & 22 & 23 \\
\hline \multicolumn{10}{|c|}{ Surface Exchange } \\
\hline & Hydro/Met Synth & 59 & 31 & 46 & 24 & 6 & 14 & 5 & 10 \\
\hline \multicolumn{10}{|c|}{ Transport/Grid System } \\
\hline & Irreg Grid Chem & 58 & 32 & 43 & 23 & 7 & 11 & 9 & 12 \\
\hline \multicolumn{10}{|c|}{ Numerics } \\
\hline & Fast Integrator & 74 & 52 & 59 & 42 & 1 & 1 & 1. & 1 \\
\hline \multicolumn{10}{|c|}{ Uncertainty } \\
\hline & Autodiff Demo & 58 & 38 & 45 & 29 & 8 & 3 & 6 & 3 \\
\hline
\end{tabular}




\subsection{APPLICATION OF DECISION ANALYSIS TO RESEARCH PORTFOLIO SELECTION}

This section describes a decision methodology for prioritizing the funding of research areas and activities. By way of example, the method is applied to research activities that were identified in the first and second workshops for the creation of the GTCMS. The methodology, as described, is generally applicable to complex research and development situations. The methodology has its basis in MAU, which has been described earlier, and valuebased planning (VBP), which will be described and illustrated here. MAU is used to identify the potential value of proposed research, and VBP is used to optimize portfolios of research according to benefit-cost ratios. The result is a prioritized ranking of proposed research activities for different budget levels. The process is carried out in two stages: 1) to prioritize individual proposals and 2) to prioritize bundles of proposals grouped by topic area. The steps to the process are as follows:

- determine categories of research and generate proposals

- prioritize individuar proposa?s

- generate research program options for each category of research

- $\quad$ prioritize research programs

- determine optimum research portfolios.

\subsubsection{Determining Research Needs}

The first step in research prioritization is to define what research to request. The exercises carried out in the first and second workshops provided illustrative examples of specific areas in which research is needed for developing the GTCMS. It is recommended that the requested research cover several major research categories. These could be the general areas of research identified in the workshops or other categories as deemed appropriate. For purposes of discussion, in this section we will assume that requests for proposals (RFPs) are written for the following major research areas:

- clouds, aerosols, and radiation

- chemistry 
- meteorology

- numerics.

It may prove advantageous to develop RFPs that address subareas within these broad categories. Thus, in this example, for the category clouds, aerosols, and radiation, the following subcategories were identified in the workshop:

- activation

- subgrid clloud processes

- aerosols

- scavenging

- actinic flux.

The illustrative examples of research activities, specific to each of these areas, that were developed in the second workshop are presented in Appendix $C$.

The next step in the prioritization process is to generate proposals through the release of an RFP. Proposals must contain all the information necessary for their evaluation; consequently, the RFPs need to specify that proposals contain the specific information that they will be evaluated on. While it may not be desirable to list specific criteria and scales in the RFP, it probably is desirable to list, in general terms, the basis for the evaluation and, possibly, which areas will be given the most consideration or weight. Consequently, thought should be given to the proposal evaluation criteria at the time the RFPs are generated. These evaluation criteria will be subject to the regulations and practices specific to the funding organization. It is recommended that the evaluation criteria include technical criteria that address the usefulness of the research in creation of a GTCMS, criteria that address the qualifications of the research institution and the principal investigators, and cost information. Criteria will be discussed further in the next section.

\subsubsection{Prioritizing Individual Proposals}

The evaluation criteria usually identify what is important in the evaluation of the proposals. Individual proposals in most institutions are evaluated on the technical merit of the research, the ability of the research 
institution to successfully support the research, the ability of the scientists to carry out the research, and the cost to the funding organization. Criteria for evaluating the technical merit of research specific to the creation of a GTCMS were developed for the exercise carried out in the second workshop. The technical criteria and their scales were shown in Table 3.7. The scales were constructed to clearly define specific levels of performance for each of these criteria. It is important that all criteria have scales that unambiguously define their levels of performance and that are broad enough +3 include the best- and worst-possible scenarios. Also shown in Table 3.7 are the numbers ranging from 0 to 100 . These numbers represent the value of the associated performance level for the overall goal of supporting research necessary for the development of the GTCMS. Thus, value functions have been incorporated directly into the scales so that the numbers not only represent the level of performance but also the value associated with achieving that level of performance.

The technical criteria and scales developed in the second workshop may be used directly as shown or they may be modified as required for the specific application. In any case, it will be necessary to develop additional criteria and scales to evaluate the ability and qualifications of the research institution and the principal investigators. Examples of some possible additional criteria are the following:

- scientific merit of proposal, including logic of research plan

- qualification and support of research institution

- academic qualifications of key personnel

- time commitment of personnel

- project management capability and organization.

To capture the relative importance of the complete set of evaluation criteria, weights must be established. Swing weighting is a standard decision analysis process that is recommended for establishing the weights. This method results in the criteria weights reflecting the ranges over which the alternatives can vary and correctly ties the weights to the scales. The 
elicited swing weights reflect the tradeoffs among the criteria in their respective units.

The swing-weighting procedure is a bottom-up process, in which the criteria within a particular category, or subcategory, are first ranked and then their ratios of relative importance determined. The swing process requires that the worst- and best-performance levels for each of the criteria be identified. The first step in the swing-weighting process is to consider a situation in which a hypothetical proposal would score at the worst level for all criteria within a particular category. Then imagine that if the hypothetical proposal could be improved to the best level on one of the criteria, for which criterion would this represent the most valuable improvement, the second most valuable, etc. This provides the basis for the rankings. Ratio judgments of the relative importance of the criteria are then obtained. The process is repeated for each of the categories and then extended to obtain judgments of relative importance across categories. The ratios of relative importance ascribed to the various criteria should then be normalized, so that the weights across all the criteria sum to 1 . A spreadsheet, developed prior to obtaining the necessary judgments. will greatly facilitate the process. The first column in the spreadshee third columns should show the wors. d list the criteria; the second and jest levels of performance for each criterion; next should be columns for ranking the criteria and rating them with the ratio judgments of relative importance. The spreadsheet can easily be developed to compute normalized weights from the raw ratio judgments of relative importance.

Weights should be obtained from each member of the evaluation panel and then averaged, providing that the differences between panel members are not too great. Substantial differences in assigned weight should be discussed and resolved.

Specific evaluation assignments will depend on the breadth of knowledge of the individual evaluators and the number of proposals received. If the evaluators are competent to rate proposals from all of the major research categories and the number of proposals is not too great, then all evaluators can rate all proposals on all criteria. The scoring should initially be made independently and then be compared. If there are large differences in 
scoring, these should be discussed, with the goal to reach consensus. The results from the individual evaluators can then be averaged to determine the ratings or score. If the evaluators do not feel competent to rate proposals from all areas, and/or the number of proposals is too large, then individuals or small teams can be assigned to rate proposals in specific research categories. It will be especially important in this case that the scales for evaluating each criterion be clearly defined. Only then will meaningful comparisons of proposals across research categories be possible. Clearly defined scales should always be developed, so that proposals can be given objective ratings rather than relative comparisons, which become very difficult when there are many proposals to rate.

Each proposal is then scored on each of the criteria according to defined scales. These scores should then be combined with the weights to determine the overall rating of the proposal. Generally, the weight and score are multiplied for each criterion and the product summed over all criteria to determine the overall rating for each individual proposal. However, this assumes the criteria are preferentially independent. In some cases, the overall rating is better reflected in a model in which some of the criteria are multiplied (Keeney and Raiffa 1976). In any case, the process is greatly facilitated by the creation of a worksheet on an electronic spreadsheet. Table 3.10 shows the layout of a typical worksheet for scoring individual proposals. Fictitious data are used to illustrate the process. The worksheet identifies the evaluator $(A B)$ at the top, with the list of the proposals being evaluated in the first column. Subsequent columns contain the scores assigned by the evaluator to each criterion for each proposal. Table 3.11 shows a spreadsheet that calculates the overall rating of an individual proposal, using the scores from several evaluators. This spreadsheet lists the criteria in the first column, then the weights, a column for the scores from each of the evaluators, and a column for the average of the evaluators' scores. The last entry in the last column is the calculated overall score, based on the average scores and the weights. In this example, the average score is multiplied by the weight for the first eight criteria; these products are then summed. This sum is then multiplied by the independent funding score divided by 100 , and the resulting product is then multiplied by probability of 
TABLE 3.10. Typical Worksheet for Scoring Proposals

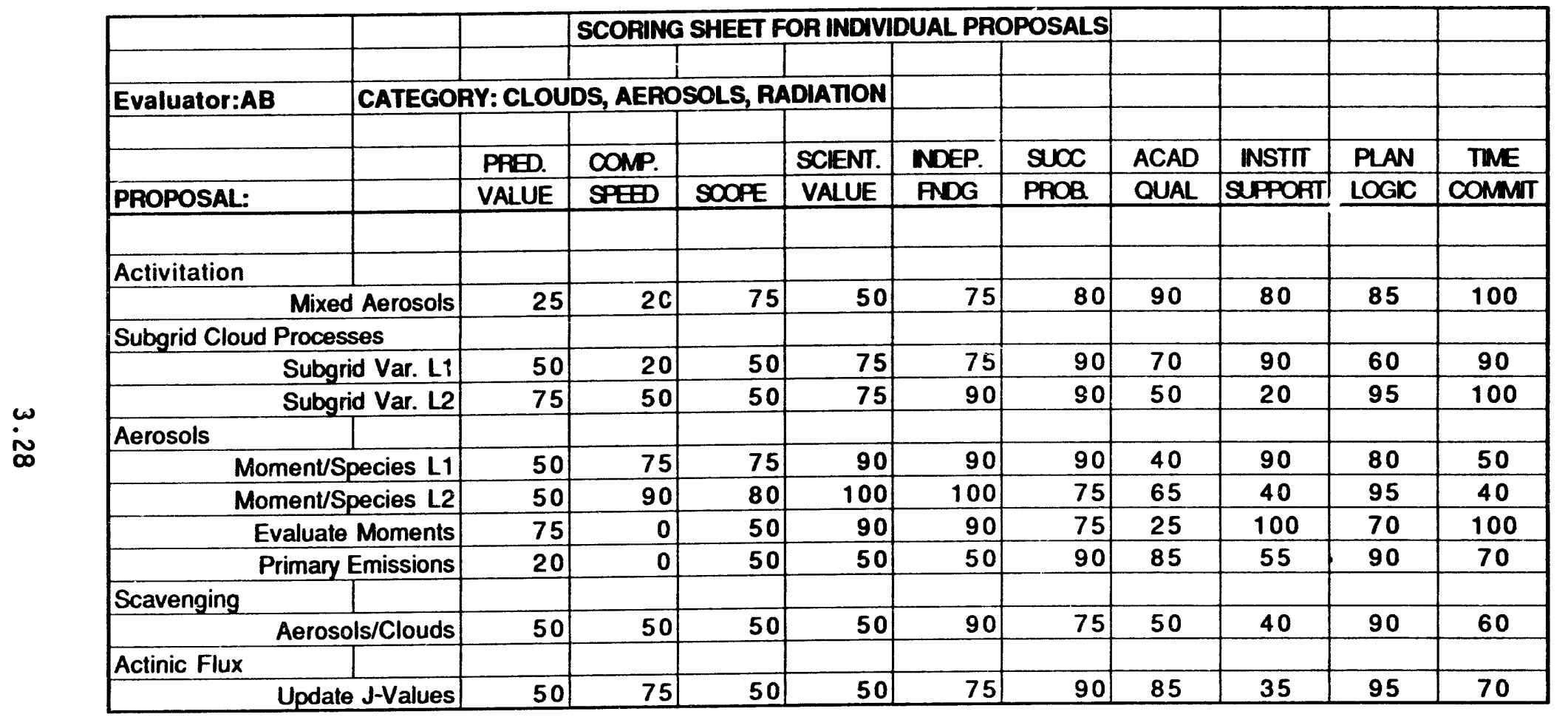


TABLE 3.11. Spreadsheet to Determine Overall Value of Individual Projects

\begin{tabular}{|c|c|c|c|c|c|}
\hline \multicolumn{6}{|c|}{ CATEGORY: Clouds, Aerosols, Radiation } \\
\hline \multicolumn{2}{|c|}{ Proposal: Mixed Aerosols } & & & \multicolumn{2}{|c|}{ Cost: $350 \mathrm{~K}$} \\
\hline & & & & & \\
\hline & & & \multicolumn{2}{|c|}{ Evaluator } & \\
\hline Criteria: & Weight & A B & $C D$ & EF & Average \\
\hline Predictive Value & 0.24 & 80 & 65 & 50 & 65 \\
\hline Computational Speed & 0.12 & 20 & 25 & 35 & 27 \\
\hline Scope & 0.10 & 90 & 70 & 75 & 78 \\
\hline Scientific Value & 0.14 & 85 & 60 & 100 & 82 \\
\hline Academic Qualifications & 0.15 & 90 & 70 & 90 & 83 \\
\hline Institutional Support & 0.05 & 80 & 75 & 85 & 80 \\
\hline Research Plan Logic & 0.10 & 85 & 75 & 90 & 83 \\
\hline Time Commitment & 0.10 & 100 & 90 & 100 & 97 \\
\hline Independent Funding & na & 100 & 80 & 70 & 83 \\
\hline \multirow[t]{2}{*}{ Probability of Success } & na & 0.9 & 0.7 & 0.6 & .73 \\
\hline & & & & Value: & 44 \\
\hline
\end{tabular}

success. In this example, the overall value is best served by a model in which the last two criteria act as discounting factors for the value determined by the other criteria.

Table 3.12 is illustrative of a spreadsheet that compares the individual proposais in a given research category. A proposal comparison spreadsheet should be created for each of the major research categories. So, for this example, there would be four spreadsheets. The spreadsheet shows the overall value of the proposals, the proposed cost, and the value to cost ratio (V/C). The lower portion of the spreadsheet gives an initial ranking of all the proposals within a given category based on the value-to-cost ratio. This portion of the table was created by duplicating the top portion and sorting the rows based on the value-to-cost ratio, with the highest ratio in the top row. An additional column added to this portion of the spreadsheet gives the cumulative cost of funding any number of proposals based on the value-to-cost rankings. (In practice, all of these spreadsheets can be created on a single large spreadsheet or the small individual spreadsheets can be "linked.") 
TABLE 3.12. Comparison of Individual Research Proposals

\begin{tabular}{|c|c|c|c|c|}
\hline \multicolumn{2}{|c|}{ CATEGORY: Clouds, Aerosols, Radiation } & & & \\
\hline & & & & \\
\hline \multicolumn{5}{|l|}{ PROPOSAL: } \\
\hline & VALUE & $\operatorname{cosT}(K)$ & $\mathrm{V} / \mathrm{C}$ & \\
\hline \multicolumn{5}{|l|}{ Activitation } \\
\hline Mixed Aerosols & 44 & 350 & 0.13 & \\
\hline \multicolumn{5}{|l|}{ Subgrid Cloud Processes } \\
\hline Subgrid Var. L1 & 55 & 200 & 0.28 & \\
\hline Subgrid Var. L2 & 65 & 460 & 0.14 & \\
\hline \multicolumn{5}{|l|}{ Aerosols } \\
\hline Moment/Species L1 & 41 & 400 & 0.10 & \\
\hline Moment/Species L2 & 54 & 780 & 0.07 & \\
\hline Evaluate Mmoments & 28 & 370 & 0.08 & \\
\hline Primary Emissions & 21 & 450 & 0.05 & \\
\hline \multicolumn{5}{|l|}{ Scavenging } \\
\hline Aerosols/Clouds & 70 & 270 & 0.26 & \\
\hline \multicolumn{5}{|l|}{ Actinic Flux } \\
\hline Update J Values & 35 & 240 & 0.15 & \\
\hline & & & & \\
\hline PROPOSAL: & & & & $\mathrm{CUM}$ \\
\hline & VALUE & $\cos T(K)$ & $\mathrm{V} / \mathrm{C}$ & $\cos T$ \\
\hline Subgrid Var. L1 & 55 & 200 & 0.28 & 200 \\
\hline Aerosols/Clouds & 70 & 270 & 0.26 & 470 \\
\hline Update J Values & 35 & 240 & 0.15 & 510 \\
\hline Subgrid Var. L2 & 65 & 460 & 0.14 & 700 \\
\hline Mixed Aerosols & 44 & 350 & 0.13 & 810 \\
\hline Moment/Species L1 & 41 & 400 & 0.10 & 750 \\
\hline Evaluate Moments & 28 & 370 & 0.08 & 770 \\
\hline Moment/Species L2 & 54 & 780 & 0.07 & 1150 \\
\hline Primary Emissions & 21 & 450 & 0.05 & 1230 \\
\hline
\end{tabular}

\subsubsection{Creating Research Programs}

Ultimately, decisions on research are made from a collection of research proposals whose overall value is not necessarily a simple sum of the values of the individual projects. For example, two proposals with high value-to-cost scores may have large overlaps in the proposed research, so that their values would not be additive. Consequently, what is needed is that the evaluators 
generate recommended combinations of proposals that make sense for each of the major research categories. Furthermore, research needs to be optimized for different levels of budgetary constraints; consequently, each group of evaluators needs to recommend combinations of proposals for several different funding levels. Typical funding levels chosen for this example are the following:

- zero--No proposals from the research category are funded.

- minimal--The least cost set of proposals that provides a modest step toward the goal. Usually, a dollar amount is set to limit the cost of the package and to constrain the choice of proposals included.

- recommended--A set of proposals that, if successfully completed, would result in significant progress toward the goal.

- enhanced--A set of proposals that, if successfully completed, would result in the major objectives for the category being met.

After ranking the individual proposals and ordering them on their value-tocost ratios, the evaluators have the information at hand necessary to generate the recommended funding packages for the different levels of funding. Having already evaluated the individual proposals, the evaluators are very familiar with specific research benefits that would result from their successful completion. Thus, they know which proposals are duplicating research, which proposals are complementary, or which are superadditive in meeting research needs. The evaluators also have in summary form the budgetary requirements of the proposals and their value-to-cost scores. With all of this information, the evaluators are in an excellent position to recommend combinations of proposals for different levels of funding within a given category. At this stage, proposals with marginal merit or proposals presented by institutions or organizations with questionable qualifications can be dropped from further consideration. It should also be pointed out that a package that represents a higher level of funding within a particular category does not necessarily include all of the proposais recommended for the next lower-level set. This is because, at a higher funding level, it may be possible to fund a combination of more valuable research but only by excluding some proposals that may have been funded at a lower level. 
Each funding package is subsequently treated as a "proposal." Therefore, some description of how the funding package addresses the evaluation criteria will be needed. As a minimum, recommended funding packages must include the list of proposals to be funded and the total cost of funding. How much additional information the packages should contain will depend on whether all evaluators rated all proposals and created all the funding packages and, consequently, would be familiar with what each package would provide. If evaluators are split along research categories, then it will be mandatory that some description be given of the benefits of funding categories at each of the levels, and it may be valuable to provide such a description in either case. Just as in the case with proposals, it was necessary to present all the information necessary for their evaluation on the criteria for which they were to be scored; so too, these package descriptions need to provide a basis for their subsequent evaluation. Thus, thought needs to be given beforehand to the criteria to be used for evaluation of combinations of proposals. The end product of this task should be a list of combinations of proposals to fund for various funding levels and a description of the benefits for each of the different levels.

\subsubsection{Prioritizing Research Programs}

The next step in the research prioritization process is to evaluate the recommended funding packages. Each of these packages needs to be scored on the criteria developed for this purpose. These criteria could possibly be the same as those used to evaluate individual proposals; however, it is more likely that they will be some variant of those criteria. For example, qualifications of researchers and institutions would probably not be an appropriate criterion at this level of evaluation. The reason is that there would probably be too many of such institutions in a particular package, and the questionable or poor performers will have already been screened out. Also, it may be necessary to add new criteria that deal with decisions at this higher level of evaluation. For example, the compatibility of the research program across the various categories may become a consideration at this level. Most likely, the criteria will mainly focus on the same technical concerns that were developed for evaluating individual proposals. 
New weights must be established for the criteria used to evaluate the funding packages. The swing-weighting process described above is the recommended method for arriving at the weights. If the criteria contain, as a subset, some of the same criteria used to evaluate the individual proposals, then it will be possible to obtain the relative weights of those criteria from the earlier work. In any case, the fact that the evaluators have already been through the exercise and are familiar with many of the scales and their end points should facilitate the process.

Scoring, tabular reporting, and summarizing the results are identical to the proposal-rating process described above (see Tables 3.10, 3.11, and 3.12). However, Table 3.13 summarizes the results of the evaluation of the funding packages in a slightly different way. The first column lists the research categories, next is the column for the overall evaluation, then a column for the cost. The next two columns show the marginal value $(\Delta V)$ and marginal cost $(\Delta C)$. The marginal value is the increase in value that would occur for funding at that level rather than the next lowest level. The marginal cost is the marginal increase in cost for that level of funding over the next lowest level. The final column is the marginal value to marginal cost ratio $(\Delta \mathrm{V} / \Delta \mathrm{C})$. As with the summary sheet for the individual proposals, the information is duplicated and sorted from highest to lowest ratio. Finally, a cumulative cost is calculated based on this sequence.

\subsubsection{Value-Based Planning}

The final step in the research prioritization process is to determine the optimum combination of funding across the various research categories subject to the overall budgetary constraints. In this example, each of the four categories can be funded at one of four funding levels, so there are 256 possible allocations. Only 12 of these are "efficient" allocations that maximize value per dollar spent. These are determined from the marginalvalue-to-marginal-cost ratios (i.e., $\Delta V / \Delta C$ ). Funding packages were ordered, based on these ratios, and the cumulative dollar amount was calculated. The efficient allocation is to fund projects in the order that maximizes marginalvalue-to-marginal-cost ratios until the budget is expended. Thus, in this example, for a budget of \$1.41M, the Clouds, Aerosols, and Radiation and 
TABLE 3.13. Comparison of Research Programs

\begin{tabular}{|c|c|c|c|c|c|}
\hline \multicolumn{6}{|l|}{ FUNDING PACKAGE: } \\
\hline & VALUE & $\operatorname{COST}(10 \mathrm{~K})$ & $\Delta V$ & $\Delta \mathrm{C}(10 \mathrm{~K})$ & $\Delta V / \Delta C$ \\
\hline \multicolumn{6}{|c|}{ CLOUDS, AEROSOLS, RADIATION } \\
\hline C-A-R:ZERO & 0 & 0 & 0 & 0 & \\
\hline C-A-R:MINIMUM & 45 & 51 & 45 & 51 & 0.88 \\
\hline C-A-R:RECOMMENDED & 65 & 75 & 20 & 24 & 0.83 \\
\hline C-A-R: ENHANCED & 80 & 115 & 15 & 40 & 0.38 \\
\hline \multicolumn{6}{|l|}{ CHEMISTRY } \\
\hline CHEM:ZERO & 0 & 0 & 0 & 0 & \\
\hline CHEM: MINIMUM & 35 & 41 & 35 & 41 & 0.85 \\
\hline CHEM: RECOMMENDED & 55 & 65 & 20 & 24 & 0.83 \\
\hline CHEM: ENHANCED & 75 & 95 & 20 & 30 & 0.67 \\
\hline \multicolumn{6}{|l|}{ METEOROLOGY } \\
\hline MET-ZERO & 0 & 0 & 0 & 0 & \\
\hline MET:MINIMUM & 40 & 52 & 40 & 52 & 0.77 \\
\hline MET:RECOMMENDED & 55 & 75 & 15 & 23 & 0.65 \\
\hline MET:ENHANCED & 70 & 108 & 15 & 33 & 0.45 \\
\hline \multicolumn{6}{|l|}{ NUMERICS } \\
\hline NUMZERO & 0 & 0 & 0 & 0 & \\
\hline NUM:MINIMUM & 20 & 35 & 20 & 35 & 0.57 \\
\hline NUM:RECOMMENDED & 35 & 68 & 15 & 33 & 0.45 \\
\hline NUM:ENHANCED & 40 & 82 & 5 & 14 & 0.36 \\
\hline & & & & & \\
\hline & & aM & & & \\
\hline & & $\operatorname{COST}(10 \mathrm{~K})$ & $\Delta \mathrm{V}$ & $\Delta \mathrm{C}(10 \mathrm{~K})$ & $\Delta V / \Delta C$ \\
\hline C-A-R:MINIMUM & & 51 & 45 & 51 & 0.88 \\
\hline CHEM:MINIMUM & & 92 & 35 & 41 & 0.85 \\
\hline G-A-R:RECOMMENDED & & 116 & 20 & 24 & 0.83 \\
\hline CHEM:RECOMMENDED & & 141 & 20 & 25 & 0.80 \\
\hline MET:MINIMUM & & 193 & 40 & 52 & 0.77 \\
\hline CHEM: ENHANCED & & 223 & 20 & 30 & 0.67 \\
\hline MET:RECOMMENDED & & 246 & 15 & 23 & 0.65 \\
\hline NUM:MINIMUM & & 281 & 20 & 35 & 0.57 \\
\hline MET:ENHANCED & & 314 & 15 & 33 & 0.45 \\
\hline NUM:RECOMMENDED & & 347 & 15 & 33 & 0.45 \\
\hline C-A-R: ENHANCED & & 387 & 15 & 40 & 0.38 \\
\hline NUM:ENHANCED & & 401 & 5 & 14 & 0.36 \\
\hline
\end{tabular}

Chemistry categories would both be funded at their recommended levels. Neither Meteorology nor Numerics would be funded. 


\subsection{REFERENCES}

Arakawa, A., and W. H. Schubert. 1974. "Interaction of a Cumulus Cloud Ensemble with the Large-Scale Environment." J.Atmos. Sci. 31:674-701.

Balkanski, Y. J., D. J. Jacob, G. M. Gardner, W. C. Graustein, and K. K. Turekian. 1993. "Transport and Residence Times of Tropospheric Aerosols Inferred from a Global Three-Dimensional Simulation of ${ }^{210} \mathrm{~Pb}$." J. Geophys. Res. 98:20573-20586.

Berkowitz, C. M., R. C. Easter, and B. C. Scott. 1989. "Theory and Results from a Quasi-Steady-State Precipitation Scavenging Model." Atmos. Environ. $23: 1555-1571$.

Brost, R. A., R. B. Chatfield, J. P. Greenberg, P. L. Haagenson, B. G. Heikes, S. Madronich, B. A. Ridley, and P. R. Zimmerman. 1988. "Three-Dimensional Modeling of Transport of Chemical Species from Continents to the Atlantic Ocean." Tellus 40B:358-379.

Chameides, W. L., and A. W. Stelson. 1992. "Aqueous-Phase Chemical Processes in Deliquescent Sea-Salt Aerosols: A Mechanism that Couples the Atmospheric Cycles of S and Sea-Salt." J. Geophys. Res. 97:20565-20580.

Charlson, R. J., S. E. Schwartz, J. M. Hales, R. D. Cess, J. A. Coakley, J. E. Hansen, and D. J. Hofmann. 1992. "Climate Forcing by Anthropogenic Aerosols." Science 255:423-430.

Clark, T. L. 1976. "Use of Log-Normal Distributions for Numerical Calculations of Condensation and Collection." J.Atmos. Sci. 33:810-821.

Clark, T. L., and W. D. Hall. 1983. "A Cloud Physical Parameterization Method Using Movable Basis Functions: Stochastic Coalescence Parcel Calculations." J.Atmos. Sci. 40:1709-1728.

Dennis, R. L., and J. H. Novak. 1991. "EPA's Third Generation Modeling System (Models-3): An Overview." In preprints of the AWMA Specialty Conference on Tropospheric Ozone and the Environment II: Effects, Modeling and Control, November 4-7, 1991, Atlanta, Georgia.

Dentener, F. J., and P. J. Crutzen. 1993. "Reaction of $\mathrm{N}_{2} \mathrm{O}_{5}$ on Tropospheric Aerosols: Impact on the Global Distributions of $\mathrm{NO}_{x}, \mathrm{O}_{3}$, and $\mathrm{OH}$." J. Geophys. Res. 98:7149-7163.

Dunker, A. M. 1984. "The Decoupled Direct Method for Calculating Sensitivity Coefficients in Chemical Kinetics." J. Chem. Phys. 81:2385-2393.

East'r, R. C., R. D. Saylor, and E. G. Chapman. 1993. "Analysis of MidTropospheric Carbon Monoxide Data Using a Three-Dimensional Global Atmospheric Chemistry Numerical Model." In Proceedings of the 20th International

Technical Meeting on Air Pollution Modeling and Its Application, November 29 to December 3, 1993, Valencia, Spain. 
Fairweather, G. 1978. Finite Element Galerkin Methods for Differential Equations, Lecture Notes in Pure and Applied Mathematics 34 . Marcel Dekker, New York.

Finlayson-Pitts, B. J., and J. N. Pitts, Jr. 1986. Atmospheric Chemistry: Fundamentals and Experimental Techniques. John Wiley \& Sons, New York.

Giorgi, F. 1986. "Development of an Atmospheric Aerosol Model for Studies of Global Budgets and Effects of Airborne Particulate Material." NCAR Cooperative Thesis, NCAR/CT-102, National Center for Atmospheric Research, Boulder, Colorado.

Griewank, A., and G. F. Corliss. 1991. Automatic Differentiation of Algorithms: Theory, Implementation, and Application. SIAM, Philadelphia, Pennsylvania.

Hall, M. C., D. G. Cacuci, and M. E. Schlesinger. 1982. "Sensitivity Analysis of a Radiative-Convective Model by the Adjoint Method." J. Atmos. Sci. 39:2038-2050.

Hesstvedt, E., 0. Hov, and I.S.A. Isaksen. 1978. "Quasi-Steady-State Approximations in Air Pollution Modeling: Comparison of Two Numerical Schemes for Oxidant Prediction." Int. J. Chem. Kinetics X:971-994.

Hoerling, M. P., T. K. Schaak, and A. J. Lenzen. 1993. "A Global Analysis of Stratosphere-Troposphere Exchange During Northern Winter." Mon. Wea. Rev. $121: 162-172$.

Intergovernmental Panel on Climate Change (IPCC). 1990. Climate Change. The IPCC Scientific Assessment. Cambridge University Press, New York, 365 pp.

Jacob, D. J., J. A. Logan, R. M. Yevich, G. M. Gardner, C. M. Spivakovsky, S. C. Wofsy, J. W. Munger, S. Sillman, M. J. Prather, M. 0. Rodgers, H. Westberg, and P. R. Zimmerman. 1993a. "Simulation of Summertime Ozone Over North America." J. Geophys. Res. 98:14797-14816.

Jacob, D. J., J. A. Logan, G. M. Gardner, R. M. Yevich, C. M. Spivakovsky, S. C. Wofsy, S. Sillman, and M. J. Prather. 1993b. "Factors Regulating Ozone Over the United States and Its Export to the Global Atmosphere." J. Geophys. Res. 98:14817-14826.

Jacobson, M. Z., and R. P. Turco. 1993. "SMVGEAR: A Sparse-Matrix, Vectorized Gear Code for Atmospheric Models." Atmos. Environ. (in press).

Kasibhatla, P. S., H. Levy, II, and W. J. Moxim. 1993. "Global $\mathrm{NO}_{x}, \mathrm{HNO}_{3}$, PAN, and NO Distributions from Fossil Fuel Combustion Emissions: A' Model Study." J. Geophys. Res. 98:7165-7180.

Kaufmarn, Y. J., R. S. Fraser, and R. L. Mahoney. 1991. "Fossil Fuel and Biomass Burning Effect on Climate - Heating or Cooling?" J.Clim. 4:578-588. 
Keeney, R. L. 1992. Value-Focused Thinking: A Path to Creative Decision Making. Harvard University Press, Cambridge, Massachusetts.

Keeney, R. L., and H. Raiffa. 1976. Decisions with Multiple Objectives: Preferences and Value Tradeoffs. John Wiley \& Sons, New York.

Kreidenweis, S. M., J. E. Penner, F. Yin, and J. H. Seinfeld. 1991. "The Effects of Dimethylsulfide upon Marine Aerosol Concentrations." Atmos. Environ. 25A:2501-2511.

Langner, J., and H. Rodhe. 1991. "A Global Three-Dimensional Model of the Tropospheric Sulfur Cycle." J.Atmos. Chem. 13:225-263.

Lelieveld, J., and P. J. Crutzen. 1991. "The Role of Clouds in Tropospheric Photochemistry." J.Atmos. Chem. 12:229-267.

Lurmann, F. W., A. C. Lloyd, and R. Atkinson. 1986. "A Chemical Mechanism for Use in Long-Range Transport/Acid Deposition Computer Modeling." J. Geophys. Res. 91:10905-10936.

Mathur, R., L. K. Peters, and R. D. Saylor. 1992. "Sub-Grid Representation of Emission Source Clusters in Regional Air Quality Modeling." Atmos. Environ. 26A:3219-3238.

Oden, J. T., and G. F. Carey. 1983. Finite Elements IV: Mathematical Aspects. Prentice Hall, Englewood Cliffs, New Jersey.

Penner, J. E., C. S. Atherton, and T. E. Gradel. 1993. "Global Emissions and Models of Photochemically Active Compounds." In 37th OHOLO Conference Series, ed. A. Slinn. Plenum Publishing Corp., New York.

Peterson, J. T. 1977. "Dependence of the $\mathrm{NO}_{2}$ Photodissociation Rate Constant on Altitude." Atmos. Environ. 11:689-695.

Savage, L. J. 1954. The Foundations of Statistics. John Wiley \& Sons, New York.

Seinfeld, J. H. 1989. "Urban Air Pollution: State of the Science." Science $243: 745-752$.

Sillman, S. 1991. "A Numerical Solution for the Equations of Tropospheric Chemistry Based on an Analysis of Sources and Sinks of Odd Hydrogen." J. Geophys. Res. 96:20735-20744.

Sillman, S., J. A. Logan, and S. C. Wofsy. 1990. "A Regional Scale Model for Ozone in the United States with Subgrid Representation of Urban and Power Plant Plumes." J. Geophys. Res. 95:5731-:748.

Slinn, W.G.N. 1993. "Some Literature Notes and Nuances." Atmospheric Chemistry Program: Monthly Update, Volume 4, Number 3, ed. J. M. Hales, ENVAIR, Kennewick, Washington. 
Spivakovsky, C. M., S. C. Wofsy, and M. J. Prather. 1990. "A Numerical Method for Parameterization of Atmospheric Chemistry: Computation of Tropospheric OH." J. Geophys. Res. 95:18433-18439.

Tie, X., C. -Y. Kao, E. J. Mroz, R. J. Cicerone, F. N. Alyea, and D. M. Cunnold. 1992. "Three-Dimensional Simulations of Atmospheric Methyl Chloroform: Effect of an Ocean Sink." J. Geophys. Res. 97:20751-20769.

Twomey, S. 1971. "The Composition of Cloud Nuclei." J.Atinos. Sci. $28: 377-381$.

Verlinde, J., P. Flatau, and W. R. Cotton. 1990. "Analytical Solutions to the Collection Growth Equation: Comparison with Approximate Methods and Application to Cloud Microphysics Parameterization Schemes." J. Atmos. Sci. $47: 2871-2880$.

von Neumann, J., and 0. Morgenstern. 1947. Theory of Games and Economic Behavior. Princeton University Press, Princeton, New Jersey.

von Winterfeldt, D., and W. Edwards. 1986. Decision Analysis and Behavioral Research. Cambridge University Press, New York.

Walcek, C. J., and G. R. Taylor. 1986. "A Theoretical Method for Computing Vertical Distributions of Acidity and Sulfate Production Within Cumulus Clouds." J.Atmos. Sci. 43:339-355.

Wayne, R. P. 1991. Chemistry of Atmospheres. Clarendon Press, Oxford, United Kingdom, 447 pp.

Wesely, M. 1989. "Parameterization of Surface Resistances to Gaseous Dry Deposition in Regional-Scale Numerical Models." Atmos. Environ. 27:1293-1304.

Whitby, K. T. 1978. "The Physical Characteristics of Sulfur Aerosols." Atmos. Environ. 12:135-159.

Whitby, E. R., P. H. McMurry, U. Shankar, and F. S. Binkowski. 1991. Modal Aerosol Dynamics Modeling. EPA 600/3-91/020 (NTIS PB91-161729/AS), U.S. Environmental Protection Agency, Research Triangle Park, North Carolina.

Yamada, T., and G. Mellor. 1975. "A Simulation of the Wangara Atmospheric Boundary Layer Data." J.Atmos. Sci. 32:2309-2329.

Ziegler, C. L. 1985. "Retrieval of Thermal and Microphysical Variables in Observed Convective Storms. Part I: Model Development and Preliminary Testing." J.Atmos. Sci. 42:1487-1509. 


$$
-1
$$




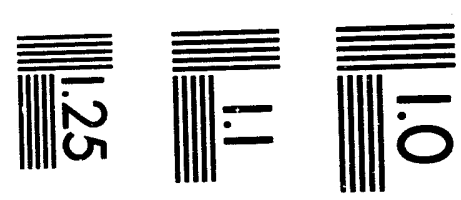

$$
\begin{aligned}
& \overline{\overline{\bar{N}}}
\end{aligned}
$$

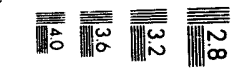

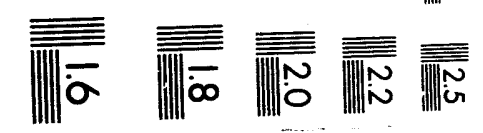



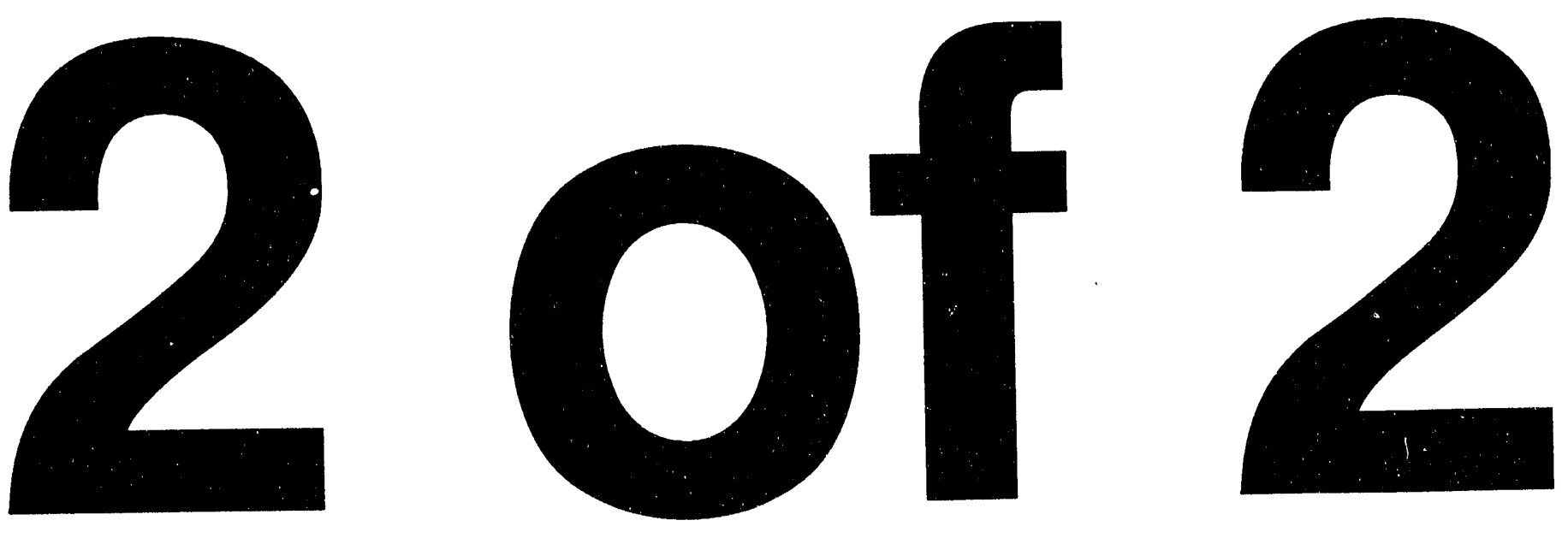
APPENDIX $A$

\section{CURRENT STATUS OF GLOBAL-SCALE CHEMICAL TRANSPORT MODELS}

Several chemical transport models (CTMs) for the global scale currently exist. These models provide the starting point for the design of the global tropospheric chemistry modeling system. An analysis of the process modules comprising these models is presented in Table A.1. By adding other options for each module to this table, a shell for designing a modular system that incorporated not only the existing practice for each module but also included new options that embody the direction of scientific development was created.

Most of the three-dimensional CTMs for the global scale are under continual improvement and several other newer CTMs are currently under development at various locations (e.g., the National Center for Atmospheric Research and Lawrence Livermore National Laboratory). In the past, three-dimensional, global-scale models either treated only tropospheric chemical processes or stratospheric processes. Currently, many formerly stratospheric-only models are being extended down into the troposphere, and tropospheric models are being extended into the lower stratosphere. Therefore, it is difficult to provide a completely up-to-date description of the current state of the science in global-scale chemical models because this is an extremely active area of atmospheric science research. In the following, a brief synopsis of several global-scale, three-dimensional tropospheric chemistry models that have an established record of published investigations is provided.

\section{A.1 GEOPHYSICAL FLUID DYNAMICS LABORATORY}

The Geophysical Fluid Dynamics Laboratory (GFDL) CTM was developed by Mahlman et al. (1980) to study the distribution of tropospheric $\mathrm{O}_{3}$ (Levy et al. 1985), the distribution and variability of $\mathrm{N}_{2} \mathrm{O}$ (Levy et al. 1982; Mahlman et a1. 1986), and reactive nitrogen chemistry and transport (Levy and Moxim 1987; Levy and Moxim 1989a, 1989b; Moxim 1990; Kasibhatla et al. 
TABLE A.1. Features of Current Chemical Transport Models for the Global Scale

\begin{tabular}{|c|c|c|}
\hline Module & $\begin{array}{l}\text { Geophysical Fluid } \\
\text { Dynamics Laboratory }\end{array}$ & Harvard University \\
\hline $\begin{array}{l}\text { CHEMISTRY } \\
\text { Gas phase } \\
\text { Aqueous phase } \\
\text { Aqueous size } \\
\text { Subgrid } \\
\text { Aerosols }\end{array}$ & $\begin{array}{l}\mathrm{CH}_{4} / \mathrm{CO}, \mathrm{NO}_{x} / \mathrm{O}_{3} \text {, performed off-line } \\
\text { none } \\
\text { none } \\
\text { instant dispersion } \\
\text { bulk/spec. int. mxd. }\end{array}$ & $\begin{array}{l}\mathrm{CH}_{4} / \mathrm{CO}, \text { mult. lumped } \mathrm{HC}, \mathrm{NO}_{x} / \mathrm{O}_{3} \\
\text { none } \\
\text { none } \\
\text { plume in grid } \\
\text { bulk/spec. int. mxd. }\end{array}$ \\
\hline $\begin{array}{l}\text { DYNAMICS } \\
\text { Boundary 1ayer/turbulence } \\
\text { Stratosphere }\end{array}$ & $\begin{array}{l}\text { K-theory, lst order } K_{z z} \\
\text { dynamic strat./tropo. exchange } \\
\text { with chemistry (domain extends } \\
\text { into lower strat.) }\end{array}$ & $\begin{array}{l}\text { K-theory, lst order } K_{z z} \\
\text { dynamic strat./tropo. exchange } \\
\text { with chemistry (domain } \\
\text { extends into lower strat.) }\end{array}$ \\
\hline $\begin{array}{l}\text { CLOUD PROCESSES } \\
\text { Microphysics } \\
\text { Scavenging } \\
\text { Subgrid } \\
\text { Activation } \\
\text { Convective clouds }\end{array}$ & $\begin{array}{l}\text { bulk } \\
\text { scavenging coefficients } \\
\text { fractional area } \\
\text { none } \\
\text { enhanced } k_{22} \text { in moist unstable } \\
\text { environments }\end{array}$ & $\begin{array}{l}\text { bulk } \\
\text { scavenging coefficients } \\
\text { fractional area } \\
\text { none } \\
\text { decoupled/Jacob et al. } \\
\quad \text { (1993a) }\end{array}$ \\
\hline SURFACE EXCHANGE & constant, species dependent & resistance methodology \\
\hline $\begin{array}{l}\text { ACTINIC FLUX } \\
\text { Radiative transfer } \\
\text { Subgrid }\end{array}$ & $\begin{array}{l}\text { look-up table } \\
\text { uniform }\end{array}$ & $\begin{array}{l}\text { look-up table } \\
\text { uniform }\end{array}$ \\
\hline $\begin{array}{l}\text { NUMERICS } \\
\text { Transport } \\
\text { Chemistry } \\
\text { Grid }\end{array}$ & $\begin{array}{l}\text { finite volume method } \\
\text { look-up table } \\
\text { uniform }\end{array}$ & $\begin{array}{l}\text { moments (Prather } 1986 \text { ) } \\
\text { polynomial fit to off-line model } \\
\text { runs } \\
\text { uniform }\end{array}$ \\
\hline SENSITIVITY/UNCERTAINTY & none & none \\
\hline
\end{tabular}


TABLE A.1. (contd)

MOGUNTIA

(NO $\angle \mathrm{O}_{3}$ or $\mathrm{S}$ version)

$\mathrm{NO} / \mathrm{O}_{3}$ and $\mathrm{CO} / \mathrm{CH}_{4}$ or $\mathrm{S}$ reactions with $\mathrm{OH}$ fields from $\mathrm{NO}_{x} / \mathrm{O}_{3}$ version

Aqueous phase

Aqueous size

Subgrid

Aerosols

DYNAMICS

Boundary layer/turbulence Stratosphere

is

CLOUD PROCESSES
Microphysics
Scavenging
Subgrid
Activation
Convective clouds

\section{SURFACE EXCHANGE}

\section{ACTINIC FLUX}

Radiative transfer

Subgrid

NUMERICS

Transport

Chemistry

Grid

SENSITIVITY/UNCERTAINTY none or sulfur reactions

none or bulk

instant dispersion

bulk/spec. int. mxd.

K-theory, 1st order $K_{z}$ dynamic strat./tropo. exchange with chemistry (domain extends into lower strat.)

\section{bulk}

scavenging coefficients

fractional area

none

decoupled/Feichter and Crutzen

(1990)

constant, species dependent

look-up table

uniform

1-D finite difference method

no published information

uniform

none
Los Alamos National Laboratory

monthly averaged $\mathrm{OH}$ and $\mathrm{O}\left({ }^{1} \mathrm{D}\right)$

from a photochemical box

model with prescribed $\mathrm{NO}_{x}, \mathrm{O}_{3}$, $\mathrm{CO}, \mathrm{HNO}_{3}$, and $\left(\mathrm{H}_{2} \mathrm{O}\right)_{\mathrm{v}}$

none

none

instant dispersion

none

K-theory, lst order $K_{z z}$ from GCM model includes strat.

none

none

none

none

none

none

look-up table

uniform

1-D finite element for horizontal, 1-D finite difference for vertical

nonstiff

uniform

none 
IABLE A.1. (contd)

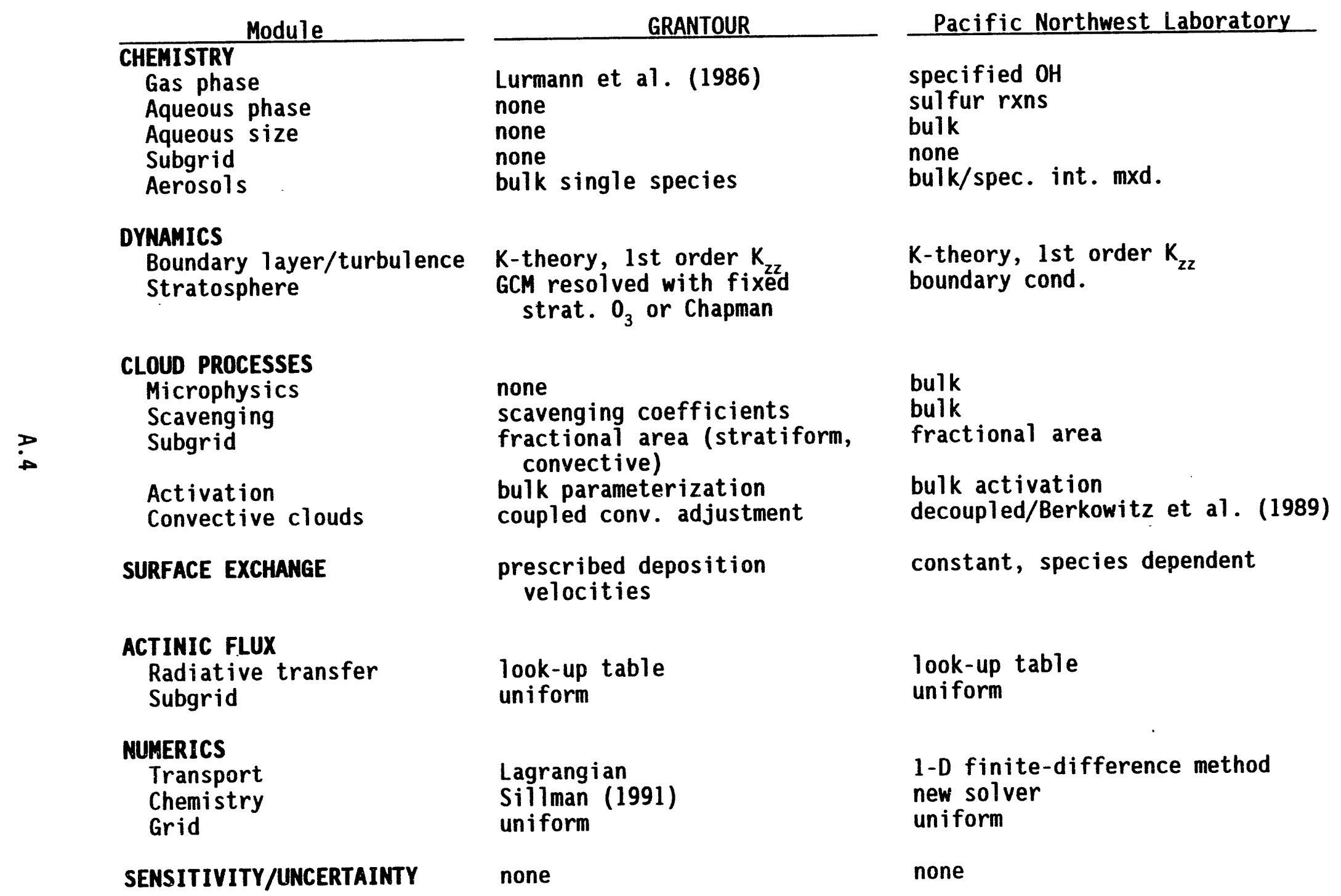


1991, 1993). The most recently published version of the GFDL CTM (Kasibhatla et al. 1993) used a horizontal resolution of $265 \mathrm{~km}$ and 11 vertical levels from the surface to $10 \mathrm{mb}$. Wind and precipitation fields, time-averaged over 6-h intervals, were obtained from the GFDL general circulation model (Manabe et al. 1974; Manabe and Holloway 1975) over a 12 -month period. The GFDL CTM transports three species ( $\mathrm{NO}_{x}, \mathrm{HNO}_{3}$, and peroxyacetyl nitrate) and uses production and loss rates for these species calculated off-line but carried in the model as temporally varying, two-dimensional fields. A parameterized wet removal process is used to simulate the precipitation scavenging of $\mathrm{HNO}_{3}$, whereby the amount of $\mathrm{HNO}_{3}$ removed from a particular grid box is a function of the local precipitation rate and is proportional to the local $\mathrm{HNO}_{3}$ mixing ratio. The parameterization differentiates between shallow and deep convective events. Model inputs to the off-line chemical module include hemispherically averaged one-dimensional profiles of $\mathrm{CO}$ and $\mathrm{NO}_{x}$ and twodimensional profiles of $\mathrm{CH}_{4}, \mathrm{O}_{3}$, water vapor, temperature, and total column $\mathrm{O}_{3}$.

\section{A.2 HARVARD UNIVERSITY}

Harvard University's global-scale CTM has been used to simulate the distributions of several trace atmospheric species, including chlorofluorocarbons (Prather et al. 1987), ${ }^{85} \mathrm{Kr}$ (Jacob et a1. 1987), $\mathrm{CH}_{3} \mathrm{CCl}_{3}$ (Spivakovsky et a1. 1990a, 1990b), ${ }^{222} \mathrm{Rn}$ (Jacob and Prather 1990; Balkanski and Jacob 1990; Balkanski et al. 1992), and ${ }^{210} \mathrm{~Pb}$ (Balkanski et al. 1993). In subhemispheric versions, the model has been used to simulate the production and export of $\mathrm{O}_{3}$ from North America (Jacob et a1. 1993a, 1993b). The most recently published version of the model (Jacob et al. 1993a) solves mass conservation equations for six species (odd oxygen, $\mathrm{NO}_{\mathrm{x}}$, peroxyacetyl nitrate, $\mathrm{CO}$, a short-lived hydrocarbon, and a long-lived hydrocarbon) on a domain with 4-degree latitude $x$ 5-degree longitude horizontal resolution and 9 vertical layers from the surface to $10 \mathrm{hPa}$. Meteorological data used to drive the CTM are derived from archives of the Goddard Institute for Space Studies general circulation model (Hansen et al. 1983) with $4-h$ averages of wind fields, mixing depths, and convective mass fluxes and 5-day averages of temperature, humidity, and cloud reflectivities. The chemical mechanism of Lurmann et al.

\section{A. 5}


(1986) is parameterized into a set of polynomials that describe the chemical environment in terms of the six computed species (Spivakovsky et al. 1990a). The transport numerics of the model are as described by Prather (1986) and tested by Jacob et al. (1989). Subgrid-scale plumes are treated via the nested plume method of Sillman et al. (1990).

\section{A.3 MOGUNTIA}

The MOGUNTIA model (Zimmerman 1988; Zimmerman et a1. 1989) was developed at the Max Planck Institute for Chemistry in Mainz, Germany, and has been used to study global $\mathrm{CFCl}_{3}$ and $\mathrm{CH}_{3} \mathrm{CCl}_{3}$ distributions (Zimmerman 1988 ), ${ }^{85} \mathrm{Kr}$ distributions (Zimmerman et a1. 1989), ${ }^{222} \mathrm{Rn}$ distributions and vertical transport (Feichter and Crutzen 1990), changes in global oxidative capacity (Crutzen and Zimmerman 1991), and heterogeneous atmospheric processes (Dentener and Crutzen 1993). Another implementation of the MOGUNTIA model has been designed for the study of the global sulfur cycle (Langner and Rodhe 1991). Horizontal resolution of the model is 10 degrees latitude $\times 10$ degrees longitude, while the vertical domain extends from the surface to $100 \mathrm{hPa}$ with 10 vertical layers. Large-scale transport, is described by monthly averaged winds (Oort 1983), while convective cloud transport is parameterized according to feichter and crutzen (1990). The chemical transformations included in MOGUNTIA account for $\mathrm{CH}_{4} / \mathrm{CO} / \mathrm{NO}_{\mathrm{x}} / \mathrm{HO}$, photochemistry in remote areas, as described in Crutzen and Zimmerman (1991). The sulfur version of the model uses monthly averaged $\mathrm{OH}$ fields from the $\mathrm{NO}_{x} / \mathrm{O}_{3}$ version to describe the gas-phase oxidation of $\mathrm{SO}_{2}$ and dimethylsulfide. Aqueous-phase sulfur oxidation is treated in a highly parameterized manner, based on average cloud lifetimes (Langner and Rodhe 1991).

\section{A.4 LOS ALAMOS NATIONAL LABORATORY}

Los Alamos National Laboratory's chemical tracer model (Tie et al. 1991) has been used for multiyear simulations of long-lived species, including $\mathrm{CH}_{4}$ (Tie et al. 1991), CFC-11 (Kao et al. 1992), and $\mathrm{CH}_{3} \mathrm{CCl}_{3}$ (Tie et al. 1992). The model accounts for emissions, advective and diffusive transport, and limited gas-phase chemistry. Meteorological data to drive the CTM simulations 
are derived from the Los Alamos general circulation model (Kao et al. 1990). Oxidant concentrations for the three-dimensional model are precalculated using an off-line two-dimensional (latitude-altitude) model that employs prescribed latitude-altitude distributions of $\mathrm{NO}_{x}, \mathrm{O}_{3}, \mathrm{CO}, \mathrm{HNO}_{3}$, and water vapor. The horizontal resolution of the model is 4.5 degrees latitude $\times 7.5$ degrees longitude, while the vertical domain extends from the surface to approximately $9 \mathrm{hPa}$ and employs 20 levels.

\section{A.5 GRANTOUR}

The GRANTOUR model was developed at the Lawrence Livermore National Laboratory (Penner et al. 1993). The distinctive feature of GRANTOUR is its use of Lagrangian air parcels to account for advection of constituents, which minimizes spurious dispersion and permits advection of a large number of species at once. The air parcels are assumed to be constant mass, which implies poor representation of vertical structure in the stratosphere. At least three versions of GRANTOUR have been developed. One focuses on $0_{3}$ and nitrogen chemistry, using the Lurmann et al. (1986) mechanism (Penner et al. 1991a). A second version simulates the sulfur cycle, using prescribed $\mathrm{OH}$ concentrations and parameterized scavenging (Erickson et a1. 1991). Aqueousphase chemistry is neglected. Sulfate mass concentration is related to aerosol number density by assuming a constant dry size, and direct scattering of sunlight is calculated using the Kohler solution of size dependence on relative humidity. A third version treats the emission, transport, and removal of biomass smoke and soot particles (Penner et al. 1991b, 1992). GRANTOUR is usually driven by winds, temperature, humidity, convective mass flux, and precipitation simulated by the Lawrence Livermore version of the National Center for Atmospheric Research's Community $\mathrm{Cl}$ imate Model.

\section{A.6 GLOBAL CHEMISTRY MODEL}

The Global Chemistry Model (GChM) was developed at Pacific Northwest Laboratory to study the global-scale reaction, redistribution, and wet removal of soluble sulfur species (Luecken et al. 1991). Recently, another version of the GChM has been developed to study the global distribution of CO (Easter

\section{A.7}


et al. 1993). The model is designed to utilize meteorological information from either observational sources or general circulation models and to account for the vertical redistribution of pollutants resulting from convective cloud transport via a parameterization as described in Luecken et a1. (1991). The sulfur version of the GChM (Luecken et al. 1991) accounts for the gas- and aqueous-phase oxidation of $\mathrm{SO}_{2}$ and dimethylsulfide through parameterized oxidation rates. Both stratiform and convective clouds are included in the model. Each provides vertical profiles of cloud water, which in turn, allows for an explicit treatment of aqueous-phase sulfur chemistry. The $\mathrm{CO} / \mathrm{CH}_{4}$ version of the GChM (Easter et al. 1993) calculates the transformation rates of $\mathrm{CO}$ and $\mathrm{CH}_{4}$, based on the gas-phase mechanism of Lelieveld and Crutzen (1991). By prescribing global distributions of $\mathrm{NO}_{x}$ and $\mathrm{O}_{3}$, and assuming a pseudo-steady state for all species in the mechanism except $\mathrm{CO}$ and $\mathrm{CH}_{4}$, the computational burden of the chemical calculations is reduced. This version of the GChM has been used to analyze midtropospheric CO data from the National Aeronautics and Space Administration's Measurement of Air Pollution by Satellites Program (Easter et a1. 1993).

\section{A.7 TWO-DIMENSIONAL GLOBAL MODELS}

Several two-dimensional global atmospheric chemistry models have been developed over the past 15 years (Isaksen and Rodhe 1978; Derwent 1982; Crutzen and Gidel 1983; Hough 1989, 1991; Law and Pyle 1993a, 1993b). Although two-dimensional models are very useful tools for general analysis of many atmospheric processes and species (Isaksen and Rodhe 1978; Rodhe and Isaksen 1980; Derwent 1982; Crutzen and Gide1 1983; Isaksen and Hov 1987; Hough 1989, 1991; Kanakidou et a1. 1991; Law and Pyle 1993a, 1993b), their usefulness is limited for the complex assessment and policy formulation activities that will be necessary over the next several decades. The social and economic changes that are likely to happen in the next century will be spatially nonuniform. As industrial development in South America, Africa, and Asia continues to accelerate, the atmospheric impacts of their growth will not be adequately modeled by zonally averaged two-dimensional models. As radiatively important trace species emissions from these areas will be 
distributed nonuniformly in both space and time and as shorter-lifetime species become more important in the global radiative balance, threedimensional atmospheric chemistry models become the most appropriate tool for detailed policy assessment and analysis.

\section{A.8 OTHER EFFORTS}

As mentioned before, global tropospheric chemistry modeling is currently a very active area of research. Many groups are presently developing capabilities for three-dimensional simulation of global tropospheric chemical processes. The above brief discussions focus on entities that have published studies involving their models in refereed journals. At a recent workshop on global tropospheric chemistry modeling (NASA 1993), sejveral groups having some level of development currently in progress in this area were represented. These groups included the National Center for Atmospheric Research, Cambridge University, Massachusetts Institute of Technology, Atmospheric and Environmental Research, Inc., Goddard Institute for Space Studies, and Lawrence Livermore National Laboratory. Some of these efforts are being built on twodimensional atmospheric chemistry models (National Center for Atmospheric Research, Lawrence Livermore National Laboratory, Atmospheric and Environmental Research, Inc.), while others are being derived from tracer implementations of general circulation models (National Center for Atmospheric Research, Goddard Institute for Space Studies). Still others are being derived from stratospheric chemistry models, extending their domain down into the troposphere (National Center for Atmospheric Research). Because all of these efforts are in relatively early developmental stages, little or no published information is available on their structure or applicability. It is indeed conceivable that some of these efforts will be abandoned in the near future as competition in this research area increases. It is also conceivable that one of these efforts or one of the more established models may form a suitable basis for the global tropospheric chemistry modeling system as described in this report. 


\section{A.9 REFERENCES}

Balkanski, Y. J., and D. J. Jacob. 1990. "Transport of Continental Air to the Subantarctic Indian Ocean." Iellus 42B:62-75.

Balkanski, Y. J., D. J. Jacob, R. Arimoto, and M. A. Kritz. 1992. "Long Range Transport of Radon-222 Over the North Pacific Ocean: Implications for Continenta1 Influence." J.Atmos. Chem. 14:353-374.

Balkanski, Y. J., D. J. Jacob, G. M. Gardner, W. C. Graustein, and K. K. Turekian. 1993. "Transport and Residence Times of Tropospheric Aerosols Inferred from a Global Three-Dimensional Simulation of ${ }^{210} \mathrm{~Pb}$." $\mathrm{J}$. Geophys. Res. 98:20573-20586.

Berkowitz, C. M., R. C. Easter, and B. C. Scott. 1989. "Theory and Results from a Quasi-Steady-State Precipitation Scavenging Model." Atmos. Environ. $23: 1555-1571$.

Crutzen, P. J., and L. T. Gidel. 1983. "A Two-Dimensional Photochemical Model of the Atmosphere. 2. The Tropospheric Budgets of the Anthropogenic Chlorocarbons, $\mathrm{CO}, \mathrm{CH}_{4}, \mathrm{CH}_{3} \mathrm{Cl}$ and the Effect of Various $\mathrm{NO}_{x}$ Sources on Tropospheric Ozone." J. Geophys. Res. 88:6641-6661.

Crutzen, P. J., and P. H. Zimmerman. 1991. "The Changing Photochemistry of the Troposphere." Tellus 43AB:136-151.

Dentener, F. J., and P. J. Crutzen. 1993. "Reaction of $\mathrm{N}_{2} \mathrm{O}_{5}$ on Tropospheric Aerosols: Impact on the Global Distributions of $\mathrm{NO}_{x}, \mathrm{O}_{3}$, and $\mathrm{OH}$." J. Geophys. Res. 98:7149-7163.

Derwent, R. G. 1982. "Two-Dimensional Model Studies of the Impact of Aircraft Exhaust Emissions on Tropospheric 0zone." Atmos. Environ. $16: 1997-2007$.

Easter, R. C., R. D. Saylor, and E. G. Chapman. 1993. "Analys is of MidTropospheric Carbon Monoxide Data Using a Three-Dimensional Global Atmospheric Chemistry Numerical Mode1." In Proceedings of the 20th International

Technical Meeting on Air Pollution Modeling and Its Application, November 29 to December 3, 1993, Valencia, Spain.

Erickson, D. J., J. J. Walton, S. J. Ghan, and J. E. Penner. 1991. "Three-Dimensional Modeling of the Global Atmospheric Sulfur Cycle: A First Step." Atmos. Environ. 25A:2513-2520.

Feichter J., and P. J. Crutzen. 1990. "Parameterization of Vertical Tracer Transport Due to Deep Cumulus Convection in a Global Transport Model and Its Evaluation with ${ }^{222}$ Radon Measurements." Tellus 42B:100-117.

Hansen J., G. Russe11, D. Rind, P. Stone, A. Lacis, S. Lebedeff, R. Ruedy, and L. Travis. 1983. "Efficient Three-Dimensional Global Models for Climate Studies: Models I and II." Mon. Weather Rev. 111:609-662. 
Hough, A. M. 1989. "Development of a Two-Dimensional Global Tropospheric Model: 1. The Model Transport." Atmos. Environ. 23:1235-1261.

Hough, A. M. 1991. "Development of a Two-Dimensional Global Tropospheric Model, Model Chemistry." J. Geophys. Res. 96:7325-7362.

Isaksen, I.S.A., and 0. Hov. 1987. "Calculation of Trends in the Tropospheric ioncentration of $\mathrm{O}_{3}, \mathrm{OH}, \mathrm{CO}, \mathrm{CH}_{4}$ and $\mathrm{NO}_{x} . "$ Tellus 398:271-285.

Isaksen, I.S.A., and H. Rodhe. 1978. A Two-Dimensional Model for the Global Distribution of Gases and Aerosol Particles in the Troposphere. Report $A C-47$, Department of Meteorology, Stockholm, Sweden.

Jacob, D. J., and M. J. Prather. 1990. "Radon-222 as a Test of Convective Transport in a General Circulation Model." Tellus 42B:118-134.

Jacob, D. J., M. J. Prather, S. C. Wofsy, and M. B. McElroy. 1987.

"Atmospheric Distribution of ${ }^{85} \mathrm{Kr}$ Simulated with a General Circulation Mode1." J. Geophys. Res. 92:6614-6626.

Jacob, D. J., S. Sillman, J. A. Logan, and S. C. Wofsy. 1989. "Least Independent Variables Method for Simulation of Tropospheric Ozone." J. Geophys. Res. 94:8497-8510.

Jacob, D. J., J. A. Logan, R. M. Yevich, G. M. Gardner, C. M. Spivakovsky, S. C. Wofsy, J. W. Munger, S. Sil1man, M. J. Prather, M. O. Rodgers, H. Westberg, and P. R. Zimmerman. 1993a. "Simulation of Summertime Ozone Over North America." J. Geophys. Res. 98:14797-14816.

Jacob, D. J., J. A. Logan, G. M. Gardner, R. M. Yevich, C. M. Spivakovsky, S. C. Wofsy, S. Sillman, and M. J. Prather. 1993b. "Factors Regulating Ozone Over the United States and Its Export to the Global Atmosphere." J. Geophys. Res. 98:14817-14826.

Kanakidou, M., H. B. Singh, K. M. Valentin, and P. J. Crutzen. 1991. "A Two-Dimensional Study of Ethane and Propane Oxidation in the Troposphere." J. Geophys. Res. 96:15395-15413.

Kao, C.-Y., G. A. Glatzmaier, R. C. Malone, and R. P. Turco. 1990. "Global Three-Dimensional Simulations of Ozone Depletion Under Postwar Conditions." J. Geophys. Res. 95:22495-22512.

Kao, C.-Y., X. Tie, E. Mroz, D. Cunnold, and F. Alyea. 1992. "Simulation of the Global CFC 11 Using the Los Alamos Chemical Tracer Model." J. Geophys. Res. 97:15827-15838.

Kasibhatla, P. S., H. Levy, II, W. J. Moxim, and W. L. Chameides. 1991. "The Relative Impact of Stratospheric Photochemical Production on Tropospheric NO Levels: A Model Study." J. Geophys. Res. 96:18631-18646. 
Kasibhatla, P. S., H. Levy, II, and W. J. Moxim. 1993. "Global $\mathrm{NO}_{x} \mathrm{HNO}_{3}$, PAN, and NO Distributions from Fossil Fuel Combustion Emissions: A Model Study." J. Geophys. Res. 98:7165-7180.

Langner, J., and H. Rodhe. 1991. "A Global Three-Dimensional Model of the Tropospheric Sulfur Cycle." J.Atmos. Chem. 13:225-263.

Law, K. S., and J. A. Pyle. 1993a. "Modeling Trace Gas Budgets in the Troposphere. 1. Ozone and Odd Mitrogen." J. Geophys. Pes. 98:18377-18400.

Law, K. S., and J. A. Pyle. 1993b. "Modeling Trace Gas Budgets in the Troposphere. 2. $\mathrm{CH}_{4}$ and CO." J. Geophys. Res. 98:18401-1841ź.

Lelieveld, J., and P. J. Crutzen. 1991. "The Role of Clouds in Tropospheric Chemistry." J. Atmos. Chem. 12:229-?67.

Levy, H., II, and W. J. Moxim. 1987. "Fate of US and Canadian Combustion Nitrogen Emissions." Nature 328:414-416.

Levy, H., II, and W. J. Moxim. 1989a. "Influence of Long-Range Transport of Combustion Emissions on the Chemical Variability of the Background Atmosphere." Nature 338:326-328.

Levy, H., II, and W. J. Moxim. 1989b. "Simulated Global Distribution and Deposition of Reactive Nitrogen Emitted by Fossil Fuel Combustion." Tellus 41B:256-271.

Levy, H., II, J. D. Mahlman, and W. J. Moxim. 1982. "Tropospheric $\mathrm{N}_{2} \mathrm{O}$ Variability." J. Geophys. Res. 87:3061-3080.

Levy, H., II, J. D. Mahlman, W. J. Moxim, and S. C. Liu. 1985. "Tropospheric Ozone: The Role of Transport." J. Geophys. Res. 90:3753-3772.

Luecken, D. J., C. M. Berkowitz, and R. C. Easter. 1991. "Use of a ThreeDimensional Cloud-Chemistry Model to Study the Transatlantic Transport of Soluble Sulfur Species." J. Geophys. Res. 96:22477-22490.

Lurmann, F. W., A. C. Lloyd, and R. Atkinson. 1986. "A Chemical Mechanism for Use in Long-Range Transport/Acid Deposition Computer Modeling." J. Geophys. Res. 91:10905-10936.

Mahlman, J. D., H. Levy, II, and W. J. Moxim. 1980. "Three-Dimensional Tracer Structure and Behavior as Simulated in Two Ozone Precursor Experiments." J. Atmos. Sci. 37:655-685.

Mahlman, J. D., H. Levy, II, and W. J. Moxim. 1986. "Three-Dimensional Simulations of Stratospheric $\mathrm{N}_{2} \mathrm{O}$ : Predictions for Other Trace Constituents." J. Geophys. Res. 91:2687-2707. 
Manabe, S., and J. L. Holloway, Jr. 1975. "The Seasonal Variation of the Hydrologic Cycle as Simulated by a Global Model of the Atmosphere." J. Geophys. Res. 80:1617-1649.

Manabe, S., D. G. Hahn, and J. L. Holloway, Jr. 1974. "The Seasonal Variation of the Tropical Circulation as Simulated by a Global Model of the Atmosphere." J.Atmos. Sci. 31:43-83.

Moxim, W. J. 1990. "Simulated Transport of NO to Hawaii During August: A Synoptic Study." J. Geophys. Res. 95:5717-5729.

National Aeronautics and Space Administration (NASA). 1993. Global Tropospheric Chemistry Model ing Workshop, Alexandria, Virginia, April 27-29.

Oort, A. H. 1983. Global Atmospheric Circulation Statistics, 1958-1973.

NOAA Prof. Pap. 14, National Oceanic and Atmospheric Administration, Rockville, Maryland.

Penner, J. E., C. S. Atherton, J. Dignon, S. J. Ghan, J. J. Walton, and S. Hameed. 1991a. "Tropospheric Nitrogen: A Three-Dimensional Study of Sources, Distributions, and Deposition." J. Geophys. Res, 96:959-990.

Penner, J. E., S. J. Ghan, and J. J. Walton. 1991b. "The Role of Biomass Burning in the Budget and Cycle of Carbonaceous Soot Aerosols and Their Climate Impact." In Global Biomass Burning, ed. J. Levine, pp. 387-393. MIT Press, Cambridge, Masschusetts.

Penner, J. E., R. Dickinson, and C. O'Neill. 1992. "Effects of Aerosol from Biomass Burning on the Global Radiation Budget." Science 256:1432-1434.

Penner, J. E., C. S. Atherton, and T. E. Gradel. 1993. "Global Emissions and Models of Photochemically Active Compounds." In 37th OHOLO Conference Series, ed. A. Slinn. Plenum Publishing Corp., New York.

Prather, M. J. 1986. "Numerical Advection by Conservation of Second-Order Moments." J. Geophys. Res. 91:6671-6681.

Prather, M., M. McElroy, S. Wofsy, G. Russe11, and D. Rind. 1987. "Chemistry of the Global Troposphere: Fluorocarbons as Tracers of Air Motion." J. Geophys. Res. 92:6579-6613.

Rodhe, H., and I.S.A. Isaksen. 1980. "Global Distribution of Sulphur Compounds in the Troposphere Estimated in a Height/Latitude Transport Model." J. Geophys. Res. 85:7401-7409.

Sillman, S. 1991. "A Numerical Solution for the Equations of Tropospheric Chemistry Based on an Analysis of Sources and Sinks of Odd Hydrogen" Geophys. Res. 96:20735-20744. 
Sillman, S., J. A. Logan, and S. C. Wofsy. 1990. "A Regional Scale Model for Ozone in the United States with Subgrid Representation of Urban and Power Plant Plumes." J. Geophys. Res. 95:5731-5748.

Spivakovsky, C. M., S. C. Wofsy, and M. J. Prather. 1990a. "A Numerical Method for Parameterization of Atmospheric Chemistry: Computation of Tropospheric OH." J. Geophys. Res. 95:18433-18439.

Spivakovsky, C. M., R. Yevich, J. A. Logan, S. C. Wofsy, M. B. McElroy, and M. J. Prather. 1990b. "Tropospheric OH in a Three-Dimensional Chemical Tracer Model: An Assessment Based on Observations of $\mathrm{CH}_{3} \mathrm{CCl}_{3}$." $\mathrm{J}$. Geophys. Res. 95:18441-18471.

Tie, X., F. N. Alyea, D. M. Cunnold, and C.-Y. Kao. 1991. "Atmospheric Methane: A Global Three-Dimensional Model Study." J. Geophys. Res. 96:1733917348.

Tie, X., C.-Y. Kao, E. J. Mroz, R. J. Cicerone, F. N. Alyea, and D. M. Cunnold. 1992. "Three-Dimensional Simulations of Atmospheric Methyl Chloroform: Effect of an Ocean Sink." J. Geophys. Res. 97:20751-20769.

Zimmerman, P. H. 1988. "MOGUNTIA: A Handy Global Tracer Mode1." In Air Pollution Modeling and Its Applications. ed. H. van Dop, Plenum Press, New York, pp. 593-608.

Zimmerman, P. H., J. Feichter, H. K. Rath, P, J. Crutzen, and W. Weiss 1989. "A Global Three-Dimensional Source-Receptor Model Investigation Using ${ }^{85} \mathrm{Kr} . "$ Atmos. Environ. 23:25-35. 


\section{APPENDIX B}

DESIGN OPTIONS FOR A GLOBAL TROPOSPHERIC CHEMISTRY MODEL 


\section{APPENDIX B}

\section{DESIGN OPTIONS FOR A GLOBAL TROPOSPHERIC CHEMISTRY MODEL}

\section{B.1 MODULE OPTIONS: A DESIGN MENU}

The design menu (Table B.1) of module options was formulated to facilitate the construction of a design vision for a global tropospheric chemistry model. As far as possible, each module that would exist within the model is represented by an underlined heading. Under each of these modules an attempt was made to 1 ist all possible options that a model designer might have in constructing that module. Each of these modules was then grouped into the broader categories of 1) chemistry, 2) dynamics, 3) cloud processes, 4) surface exchange, 5) actinic flux, 6) numerics, and 7) sensitivity/uncertainty. To ciesign a version of the model, one chooses appropriate options from each module, keeping in mind that some combinations of options would not be good overall designs. For example, choosing a size-resolved/species-resolved treatment of aerosols would not be appropriate with only a bulk treatment of cloud microphysics and aerosol activation. Thus, the design menu serves as an organizing tool for an experienced model designer and would not be useful for persons with limited atmospheric chemistry modeling experience. The following is an expanded description of the possible choices for each module in the design menu.

\section{B.1.1 Chemistry}

\section{B.1.1.1 Gas Phase}

In this module, a wide variety of possible combinations of included chemical reactions and approaches exists. Each of the individual options is described below:

- $\mathrm{NO}_{\mathrm{x}} / \mathrm{O}_{3}$--basic $\mathrm{NO}_{\mathrm{x}} / \mathrm{O}_{3}$ photochemistry, including nighttime $\mathrm{NO}_{\mathrm{x}}$ conversion

- $\mathrm{CH}_{4} / \mathrm{CO}$--chemistry for the tropospheric oxidation of $\mathrm{CH}_{4}$ to $\mathrm{CO}$ 
TABLE B.1. Module Options for a Global Tropospheric Chemistry Model

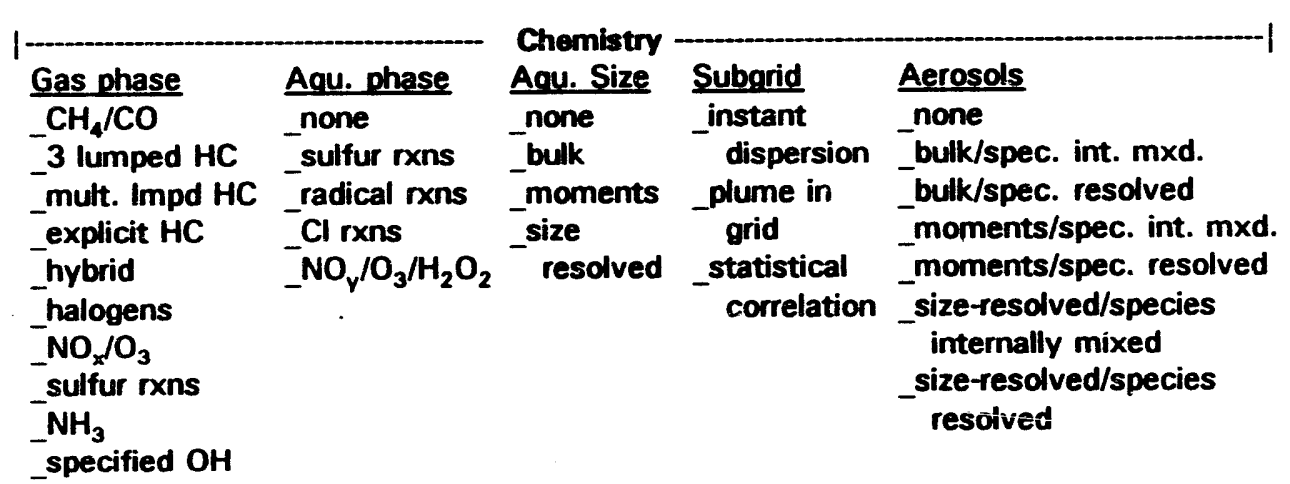

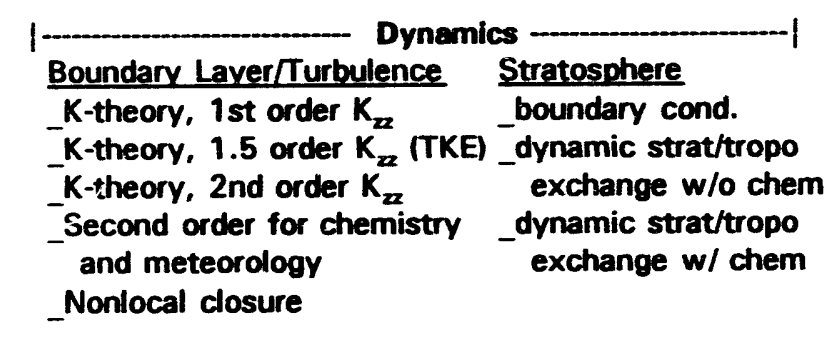

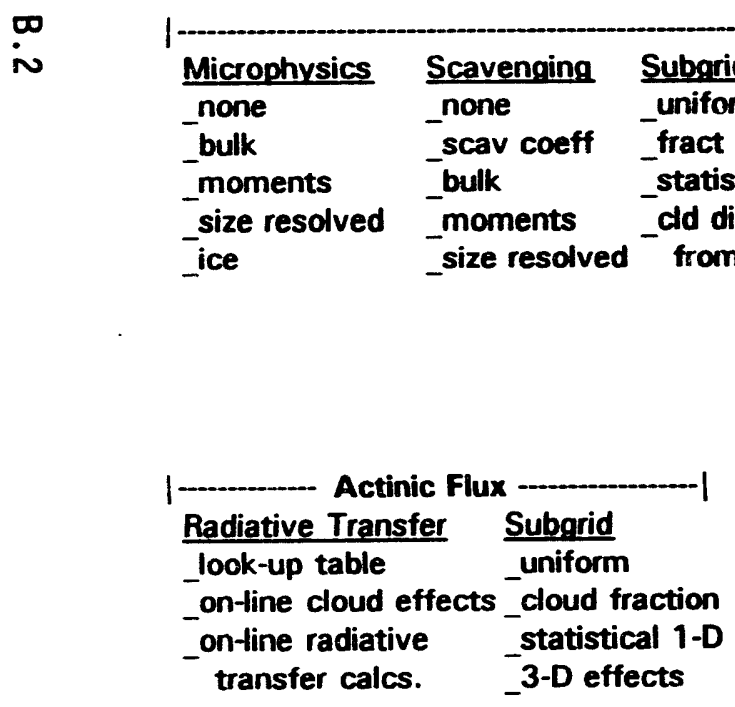

\begin{tabular}{ll}
$\begin{array}{l}\text { Cloud Processes - } \\
\text { Activation }\end{array}$ & Convective Clouds \\
\hline none & none \\
-bulk activation & -decoupled/Walcek\&Taylor \\
-moments activation & -decoupled/Berkowitz et al. \\
\hline size-resolved & _coupled/convective adj. \\
activation & -coupled/Kuo scheme \\
& _coupled/Arakawa-Schubert \\
& _coupled/3rd generation"
\end{tabular}
|-...-- Surface Exchange -
constant, species dependent
_resistance methodology
_surface exchange model

coupled/Kuo scheme

coupled/"3rd generation"

\begin{tabular}{|c|c|c|}
\hline $\begin{array}{l}\text { Transport } \\
\text { lagrangian } \\
\text { (GRANTOUR) } \\
\text { 1-D FDM } \\
\text {-1-D FEM } \\
\text {-2-D FEM } \\
\text {-moments } \\
\text { (Prather) }\end{array}$ & $\begin{array}{l}\text { Chemistry } \\
\text {-Sillman } \\
\text { - OSSA } \\
\text { - hybrid } \\
\text {-Gear } \\
\text {-new sol } \\
\text {-non-stiff } \\
\text { - } \\
\text { solver }\end{array}$ & $\begin{array}{l}\text { Grid } \\
\text { _uniform } \\
\text { _irregular } \\
\text { _adaptive }\end{array}$ \\
\hline
\end{tabular}
|- Sensitivity/Uncertainty --1
none
Monte Carlo
direct decoupled
adjoint
stochastic variables
_automatic differentiation


- 3 lumped HC--chemical reactions for two lumped surrogate anthropogenic species and one biogenic species

- mult. Impd HC--chemical reactions for lumped hydrocarbon (HC) species for the major classes (e.g., alkanes, alkenes, aldehydes, aromatics, etc.)

- explicit $H C$--chemical reactions for all important HC species included and represented explicitly

- sulfur rxns--chemical reactions for the oxidation of $\mathrm{SO}_{2}$ and dimethylsulfide

- halogens--chemical reactions of $\mathrm{Cl}$ and $\mathrm{Br}$ species in the troposphere

- $\mathrm{NH}_{3}$--chemical reactions of $\mathrm{NH}_{3}$

- hybrid--a technique whereby simple background chemistry is used in remote areas, while a more detailed mechanism that includes $H C$ is employed in polluted areas

- specified $\mathrm{OH}$--techniques whereby hydroxyl radical concentrations are specified through an empirical parameterization or by the specification of precursor species.

\section{B.1.1.2 Aqueous Phase}

As in the gas-phase module, several possible combinations of aqueousphase chemical treatments are possible. The individual options are described below:

- none--no aqueous-phase reactions are included

- $\mathrm{NO}_{y} / \mathrm{O}_{3} / \mathrm{H}_{2} \mathrm{O}_{2}$--basic $\mathrm{NO}_{y} / \mathrm{O}_{3} / \mathrm{H}_{2} \mathrm{O}_{2}$ dissolution and equilibria

- radical rxns--aqueous-phase radical dissolution, equilibria, and reactions (e.g., aqueous-phase mechanism of Lelieveld and Crutzen 1991)

- sulfur rxns--aqueous-phase oxidation reactions of S(IV) species to $S(V I)$ species

- Cl rxns--aqueous-phase $C l$ dissolution, equilibria, and reactions.

\section{B.1.1.3 Aqueous-Phase Size Dependence}

Recent research has indicated that different-size aqueous droplets may have significantly different species concentrations and rates of reaction. 
This module accounts for the possibility of various treatments of aqueousphase size dependence. Either a bulk, moments, or size-resolved treatment may be chosen in this category. The bulk treatment assumes one size droplet for each aqueous phase, while the size-resolved treatment employs several discrete size bins for each aqueous phase. A moments treatment would require the specification of a distribution of droplet sizes for each aqueous phase with associated chemical differences.

\section{B.1.1.4 Subgrid}

This category refers to the treatment of species emissions as they are introduced into the model grid. Either instantaneous dispersion, plume-ingrid, or statistical correlation treatments may be chosen in this category. In most current regional-scale models, emissions within a grid cell are lumped, emitted, and instantaneously mixed throughout the local grid cell volume. Of course, in the real situation, plumes often can retain a coherent identity over scales that span a typical horizontal grid cell spacing. Significant differences can then occur in the representation of chemical transformations that occur within those plumes as compared to the reduced reaction rates that occur as a result of instantaneous dispersion. Some modelers have, therefore, devised schemes that explicitly calculate plume concentrations from major sources located in the subgrid domain and translate them to concentrations that occur at the model's grid nodes. Another possible technique to account for subgrid chemical behavior is the statistical correlation method, whereby each species is represented by a subgrid statistical distribution. Using the species distributions, cross correlations can be calculated and incorporated into subgrid chemical calculations.

\section{B.1.1.5 Aerosols}

Treatment of aerosols involves both their physical size distribution and their chemical composition. There are three options for the physical size. The bulk treatment only predicts the aerosol volume, and no size information is provided. (Actually, the mass of different chemical components in the aerosol would be predicted, such as sulfate, elemental carbon, organics, etc.) The size-resolved treatment predicts the size distribution by dividing the aerosol population into a set of size bins, but is computationally expensive. 
The moments method assumes that each mode of the aerosol population (nuclei, accumulation, coarse) can be represented by a log-normal size distribution. The log-normal distribution is determined by three parameters that the model predicts. The moments method is computationally less expensive than the sizeresolved method but also less rigorous.

\section{B.1.2 Dynamics}

\section{B.1.2.1 Boundary Layer and Turbulent Exchange}

The K-theory, or first-order closure approach for turbulent mixing, which is used in most atmospheric chemistry models, parameterizes the vertical turbulent flux of a species in terms of the vertical gradient of the species. This approach requires obtaining a vertical exchange coefficient from the moteorological driver model. The meteorological driver itself will have some turbulence parameterization (first-order closure; one- and one-half-order closure, which is called the turbulent kinetic energy approach; or secondorder closure). Note that the parameterization used in the meteorological driver influences the values but not the form of the vertical exchange coefficients. Another approach is to use second-order closure in both the chemistry and meteorological models. This requires simulation of both mean concentrations and turbulent fluctuations of concentrations and, to date, has not been used in any operational model. In both the first-and second-order closure approaches, material is transported from one layer to an adjacent layer and then mixes throughout that layer. The nonlocal closure approach recognizes that eddies responsible for turbulent transport may move across several vertical layers before they stop and dissipate. Mathematically, turbulent transfer can occur between every pair of layers in the mode1. The basis for determining the exchange rates is less well developed than $K$-theory.

\section{B.1.2.2 Stratospheric Exchange}

Mass exchange between the troposphere and stratosphere is a very important process for many species in tropospheric chemistry. A significant source of $\mathrm{O}_{3}$ and $\mathrm{NO}_{\mathrm{y}}$ in the troposphere is thought to be transported from the stratosphere. The upper boundary of the model could be placed either at the tropopause or within the lower stratosphere. A simple boundary condition can be

\section{B.5}


applied in either situation, or with the upper boundary within the stratosphere, dynamic exchange can take place across the tropopause, based on transport quantities provided by the driving general circulation model. With the upper boundary within the lower stratosphere, chemistry could be calculated explicitly or a chemical climatology could be specified.

\section{B.1.3 Cloud Processes}

The treatment of cloud processes, such as microphysics, aerosol activation and scavenging, and vertical transport, offers a variety of options. Microphysics can be neglected entirely for insoluble species. For most chemical species, cloud microphysics must be represented in some manner. For a comprehensive treatment of clouds, the size distributions of cloud variables and cloud processes would be explicitly resolved into a number of size bins. For many purposes, a bulk approach is acceptable, in which only the mass of cloud water and precipitation is allowed to vary. A more general approach considers variations in other moments of the cloud particle-size distribution; variations in droplet number concentration are of particular relevance to aerosol interactions. One may wish to distinguish the ice from the liquid phase for certain applications.

The treatments of aerosol activation and scavenging largely follow the representation of the cloud and aerosol variables. If the bulk approach is used for clouds and aerosols, it should be used for activation and scavenging. If the size distribution of cloud particles and aerosols is explicitly resolved, so could be the treatment of activation and scavenging. If cloud microphysics is not treated, scavenging could still be treated using the simulated or observed precipitation rates and prescribed scavenging coefficients.

Subgrid-scale variations in cloud processes can either be neglected entirely, expressed in terms of a parameterized, homogeneous, cloudy grid cell fraction, or treated using idealized probability distributions for the cloud variables, in which the parameters of the probability distributions are related to a few predicted moments of the probability distributions. A final

option applicable for a model that is driven by the meteorological fields from a general circulation model is to use the clouds' fields derived within that model. 
Vertical transport of soluble and insoluble species by convective clouds can be treated using the off-line schemes of Walcek and Taylor (1986) or Berkowitz et a1. (1989). Other optional schemes are derived from general circulation models; namely, the moist convective adjustment, the Kuo scheme, or the Arakawa and Schubert (1974) parameterization. Each of these schemes has shortcomings, so that one might consider developing a "third generation" convective parameterization. It should be recognized that, because each scheme is based on different equilibrium assumptions, the scheme selected for the model should be the same as that used in the host general circulation model; otherwise, highly inconsistent vertical transport is diagnosed.

\section{B.1.4 Surface Exchange}

Chemical exchange between the atmosphere and land or ocean surface will be an important aspect of the model. This exchange can be implemented through temporally constant, species-dependent surface fluxes, based on empirical information or through the resistance analogy methodology summarized by Wesely (1989). A more sophisticated surface-exchange model could also be developed, wherein dynamic fluxes of material may be exchanged in either direction, based on the currently prevailing chemical and meteorological conditions. The construction of the surface-exchange model could benefit greatly from research carried out in the agricultural and oceanographic communities.

\section{B.1.5 Actinic Flux}

Actinic flux depends on the solar zenith angle, the profile of trace chemical concentrations, the surface reflectivity, and the distribution of clouds. Actinic flux has in the past been evaluated using look-up tables for a predetermined combination of solar zenith angle, surface reflectivity, and chemical and cloud profiles. Given the large variability of clouds and the weak wavelength dependence of scattering by clouds, one option would be to retain the look-up approach for the clear-sky actinic flux for each absorption line, but apply an on-line modification factor associated with the influence of clouds on the actinic flux profile. A third option is to abandon look-up tables entirely; instead, calculating the full radiative transfer for each absorption band. Subgrid cloud effects could be neglected or treated using the simple homogeneous cloud fraction approach (with various cloud overlap 
assumptions) or a more general statistical description of the subgrid distribution of cloud optical properties.

\section{B.1.6 Numerics}

\section{B.1.6.1 Iransport}

Several numerical techniques are currently used in regional- and global-scale atmospheric chemistry models for the solution of the species transport equations. The possible choices listed in this category include 1) the Lagrangian parcel technique of Walton et al. (1988); 2) the secondorder moments method of Prather (1986); 3) time splitting of the threedimensional equation into several one-dimensional equations, which are then solved by finite-difference methods (e.g., Bott 1989); 4) time splitting with the one-dimensional equations solved by finite-element methods (e.g., Galerkin methods); or 5) time splitting of the three-dimensional equation into a twodimensional horizontal transport equation and a one-dimensional vertical equation, which are then solved by finite-element methods (this technique allows for the possibility of irregular or adaptive grid techniques).

\section{B.1.6.2 Chemistry}

The solution of the system of ordinary differential equations that describe the chemical transformations of modeled species is the most computationally intensive portion of atmospheric chemistry models. Consequently, the choice of the ordinary differential equation solver for these calculations is critically important. Several techniques are currently used, including the methodology of Sillman (1991), which is limited to tropospheric chemical simulation only; the quasi-steady-state approximation methodology of Hesstvedt et a1. (1978), which is used extensively by current regional-scale models; the hybrid predictor-corrector methodology of Odman et al. (1992), which is also used by several current regional-scale models; or the traditional Gear methodology. Also included as choices in this category are a new solver, which does not exist currently, but is wished for by all atmospheric chemistry modelers, and a simple nonstiff solver, which would be used only if $\mathrm{CH}_{4} / \mathrm{CO}$ chemistry and specified $\mathrm{OH}$ were chosen under the gas-phase module.

\section{B.8}




\section{B.1.6.3 Grid}

A uniform horizontal grid (possibly with a nonuniform vertical grid) has been the predominant type of grid structure used in the past for regional - and global-scale models. Only recently (Mathur et al. 1992) have irregular grid structures been employed in regional-scale models. The purpose of irregular grids is to specify a priori a grid structure that has greater resolution in areas where steep concentration gradients are expected or where subgrid chemical effects may be the largest (i.e., near major sources). For a global model, an irregular grid application would most likely result in a finer grid over continental areas and a much coarser grid over ocean areas. Adaptive grid techniques have been used for many years in advanced computational fluid dynamics calculations (e.g., shock wave propagation), but have not been used in atmospheric chemistry models to date. In the adaptive grid methodology, an irregular grid is used and modified dynamically during run time, based on changing concentration gradients or meteorological features. Adaptive grid techniques, though extremely powerful in the efficient computation of a highly accurate solution, are computationally expensive. of course, the grid structure that is ultimately chosen must be closely tied to the numerical technique chosen for solution of the transport equations. Although a uniform grid can be used with most numerical techniques, this is not true for irregular or adaptive grids. The most straightforward application of the irregular or adaptive grid techniques comes with the use of multidimensional finite-element techniques.

\section{B.1.7 Uncertainty/Sensitivity}

A full discussion of the various approaches to uncertainty and sensitivity analysis is given in the text of this report. There will be no one module within the model that handles uncertainty or sensitivity. Rather, the means for obtaining information on uncertainty or sensitivity must be built into individual modules or be determined by manipulating the model after it is completed. It is recommended that approaches to uncertainty and sensitivity estimation be built into the modules and model as the codes are being developed. 


\section{B.2 REFERENCES}

Arakawa, A., and W. H. Schubert. 1974. "Interaction of a Cumulus Cloud Ensemble with the Large-Scale Environment." J.Atmos. Sci. 31:674-701.

Berkowitz, C. M., R. C. Easter, and B. C. Scott. 1989. "Theory and Results from a Quasi-Steady-State Precipitation Scavenging Model." Atmos. Environ. $23: 1555-1571$.

Bott, A. 1989. "A Positive Definite Advection Scheme Obtained by Nonlinear Renormalization of the Advective Fluxes." Mon. Weather Rev. 117:1006-1015.

Hesstvedt, E., 0. Hov, and I.S.A. Isaksen. 1978. "Quasi-Steady-State Approximations in Air Pollution Modeling: Comparison of Two Numerical Schemes for Oxidant Prediction." Int. J. Chem. Kinetics X:971-994.

Lelieveld, J., and P. J. Crutzen. 1991. "The Role of Clouds in Tropospheric Photochemistry." J.Atmos. Chem. 12:229-267.

Mathur, R., L. K. Peters, and R. D. Saylor. 1992. "Sub-Grid Representation of Emission Source Clusters in Regional Air Quality Modeling." Atmos. Environ. 26A:3219-3238.

Odman, M. T., N. Kumar, and A. G. Russell. 1992. "A Comparison of Fast Chemical Kinetic Solvers for Air Quality Modeling." Atmos. Environ. 26A:1783-1789.

Prather, M. J. 1986. "Numerical Advection by Conservation of Second-Order Moments." J. Geophys. Res, 91:6671-6681.

Sillman, S. 1991. "A Numerical Solution for the Equations of Tropospheric Chemistry Based on an Analysis of Sources and Sinks of Odd Hydrogen." J. Geophys. Res, 96:20735-20744.

Walcek, C. J., and G. R. Taylor. 1986. "A Theoretical Method for Computing Vertical Distributions of Acidity and Sulfate Production Within Cumulus Clouds." J.Atmos. Sci. 43:339-355.

Walton, J. J., M. C. MacCracken, and S. J. Ghan. 1988. "A Global-Scale Lagrangian Trace Species Model of Transport, Transformation, and Removal Processes." J. Geophys. Res. 93:8339-8354.

Wesely, M. 1989. "Parameterization of Surface Resistances to Gaseous Dry Deposition in Regional-Scale Numerical Models." Atmos. Environ. 27:1293-1304. 


\section{APPENDIX C}

RESEARCH ACTIVITIES DEFINED AT THE SECOND WORKSHOP 


\section{APPENDIX C}

\section{RESEARCH ACTIVITIES DEFINED AT THE SECOND WORKSHOP}

Small groups were convened to discuss the research that would be required to develop the modules needed by the three classes of chemical transport models (CTMs) in the global tropospheric chemistry modeling system (GTCMS). These groups were selected according to the area of expertise of the participants. As areas in which research was needed were identified, each group produced a very brief, often sketchy description of the research activity. These unedited, hand-written descriptions were then distributed to all participants for the purpose of scoring the activities according to criteria developed at the workshop. The research activities presented in this appendix are heavily edited versions of those raw descriptions. For many activities, the specification of more than one level of effort is an added refinement not available at the time of the workshop. For the purpose of defining research, further development of the descriptions of what each research activity entails will be needed.

Research Area:

Activity Title:

Description:
Aerosols/Nucleation

Investigate Nucleation on Mixed Aerosols Laboratory and theoretical research is needed to improve understanding of the influence of aerosol surface properties on the nucleation process. Laboratory measurements are needed to characterize aerosol surface properties sufficiently that theoretical models can be evaluated against measured nucleation supersaturation.

Estimated Level of Effort and Time:
1 person-year for 3 years (split between an experimentalist and a theoretician) 
Research Area:

Activity Title:

Description:

Estimated Level of Effort and Time:
Clouds/Subgrid

Develop Treatment of Subgrid Variability in Clouds and Cloud Processes

Subgrid-scale variability in cloud properties and cloud processes has a strong influence on soluble gases and aerosols through deposition, heterogeneous oxidation, activation, scavenging, and resuspension. A physicaliy based treatment of subgrid cloud variability is needed to account for the influence of the variability of soluble gases and aerosols. A statistical description of subgrid variability is recommended, in which variability in cloud microphysical properties is expressed in terms of idealized probability distributions of each cloud variable. The parameters of the probability distribution are related to various statistical moments of the distribution (e.g., mean and variance), which are predicted from conservation equations. The influence of subgrid variability on cloud processes would be treated by integrating each cloud process over the probability distribution of the appropriate cloud variables. The subgrid variance should be related to subgrid variance in vertical velocity, which would be parameterized in terms of cumulus convection, three-dimensional turbulence, and mesoscale circulation.

Level I. Develop numerical solutions to the conservation equations for the moments of the subgrid variability of cloud variables.

Level II. Develop and test parameterizations of the subgrid variability of cloud variables that are suitable for use in a GTCMS.

Level I. 1 person-year for 3 years

Leve1 II. 2 person-years for 3 years 
Research Area:

Activity Title:

Description:

Estimated Level of

Effort and Time:

\section{Aerosois/General}

Develop Parameterized Moments of Species-Resolved Aerosol-Size Distributions

Aerosol-size distributions can often be approximated in terms of a sum of a few log-normal distributions. This approach has already been used for single-component aerosols. However, different aerosol types arise from the diversity of aerosol sources. Although some aerosols are rather pure in composition, most are mixtures of different components. The efficient representation of mixtures of aerosol components within the context of the method of moments is a challenging research topic. Although a complete treatment of aerosol mixtures using joint-size distributions is possible, it is extremely computationally intensive. Research is needed to develop approximate representations of aerosol mixtures and their influence on aerosol processes. The nucleation, accumulation, and coarse aerosol-size modes must be distinguished. Aerosol species to be treated include $\mathrm{H}_{2} \mathrm{SO}_{4},\left(\mathrm{NH}_{4}\right)_{2} \mathrm{SO}_{4}, \mathrm{NH}_{4} \mathrm{HSO}_{4}$, elemental carbon, crustal, and organics. Treatments of the influence of aerosol nucleation, condensation, coagulation, deliquescence, activation, resuspension, scavenging, and gravitational settling on each moment and each component are required. Note that this research activity is linked with the "Develop Moments Method for Aerosol Processing by Clouds" activity.
Research Area:

Activity Title:

Description:

\section{Aerosols/General}

Evaluate Species-Resolved Moments Method for Aerosols

Although the moments method for single-component aerosol dynamics is well established and evaluated to some extent, much remains to be done for the case of mult $i$ component aerosols. Multicomponent moments models need to be compared with explicit model calculations. Explicit models, in turn, need to be compared with laboratory experiments, particularly for aerosol mixtures under a variety of conditions, particularly those that isolate condensational growth and coagulation.

Estimated Level of 1 person-year for 3 years 
Research Area:

Activity Title:

Description:

Estimated Level of Effort and Time:

\section{Aerosols/General}

Develop Emissions Inventories of Aerosols and Their Precursors

To be useful as a policy analysis tool, the GTCMS requires reliable global inventories of the different anthropogenic and biogenic sources of aerosols and aerosol precursors. Emissions inventories are needed for sulfate precursors ( $\mathrm{SO}_{2}$ and dimethylsulfide [DMS]), nitrate precursors $\left(\mathrm{NO}_{x}\right), \mathrm{NH}_{3}$, elemental carbon, organics (primary aerosol emissions and precursor gases), and mineral dust. For those emissions that depend on meteorological conditions (e.g., wind speed in the case of dust and DMS), emissions should be parameterized in terms of surface concentrations and meteorology. For other components, any seasonality in the emissions should be accounted for.

Level I. Compile existing oceanic and developing country inventories and recommend how they should be used in the GTCMS.

Level II. Improve by refining, expanding, and automating the emission inventories for the world's oceans and developing nations and provide the interface to the GTCMS.

Level I. 1 person-year for 1 year

Level II. 3 person-years for 3 years
Research Area:

Activity Title:

Description:

\section{Aerosols/Scavenging}

Develop Moments Method for Aerosol Processing by Clouds

For the aerosol model, the method of moments is recommended for the representation of both aerosols and cloud particles. Research is needed to express cloud processing of aerosols in terms of moments of both aerosols and clouds. The influence of aerosol activation, droplet coalescence, scavenging of interstitial aerosol, aqueous reactions, and resuspension on the moments of the aerosol size needs to be treated in a manner consistent with the moments representation of aerosol and cloud particle-size distributions. A complete treatment of the problem would require a joint droplet/aerosol-size distribution; a simplified treatment is required that distinguishes between activated and interstitial aerosols but does not employ the full joint-size distribution. 
Estimated Level of

Effort and Time:

1 person-year for 2 years

Research Area:

Radiation

Activity Title:

Update Actinic Flux J-Value Look-Up Tables

Description:

Photolysis rate look-up tables used in many current models were developed 10 years ago. These look-up tables should be updated to include recent information on quantum yield and absorption cross sections.

Altitude effects and modification of radiation fields by clouds (on-line) should be included.

Estimated Level of 0.5 person-year for 2 years

Effort and Time:

Research Area:

Activity Title:

Description:
Chemistry/Gas Phase

Develop a Gas-Phase $\mathrm{NO}_{x} / \mathrm{O}_{3} / \mathrm{HC}$ Chemical Mechanism for the Short-Lived CTM

Develop a gas-phase chemical mechanism that includes multiple hydrocarbon (HC) categories and appropriate secondary organic products for the short-1ived species CTM. This includes appropriate selections of anthropogenic ard biogenic $H C$ species. The mechanism must be flexible to allow advances in understanding to be readily incorporated. Also, the mechanism must emphasize radical-radical interactions for low-NO regimes that will occur in remote areas over the globe.

Level I. Review gas-phase chemical mechanisms currently in use in global tropospheric models and make an appropriate choice for the CTM. Conduct a workshop to bring together atmospheric chemists and modelers to compile the latest understanding of gas-phase photochemistry as it would be implemented in the CTM.

Level II. Develop a gas-phase chemical mechanism that contains imited HC speciation for initial implementation and testing in the CTM.

Level III. Develop a gas-phase mechanism for the CTM that contains appropriate HC speciation and sulfur chemistry based on current laboratory and field data.

\section{5}


Estimated Level of Level I. 1 person-year for 1 year

Effort and Time:

Level II. 1 person-year for 2 years

Level III. 3 person-years for 3 years

Research Area:

Activity Title:

Description:
Chemistry/Gas Phase

Evaluate the Effect of Grid Resolution on Subgrid $\mathrm{NO}_{x}$ Cycling and $\mathrm{O}_{3}$ Production

Evaluate the effect of grid resolution (and grid irregularity) on subgrid $\mathrm{NO}_{x}$ cycling and $\mathrm{O}_{3}$ production. Determine what global grid resolution will be appropriate for the accurate prediction of subgrid behavior: Also investigate the tradeoffs between interpolating meteorological data to an irregular grid versus the loss of subgrid chemical nonlinearities on a uniform grid.

Level I. Review literature on subgrid chemical nonlinearities and make appropriate choices for GTCMS implementation.

Level II. Perform modeling studies to evaluate the effect of uniform grid-resolution differences on subgrid $\mathrm{NO}_{x} / \mathrm{O}_{3}$ chemistry and determine appropriate parameterizations or recommendations for GTCMS implementation.

Level III. Perform modeling studies to evaluate the effect of uniform and nonuniform gridresolution differences on subgrid $\mathrm{NO}_{x} / \mathrm{O}_{3}$ chemistry and determine appropriate parameterizations or recommendations for GTCMS implementation.

Estimated Level of Level I. 1 person-year for 1 year Effort and Time:

Level II. 1 person-year for 2 years

Level III. 2 person-years for 2 years
Research Area:

Chemistry/Gas Phase

Activity Title:
Develop a Gas- and Aqueous-Phase Chemical Module for the Aerosol CTM 
Description:

Develop a gas - and aqueous-phase chemical module for the aerosol CTM, including both natural and anthropogenic sources of aerosols and precursors, such as windblown dust, biomass burning emissions, $\mathrm{SO}_{2}$, DMS, $\mathrm{HNO}_{3}, \mathrm{NH}_{3}$, etc. This module will be significantly different from the gas - and aqueous-phase modules of the short-lived species model, in that many species important for the aerosol model will not be as important for the short-lived species model.

Level I. Review gas - and aqueous-phase chemical mechanisms in current aerosol models and make appropriate recommendations for implementation in the aerosol CTM.

Level II. Evaluate existing gas- and aqueous-phase chemical mechanisms in aerosol models, based on appropriateness for the GTCMS and the most recent laboratory and field data, and implement for the aerosol CTM.

Level III. Develop a gas- and aqueous-phase chemical mechanism for the aerosol CTM, based on the most recent laboratory and field data.

Estimated Level of Level I. 0.5 person-year for 1 year Effort and Time:

Level II. 1 person-year for 1 year

Level III. 2 person-years for 2 years

Research Area:

Activity Title:

Description:
Chemistry/Emissions

Develop Emissions Inventories Required for the GTCMS

Analyze the scientific needs of the short-lived, longlived, and aerosol CTMs in terms of needed emissions inventories. Both the species required and the characteristics (e.g., temporal and spatial resolution) of the inventories as they will be applied to the different models should be included in the analysis. Emissions of sulfur compounds, $\mathrm{NO}_{x}, \mathrm{NH}_{3}, \mathrm{CH}_{4}$, and other $\mathrm{HCS}$ by the world's oceans and from the developing nations will play a major role in global-scale chemical modeling.

Level I. Develop an interface between available emissions inventories and the GTCMS. 
Level II. Develop or improve inventories for all the radiatively important trace species and their precursors for the world's oceans and developing nations and make compatible with the input needs of the GTCMS.

Estimated Level of Level I. 0.5 person-year for 1 year Effort and Time:

Level II. 2 person-years for 3 years

Research Area:

Activity Title:

Description:

\section{Chemistry/Aqueous Phase}

Evaluate the Effect of Aerosols on Tropospheric $\mathrm{O}_{3}$ Investigate the impact of aerosols on the tropospheric photochemical $\mathrm{O}_{3}$ cycle. Recent research indicates that there may be a link between photochemical $\mathrm{O}_{3}$ production/destruction and aerosols, particularly in the marine troposphere. Examine these processes in the context of their significance for inclusion in the GTCMS. The results of this study will feed directly into the development of the short-lived species chemical mechanism and the aerosol model mechanism.

Level I. Evaluate available literature on the effect of aerosols on tropospheric $\mathrm{O}_{3}$ and make recommendations for implementation into the GTCMS.

Level II. Perform a model analysis of the effect of aerosols on $\mathrm{O}_{3}$ and make recommendations for implementation into the GTCMS.

Estimated Level of Level I. 0.5 person-year for 1 year Effort and Time:

Level II. 2 person-years for 1 year

Research Area:

Activity Title:

Description:

\section{Chemistry/Aqueous Phase}

Evaluate the Effect of Clouds on Tropospheric $\mathrm{O}_{3}$

Extend the results of recent research on the effect of clouds on tropospheric $\mathrm{O}_{3}$ production/destruction by performing analyses that include more realistic cloud microphysics/dynamics and applying the analysis to various chemically coherent regions of the troposphere. Recent research has indicated that $0_{3}$ production/ destruction may be significantly affected by aqueousphase processes in the troposphere. The results of this study will feed directly into the development of the short-lived species chemical mechanisms. 
Leve1 1. Evaluate available literature on the effect of clouds on $\mathrm{O}_{3}$ and make recommendations for implementation in the GTCMS.

Level II. Perform a model analysis to evaluate the effect of clouds on $\mathrm{O}_{3}$ and make recommendations for implementation in the GTCMS.

Estimated Level of Level I. 0.5 person-year for 1 year Effort and Time:

Level II. 2 person-years for 1 year

Research Area:

Activity Title:

Description:

\section{Chemistry/Gas Phase}

Evaluate the Role of Clouds in $\mathrm{CH}_{4} / \mathrm{CO}$ Tropospheric Chemistry

Evaluate whether clouds play an important enough role in global $\mathrm{CH}_{4} / \mathrm{CO}$ chemistry that they should be included in the long-lived species CTM. The vision identified for the long-lived species CTM did not include cloud processes. To a first approximation, this omission is justified because of the relatively small direct impact that aqueous-phase processes have on $\mathrm{CH}_{4}$ and $\mathrm{CO}$ concentrations. However, HCHO, which is an intermediate species in the oxidation of $\mathrm{CH}_{4}$ to $\mathrm{CO}$, is relatively soluble in cloud and precipitation droplets and its distribution may be significantly affected by cloud processes. An investigation should be carried out to evaluate the potential significance of the neglect of these processes and to recommend alternative designs of the long-lived species CTM, if necessary.

Level I. Evaluate available literature on the effect of clouds on $\mathrm{CH}_{4} / \mathrm{CO}$ chemistry and make recommendations for implementation in the GTCMS.

Leve1 II. Perform a box-model or column-mode1 analysis to evaluate the effect of clouds on $\mathrm{CH}_{4} / \mathrm{CO}$ chemistry and make recommendations for implementation in the long-lived species CTM.

Leve1 III. Perform a full three-dimensional model analysis to evaluate the effect of clouds on $\mathrm{CH}_{4} / \mathrm{CO}$ chemistry and make recommendations for implementation in the long-lived species CTM.

\section{C.9}


Estimated Level of Level I. 0.5 person-year for 1 year

Effort and Time:

Leve1 II. 1 person-year for 1 year

Level III. 2 person-years for 1 year

Research Area:

Activity Title:

Description:

Estimated Level of Effort and Time:

\section{Chemistry/Gentral}

Develop an Interface Between the Short-Lived Species and the Long-Lived Species and Aerosol CTMs

Develop the design of the structural interface and methodology to allow the short-lived species CTM to provide oxidant fields to the long-lived species and aerosol CTMs. As described in the research activity "Evaluate Use of the Short-Lived CTM in Providing OH Fields for Use in the Long-Lived and Aerosol CTMs," one way to implement the GTCMS would be to design the longlived species and aerosol CTMs as engineering models. Full short-lived species CTM simulations would provide oxidant fields for detalled scenario analyses performed by the less computationally expensive engineering models. Once the engineering model concept has been verified, an interface should be designed to allow the oxidant fields to be efficiently transferred from the short-lived species CTM to the engineering models. The interface should allow for both a "screening mode"

(with coarse temporal and spatial resolution) transfer of information and a "detalled mode" (with fine temporal and spatial resolution).
Research Area:

Activity Title:

Description:

\section{Chemistry/General}

Evaluate Use of the Short-Lived CTM in Providing $\mathrm{OH}$ Fields for Use in the Long-Lived and Aerosol CTMs

Evaluate the feasibility of using $\mathrm{OH}, \mathrm{O}_{3}$, and $\mathrm{H}_{2} \mathrm{O}_{2}$ fields generated by the short-lived species CTM as input data for the long-lived and aerosol CTMs. One way to implement the GTCMS would be to design the longlived species and aerosol CTMs as engineering models. Full short-lived species CTM simulations would provide oxidant fields for detailed scenario analyses performed by the less computationally expensive engineering models. An evaluation must be performed to establish the feasibility of this design. 
Estimated Level of

1 person-year for 3 years

Effort and Time:

Research Area:

Activity Title:

Description:

Estimated Level o

Effort and Time:

\section{Chemistry/General}

Evaluate Adequacy of Gas-Phase Chemical Oxidation Mechanisms of DMS and the Resulting Production of Cloud Condensation Nuclei

Evaluate the current understanding of the gas-phase chemistry of DMS in the troposphere, including production of $\mathrm{SO}_{2}$ and methanesulfonic acid (MSA) and the relative amounts produced of each. Examine existing mechanisms and evaluate their predictive ability based on available DMS/SO, MSA measurements. Al so evaluate the current understanding of cloud condensation nucle $i$ (CCN) production from DMS oxidation products. Develop an appropriate gas-phase chemical mechanism for DMS oxidation for the GTCMS and provide evaluated parameterizations for the production of CCN from DMS oxidation products.

Level 1. Compile and evaluate existing mechanisms for DMS oxidation and parameterizations for CCN production and make appropriate choices for the GTCMS, based on current literature.

Level II. Develop a new DMS oxidation mechanism and a new CCN parameterization for the GTCMS, based on the most recent laboratory and field data.

Level I. 1 person-year for 1 year

Level II. 2 person-years for 2 years
Research Area:

Dynamics/Stratosphere

Activity Title:

Description: Parameterization
Develop Stratosphere/Troposphere Exchange

Exchange of trace species mass between the stratosphere and troposphere is expected to dominate the upper boundary condition for a tropospheric chemistry model. This exchange must be accurately simulated in the GTCMS. Higher-order resolution modeling and observations should be used to develop and test a parameterization for the exchange of trace species mass between the stratosphere and troposphere suitable for use in a global-scale model. 
Estimated Level of 2 person-years for 3 years

Effort and Time:

Research Area:

Activity Title:

Description:
Dynamics/Boundary Layer Turbulence

Develop Nonlocal Turbulence Closure Methods for Global Models

Nonlocal turbulence closure methods allow transport of trace species, heat, and water vapor against the gradient. This is possible because turbulence can transport parcels with high (low) concentrations through layers with low (high) concentrations without mixing. Application of nonlocal turbulence closure to regional-scale models has resulted in significant differences to regional-scale transport. However, the methods used need to be refined to improve the efficiency of computations needed.
Estimated Level of Effort and Time:

\section{5 person-years for 3 years}

Research Area:

Activity Title:

Description:

\section{Surface Exchange}

Synthesize Emissions, Surface Flux, Deposition, and Hydrologic Models

A single, selfconsistent modeling framework is needed for hydrologic, emissions, surface flux, and deposition models. This framework can then be used to synthesize these models into a single-surface flux module for the GTCMS that has the capability to handle a wide range of surface types, including vegetation, wetted surfaces, water, and land.

Estimated Leve1 of Effort and Time:

Research Area:

Activity Title:

Description:
Transport/Grid

Develop an Irregular Grid Method for Chemistry

Develop the means to apply an irregular grid, or more specifically, a nested grid system to the chemical mechanism. Methods are needed to define the inflow and outflow conditions between the nested and global grid systems in an efficient manner. The method must demonstrate an accuracy within the nested grid that is equal or better than in the global grid. 
Estimated Level of

2 person-years for 2 years

Effort and Time:

Research Area:

Numerics

Activity Title:

Develop a Computationally Fast Chemistry Integrator

Description:

A computationally fast and flexible chemistry integrator with the computational complexity of Sillman (1991) and quasi-steady-state approximation (QSSA) (Hesstvedt et a1. 1978) is needed to accommodate a wide range of chemical mechanisms and to adapt easily to new mechanisms. The QSSA method handles stiffness by eliminating stiff species and lumping together species of similar chemical type. The code for the QSSA method needs to be modified when the mechanism is changed.

The proposed integrator will generate automatically the differential equations, reorder species (as done by Sillman 1991) and use implicit Runga Kutta methods, which are suitable for stiff equations yet have reduced computational complexity because of the reordering of species.

Estimated Level of 2 person-years for 3 years

Effort and Time:

Research Area:

Activity Title:

Description:
Uncertainty

Demonstrate Effectiveness of Autodifferentiation

Techniques have recently been developed to automatically generate a computer code that provides the sensitivity coefficients for a given set of equations that are to be solved numerically. The effectiveness of these techniques, with the equations being solved for tropospheric chemistry, cloud microphysics, and aerosols, needs to be demonstrated. The techniques should be applied to a module for which sensitivity coefficients can be determined by other means, so that the results can be compared and the effectiveness of the method evaluated.

1 person-year for 1 year

Estimated Level of

Effort and Time: 


\section{REFERENCES}

Hesstvedt, E., 0. Hov, and I.S.A. Isaksen. 1978. "Quasi-Steady-State Approximations in Air Pollution Modeling: Comparison of Two Numerical Schemes for Oxidant Prediction." Int. J. Chem. Kinetics X:971-994.

Sillman, S. 1991. "A Numerical Solution for the Equations of Tropospheric Chemistry Based on an Analys is of Sources and Sinks of Odd Hydrogen."

J. Geophys. Res. 96:20735-20744. 
PNL -9012

UC -000

\section{DISTRIBUTION}

No. of

Copies

\section{OFFSITE}

2 DOE Office of Scientific and Technical Information

G. R. Carmichael

Dept. of Chemical and Biochemical Engineering 125A Chemistry Building

University of Iowa

Iowa City, IA 52242

G. Fairweather

Dept. of Mathematics

715 Patterson Office Tower

University of Kentucky

Lexington, KY 40506-0027

P. Finkelstein

U.S. EPA/AREAL, MD-75

Research Triangle Park, NC 27711

L. K. Peters

Vice Provost for Research and Dean of the Graduate School

306 Burruss $\mathrm{Hall}$

Virginia Polytechnic Institute and State University

Blacksburg, VA 24061-0244

F. A. Potra

Professor of Mathematics

IP McLean Hall

University of Iowa

Iowa City, IA 52242

7 J. Sickles

U.S. EPA/AREAL, MD-75

Research Triangle Park, NC 27711
No. of

Copies

T. T. Tsang

Dept. of Chemical Engineering 159 Anderson $\mathrm{Hall}$

University of Kentucky

Lexington, KY 40506-0046

D. von Winterfeldt

Dept. of Systems Science

Institute of Safety and

Systems Management

University of Southern

California

University Park-Los Angeles,

CA 90089-0021

\section{ONSITE}

DOE Richl and Operations office

P. Kruger

27 Pacific Northwest Laboratory

W. R. Barchet (5)

C. M. Berkowitz

A. J. Brothers (8)

R. C. Easter

S. J. Ghan

F. L. Greitzer

W. A. Hesser

R. J. Nesse

M. J. Quadrel

R. D. Quinn

S. F. Rayner

R. D. Saylor

D. A. Seaver

C. S. Sloane

W. G. Stillwell

Routing

R. M. Ecker

M. J. Graham

P. M. Irving

P. C. Hays

B. V. Johnston (Last) 

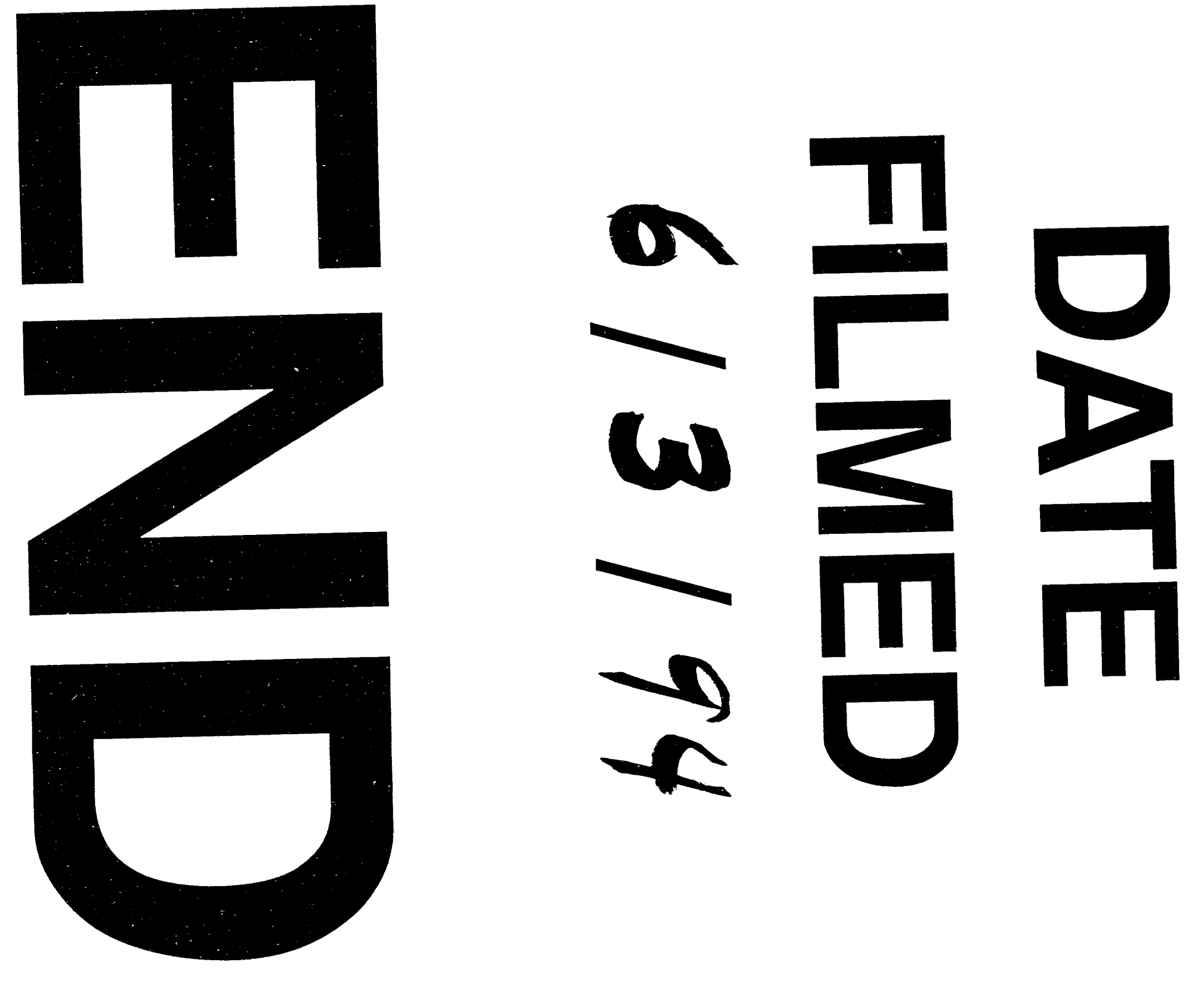
